\title{
Getting Connected: Exploring the Role of Sustainability Labels In Tourism Marketing Communications
}

\author{
Elvira Kizilova \\ West Virginia University, enk0001@mix.wvu.edu
}

Follow this and additional works at: https://researchrepository.wvu.edu/etd

Part of the Marketing Commons

\section{Recommended Citation}

Kizilova, Elvira, "Getting Connected: Exploring the Role of Sustainability Labels In Tourism Marketing Communications" (2021). Graduate Theses, Dissertations, and Problem Reports. 8312.

https://researchrepository.wvu.edu/etd/8312

This Dissertation is protected by copyright and/or related rights. It has been brought to you by the The Research Repository @ WVU with permission from the rights-holder(s). You are free to use this Dissertation in any way that is permitted by the copyright and related rights legislation that applies to your use. For other uses you must obtain permission from the rights-holder(s) directly, unless additional rights are indicated by a Creative Commons license in the record and/ or on the work itself. This Dissertation has been accepted for inclusion in WVU Graduate Theses, Dissertations, and Problem Reports collection by an authorized administrator of The Research Repository @ WVU.

For more information, please contact researchrepository@mail.wvu.edu. 


\title{
GETTING CONNECTED: EXPLORING THE ROLE OF SUSTAINABILITY LABELS IN TOURISM MARKETING COMMUNICATIONS
}

\author{
Elvira Kizilova \\ Dissertation submitted to the College of Business and Economics \\ at West Virginia University \\ in partial fulfillment of the requirements \\ for the degree of \\ Doctor of Philosophy \\ in \\ Marketing
}
Michael F. Walsh, $\mathrm{PhD}$ (Chair)
Ajay Aluri, $\mathrm{PhD}$
Emily C. Tanner, $\mathrm{PhD}$
Xinchun Wang, $\mathrm{PhD}$
Department of Marketing
Morgantown, West Virginia
2021

Keywords: sustainable tourism, labeling, anthropomorphism, greenhushing.

Copyright 2021 Elvira Kizilova 


\title{
ABSTRACT \\ GETTING CONNECTED: EXPLORING THE ROLE OF SUSTAINABILITY LABELS IN TOURISM MARKETING COMMUNICATIONS
}

\author{
Elvira Kizilova
}

While sustainability has become an important brand differentiator in many industries, current research suggests that tourism businesses rarely use sustainability labels in their communications, e.g., on their websites or other types of advertisements.

This dissertation examines the role of sustainability labels in increasing consumer preferences for sustainable travel destinations. Drawing on social exchange theory and anthropomorphism framework, we propose that sustainability labels increase consumer visit intentions, willingness to recommend a destination to someone else, and willingness to pay price premium for the sustainable offer. These effects are mediated by perception of goal congruence and connectedness with a destination. We further propose that increase in positive consumer responses to sustainable communications occurs due to inclusion of anthropomorphic elements in sustainability labels.

Three pretests and one study are designed to examine the hypothesized relationships. This research contributes to the literature by identifying goal congruence and connectedness as two important mechanisms that mediate relationships between presence of sustainability labels and positive behavioral intentions. 


\section{DEDICATION}

This dissertation is dedicated to my mother Antonina and my son Artem who supported me in all my endeavors. 


\section{ACKNOWLEDGMENTS}

I could not complete my dissertation without the support and encouragement of many people.

I would like to express my deepest gratitude to my dissertation chair, Dr. Michael Walsh. He guided me through my dissertation, taught me how to critically evaluate my research ideas, and instilled confidence in me when I needed it.

I would like to thank Dr. Ajay Aluri, Dr. Emily Tanner, and Dr. Xinchun Wang for being my committee members and providing their helpful feedback on this dissertation. Also, I thank Dr. Jonathan Fluharty-Jaidee and Volodymyr Andrushchak for helping me out with web scraping.

I would also like to thank all the faculty members and doctoral students in the Marketing Department for being so supportive and friendly. I was truly blessed to have such a wonderful academic family during my $\mathrm{PhD}$ program.

I want to thank two amazing people -Margarita Grankina and Iryna Myroshnichenko who suggested for me to consider pursuing a degree in the United States. Unfortunately, Iryna has recently passed away but I am sure she would have been proud of my achievements.

I thank Dr. Christopher Kelley, Jeffrey Lubbe, and Volodymyr Kostkiv who recommended me for a PHD program at West Virginia University.

I would like to thank my mother and my son whose love and support helped me to believe in myself and to pursue my dream. I specifically thank my son Artem for helping me out with my research projects and conference presentations and being so patient and supportive. And, last but not least, I am truly thankful to all my friends from around the world for sending me good vibes whenever I needed it. 


\section{TABLE OF CONTENTS}

ACKNOWLEDGMENTS ..................................................................................................... iv

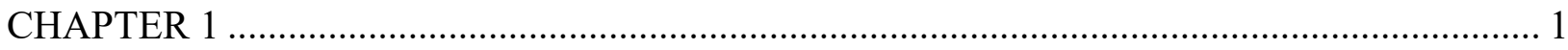

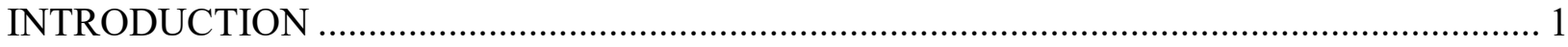

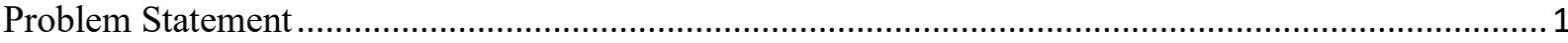

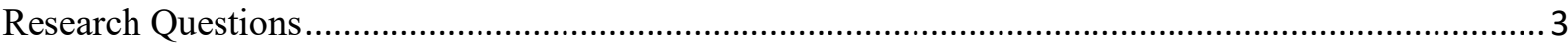

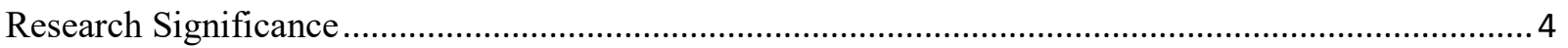

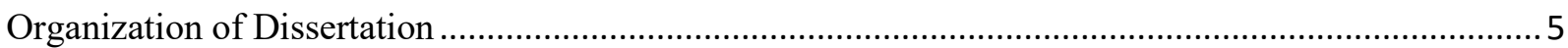

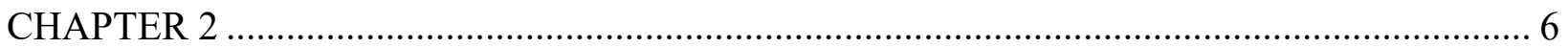

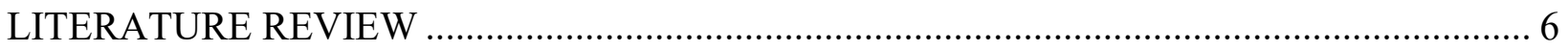

Sustainability and Consumer Behavior .......................................................................................... 7

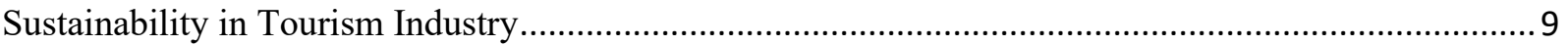

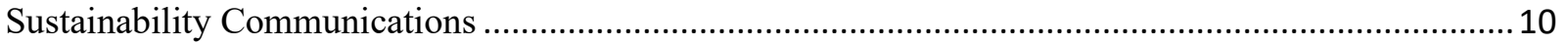

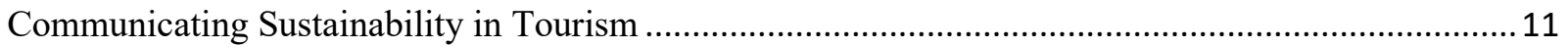

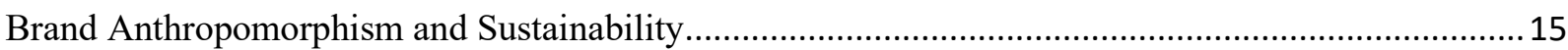

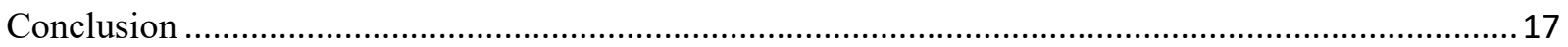

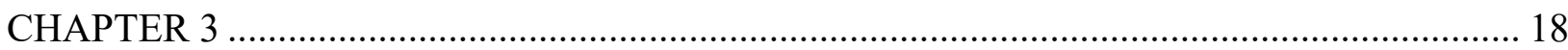

CONCEPTUAL MODEL AND HYPOTHESES ......................................................... 18

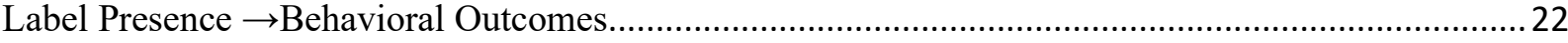

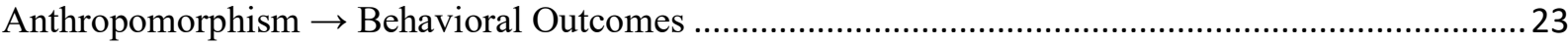

Mediating Effects of Connectedness and Goal Congruence........................................................... 25

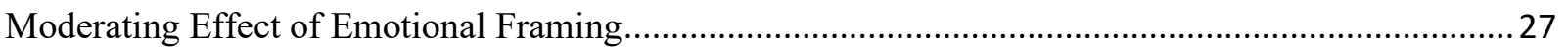

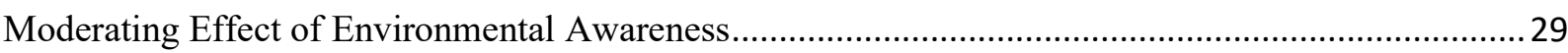

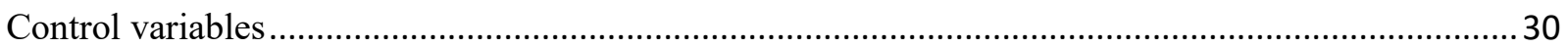

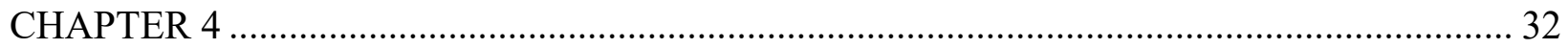

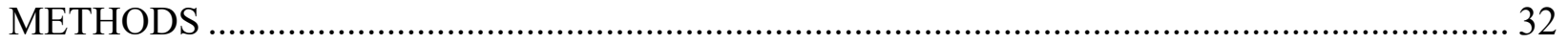

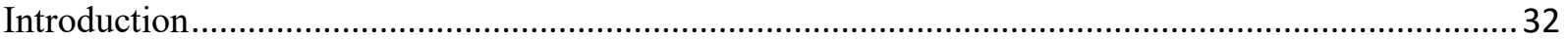

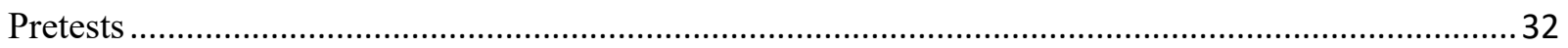

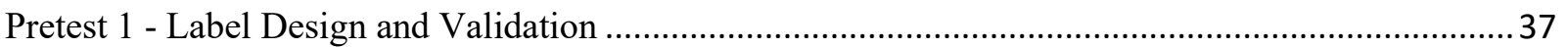

Pretest 2 - Travel Destination Name Design and Validation .............................................................. 39

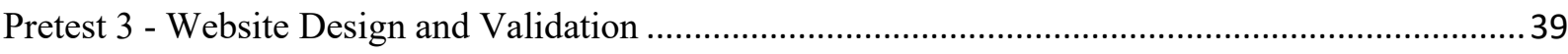

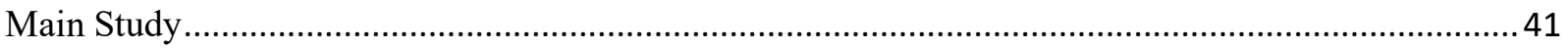

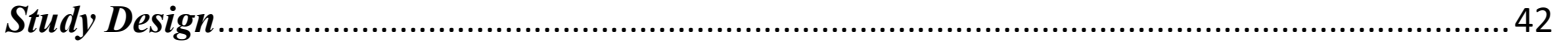


Sample

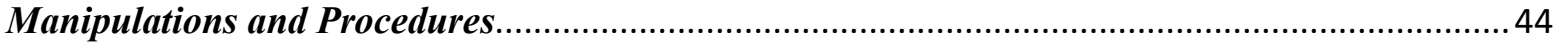

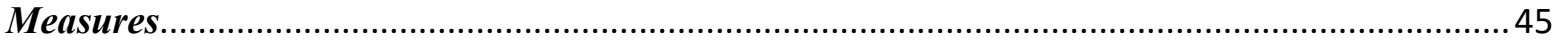

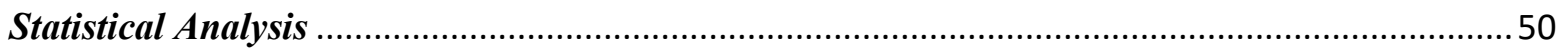

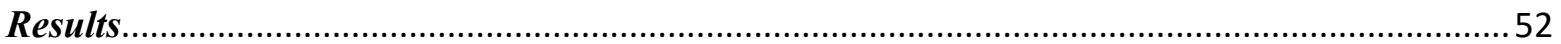

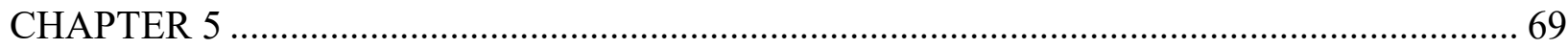

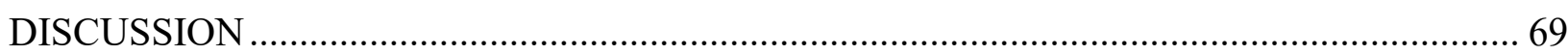

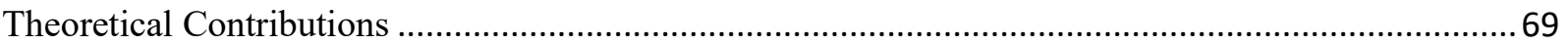

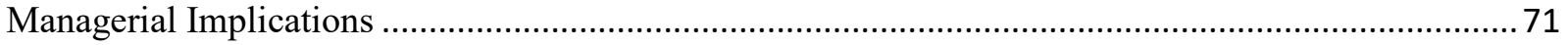

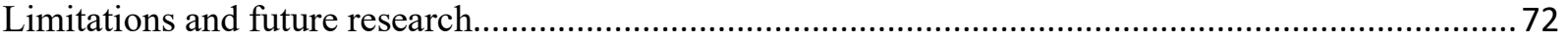

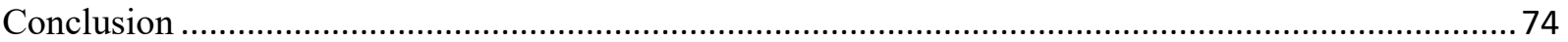

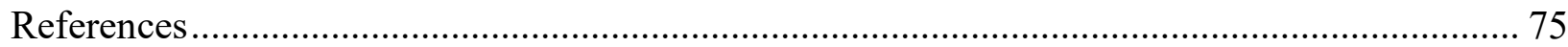

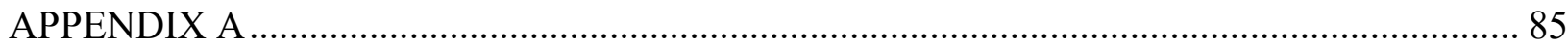

Examples of Sustainability Labels in Different Industries .................................................. 85

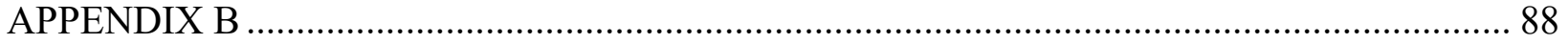

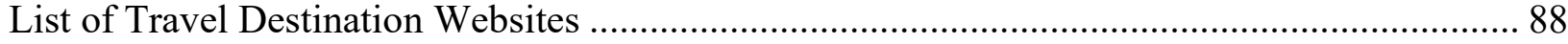

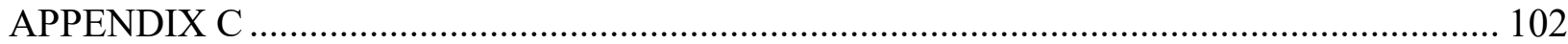

Python Code for Text Scraping and LDA Analysis............................................................ 102

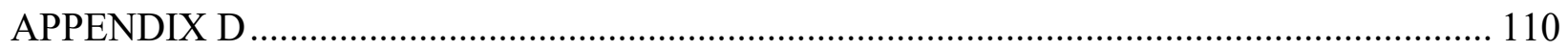

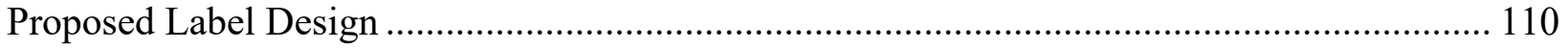

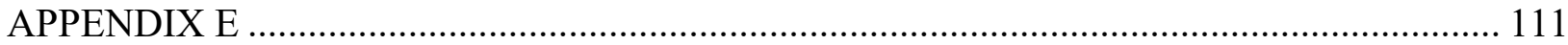

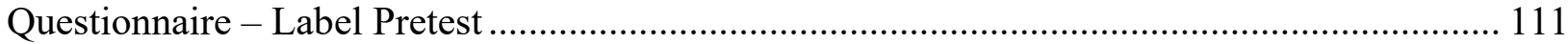

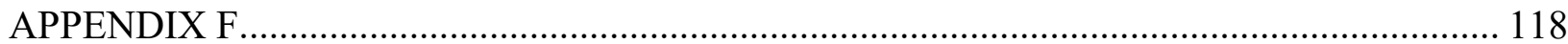

Questionnaire - Travel Destination Name Pretest............................................................. 118

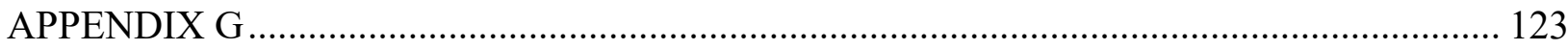

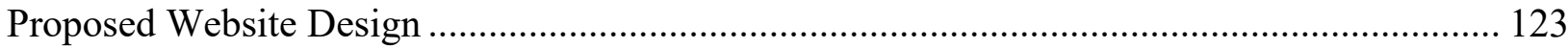

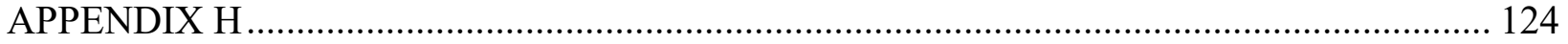

Qualtrics Questionnaire - Website Pretest ................................................................... 124

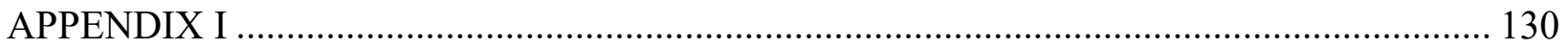

Qualtrics Questionnaire - Website Pretest ................................................................. 130 


\section{LIST OF TABLES}

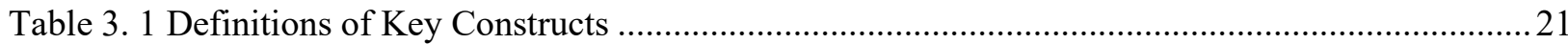

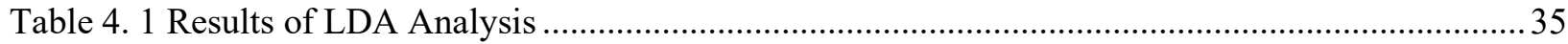

Table 4. 2 Inter-Construct Correlations and Descriptive Statistics.....................................................51

Table 4. 3 Moderated Mediation Results with Confidence Intervals - Connectedness .............................59

Table 4. 4 Moderated Mediation Results with Confidence Intervals - Goal Congruence..........................6 65

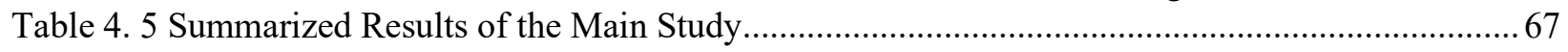

\section{LIST OF FIGURES}

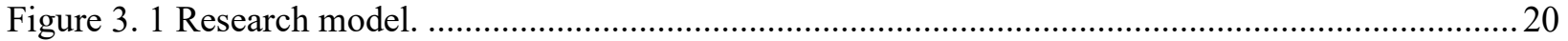

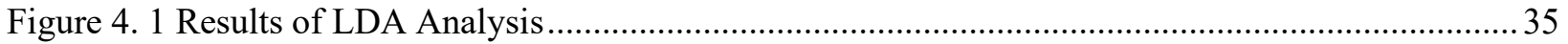

Figure 4. 2 Moderated Mediation - Label $\rightarrow$ Connectedness $\rightarrow$ Visit Intention......................................5 55

Figure 4. 3 Moderated Mediation - Label $\rightarrow$ Connectedness $\rightarrow$ WOM................................................... 56

Figure 4. 4 Moderated Mediation - Label $\rightarrow$ Connectedness $\rightarrow$ WTP...................................................... 57

Figure 4. 5 Interaction Effects of Label Presence/Absence and Environmental Awareness on

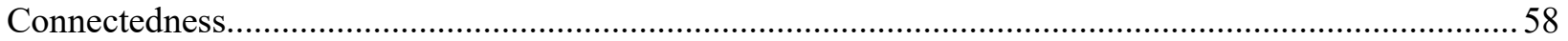

Figure 4. 6 Moderated Mediation - Label $\rightarrow$ Goal congruence $\rightarrow$ Visit intention.................................. 61

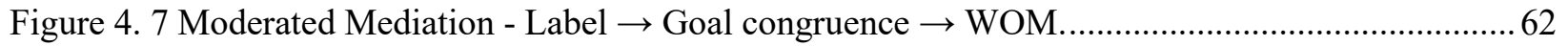

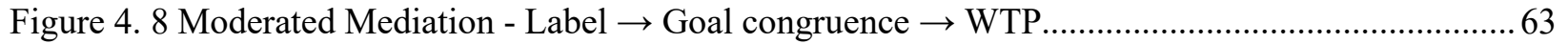

Figure 4. 9 Interaction Effects of Label Presence/Absence and Environmental Awareness on Goal

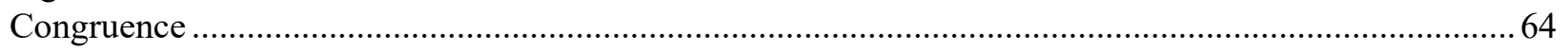




\section{CHAPTER 1}

\section{INTRODUCTION}

\section{Problem Statement}

Sustainability has received much attention over the few last decades. It refers to the "development that meets the needs of the present generation without compromising the ability of future generations to meet their own needs" (World Commission on Environment and Development 1987). Sustainable development is a priority governance principle for the United Nations Member States and is reflected in "The 2030 Agenda for Sustainable Development." Sustainability is also a source of competitive advantage for businesses (e.g. Lansing and De Vries 2007; Nidumolu, Prahalad, and Rangaswami 2009; d'Angella and De Carlo 2016). Thus, sustainability becomes a key differentiator for successful businesses.

Tourism accounts for $30 \%$ of the world's services exports and $7 \%$ of the world's export (UNWTO 2018), making a significant contribution to the world economy; but, at the same time, it is the industry which may negatively impact ecological systems and cause damage or even loss of cultural heritage (Lansing and De Vries 2007). World Tourism Organization (UNWTO) predicts world tourism growth and expansion in the long run, which will increase the negative impact on travel destinations and emphasize the need to promote sustainable tourism (UNWTO 2019). Other global environmental concerns, such as climate change, deforestation, or excessive amount of waste, will also affect travel destinations' well-being and development. Considering these global challenges and trends, travel destinations may have to address sustainability in terms of future planning. The World Tourism Organization encourages all countries and tourism 
stakeholders to focus on sustainable tourism development in their policies, agendas, and actions (UNEP and UNWTO 2005).

On the other hand, more tourists now are interested in traveling sustainably (e.g., Booking.com 2018; Virtuoso 2018) and in receiving more information about sustainable tourism offers including information on certification of sustainable destinations and facilities.

These recent trends suggest that travel destinations might gain advantage by positioning themselves as "sustainable." While many industries have aggressively promoted sustainability communications in form of various labels and symbols, research suggests that in the tourism segment the opposite is true. Tourism businesses report and communicate to consumers only $30 \%$ of their sustainable initiatives thus engaging in "greenhushing" - a deliberate concealment of information about their sustainability practices (Font, Elgammal, and Lamond 2017).

There are two possible explanations for the counterintuitive use of greenhushing. First, marketing and sustainability goals may be viewed as incompatible and hinder consumer rights for consumerism (Font and McCabe 2017). Second, sustainable products are often viewed as less effective and more expensive (Gleim et al. 2013), and sustainable tourism is perceived as the one that limits consumer experiences and does not deliver positive emotions and perception of luxury (Baker, Davis, and Weaver 2014). Against this backdrop, this dissertation provides further insights into the challenges related to sustainable tourism communications and promotion and developing practical solutions for tourism.

To address the above-mentioned problem and drawing on social exchange theory (Blau 1964), we propose that the relationship between sustainability labels and positive consumer attitudes and behavioral intentions will occur through two mechanisms - goal congruence and 
connectedness. We also propose that anthropomorphism that is used in brand and product marketing (Aggarwal and McGill 2007, 2012; Chandler and Schwarz 2010) will increase consumer positive reactions to sustainable travel offers. Research has found that inclusion of anthropomorphic characteristics, such as humanlike faces and textual personifications, in product design and marketing communications increases positive attitudes toward the products and purchasing intentions (Aggarwal and McGill 2007; (Ahn, Kim, and Aggarwal 2014; Labroo, Dhar, and Schwarz 2008; Letheren, Martin, and Jin 2017).

In tourism marketing, anthropomorphism is mostly used in communicating a destination or event personality, i.e., in the form of a country's or an event's mascot (e.g., Olympics mascots). To the best of our knowledge, anthropomorphism is not widely applied in sustainable tourism promotions and little research has been conducted on this topic.

\section{Research Questions}

The current research uses social exchange theory (Blau 1964; Emerson 1976) and anthropomorphism framework (Epley, Waytz, and Cacioppo 2007) to examine the effects of humanized sustainability labels on consumer behavioral intentions in the tourism context: word of mouth, intention to visit a travel destination, and willingness to pay price premium. Tourist arrivals (visits) and tourism expenditures are the key indicators of both global and regional tourism performance (UNWTO n.d.). Word of mouth is one of the most important channels of communication that influences consumer behaviors and attitudes (Allsop, Bassett, and Hoskins 2007; Roy et al. 2016).

Furthermore, this dissertation explores two parallel mechanisms that mediate these relationships: connectedness with a destination and goal congruence. Finally, this research 
examines levels of consumer environmental awareness and emotional message framing (positive vs. neutral) as potential moderators.

Specifically, this research addresses the following questions:

1. Do sustainability labels increase consumer connectedness with a travel destination and perception of goal congruence?

2. Do sustainability labels increase consumer positive behavioral intentions (word of mouth, intention to visit a travel destination, and willingness to pay price premium)?

3. Is connectedness with a travel destination and perception of goal congruence higher for consumers with higher levels of environmental awareness?

4. Does inclusion of anthropomorphic elements in sustainability label design increase connectedness with a travel destination and perception of goal congruence?

5. Does positive emotional message framing increase connectedness with a travel destination and perception of goal congruence?

\section{Research Significance}

While sustainability became an overarching developmental goal for the global community (United Nations 2016), the biggest challenge in promoting sustainability as a competitive advantage for businesses is expressing this as a benefit for consumers. Research has shown mixed results about the effectiveness of sustainable communications in various industry sectors (Ketron and Naletelich 2019). It was found that sustainability labels increase consumption of sustainable food products (e.g., De Pelsmacker et al. 2005) and in energy sector (Banerjee and 
Solomon 2003). However, little research has been conducted on effective communication of sustainable tourism. This dissertation aims to examine sustainable communication in tourism sector and to offer solutions to the problem of greenhushing.

This dissertation seeks to identify a communication strategy that will deliver benefits and advantages of sustainable tourism to consumers. The theoretical foundation of this paper draws on relational and anthropomorphism literature. We intend to demonstrate how the use of anthropomorphic messages and positive framing is expected to increase consumer positive behavioral intentions toward the sustainable destination brand.

This research also aims to understand the underlying mechanism of how sustainable communication messaging is transferred to the consumer. The existing research suggests that anthropomorphic representation of a sustainable offer elicits consumer response through the activation of negative feelings, such as guilt and sympathy (Ahn, Kim, and Aggarwal 2014; Ketron and Naletelich 2019; Tam, Lee, and Chao 2013). However, negative emotions and savior effects seem to be incompatible with hedonic nature of travels. This research extends the existing literature on anthropomorphism and explains how anthropomorphism helps mitigate barriers to sustainable traveling through connectedness and perceived goal congruence with a travel destination.

\section{Organization of Dissertation}

The remainder of this dissertation is organized as follows. The literature on sustainability communications is reviewed in Chapter 2. In the literature review, we also discuss social exchange theory and anthropomorphism framework and the effect of anthropomorphic messages in sustainable communications. In Chapter 3, we develop the conceptual model and hypotheses. 
Further, in Chapter 4, we discuss research methodology to empirically test hypotheses. Finally, in Chapter 5, we conclude with a discussion of theoretical contributions, managerial implications, limitations, and future research directions.

\section{CHAPTER 2}

\section{LITERATURE REVIEW}

This chapter reviews the literature on sustainability communications. While sustainability is found to be a source of competitive advantage for businesses (e.g. Lansing and De Vries 2007; Nidumolu, Prahalad, and Rangaswami 2009; d'Angella and De Carlo 2016) and an emerging trend for tourists (Virtuoso 2018), research has also found that not all industries benefit equally from incorporating sustainability messages in their marketing communications (Ketron and Naletelich 2019). Specifically, in the tourism industry, companies often do not communicate all their sustainability efforts to customers thus engaging in greenhushing (Font, Elgammal, and Lamond 2017). This literature review provides a foundation for the conceptual model developed in Chapter 3.

The literature review is organized as follows. First, the concept of sustainability and importance of sustainable development in tourism industry will be explained. Next, greenhushing, or intentional withholding of information on sustainable actions, will be discussed as one of the challenges of sustainable communications. Further, anthropomorphism framework will be introduced to address the issue of greenhushing. To conclude, research in communicating sustainable tourism will be summarized, highlighting the gaps that this dissertation intends to fill. 


\section{Sustainability and Consumer Behavior}

Sustainability has received much scholarly focus during the last three decades due to climate change, natural disasters, rising inequalities between countries, and natural resource depletion that are threatening to reverse the developmental progress (United Nations 2016). The most recent case of the COVID-19 pandemic has demonstrated that stability can become fragile and has emphasized the importance of sustainable actions and behaviors. For example, shutdown of industries and cancelled air travels caused a 25\% drop of $\mathrm{CO}_{2}$ emissions in China (Burch 2020). Italy, where dramatically increasing numbers of coronavirus cases and deaths led to lockdown and numerous restrictions, has experienced unintended benefits: water in Venice canals got cleaner (Chow 2020; Rizzo 2020). After the outbreak, humanity may rethink some habits and behaviors toward being more sustainable.

Sustainability refers to the "development that meets the needs of the present generation without compromising the ability of future generations to meet their own needs" (World Commission on Environment and Development 1987). The concept of sustainable development and the 17 key sustainable development goals (SDGs), which are the course of action for all countries and all industries, are outlined in the United Nations Member States' fundamental document "The 2030 Agenda for Sustainable Development" (United Nations 2016). The document posits that the concept of sustainable development is a much broader concept than environmental protection and eco-movement. In addition to the widely known SDGs, such as clean water and energy, climate action, or preservation of living species, SDGs also include economic (e.g., poverty elimination, decent work and economic growth, industry innovation and infrastructure, etc.) and social development objectives (e.g., quality education, gender equality, good health and well-being, peace, justice, and strong institutions) (United Nations 2016). 
Sustainable development involves multiple stakeholders that can be classified into the main stakeholder groups:

- Governments (national, regional, and local).

- Organizations: business and industry; scientific and technological community; NGOs; trade unions; education and academia.

- Individuals: age and gender groups (children and youth, women, ageing), workers, indigenous people, and persons with disabilities (United Nations n.d.).

Thus, sustainability is both a social philosophy and an important governance principle. It also can serve as a source of a competitive advantage for businesses. Research has shown that a shift towards sustainable practices and corporate social responsibility increases customer satisfaction (Luo and Bhattacharya 2006), positive attitudes towards the company and its products (Brown and Dacin 1997), and provides economic benefits such as cost reductions and additional revenues (Nidumolu, Prahalad, and Rangaswam 2009). Moreover, non-sustainable practices can cause the wave of criticism and even resentment that may damage the reputation of the company as it happened with Burberry, the British luxury brand that used to get rid of unsold merchandize by burning it instead of reusing it or selling at discounted prices. This attempt of the brand to "maintain its brand value" resulted in the opposite effect, and the company immediately stopped burning unsold goods and, in addition, using animal fur in their products (Paton 2018).

Sustainable principles are evident in a variety of major industries, such as agriculture, energy production, construction, food production, etc. Corporate Knights, a Canada-based sustainability-focused company, ranks large firms worldwide on their efforts on carbon emission reduction, gender diversity and fair payment, and revenues obtained from sustainable products. 
The top three most sustainable companies, Chr. Hansen Holding (Denmark), Kering SA (France), and Nestle Corporation (Finland), derive 25 to $80 \%$ of their revenues from sustainable production (Strauss 2019).

\section{Sustainability in Tourism Industry}

In recent years, tourism provided $30 \%$ of the world's services exports and $7 \%$ of the world's exports (1.6 trillion in USD or 10\% of the world's GDP) and created one out of ten jobs (UNWTO 2018). The increasing number of travelers has already resulted in the increase of possible challenges and threats for travel destinations, such as carbon footprints and impact on local environments, communities, and cultural heritage (UNWTO 2019). Other global environmental problems, such as climate change, deforestation, disposal of waste, etc. will also affect well-being of travel destinations and their communities. In face of these challenges, travel destinations will have to be re-oriented towards sustainability.

Sustainable tourism "takes full account of its current and future economic, social and environmental impacts, addressing the needs of visitors, the industry, the environment and host communities" (UNEP and UNWTO 2005, p. 11). Sustainability principles in tourism refer to the optimal use of environmental, socio-cultural, and economic resources of host communities and informed participation of all relevant stakeholders (UNEP and UNWTO 2005). Thus, tourism can contribute to most SDGs identified by the United Nations countries.

Tourism is one of the sectors that was heavily impacted by outbreak of COVID-19: the pandemic dramatically impacted tourism industry causing a $87 \%$ decline in tourist arrivals in January 2021 compared to 2020 (UNWTO 2021). However, UNWTO predicts a rebound in international travel in the second half of 2021 due to vaccination programs and lifts of travel 
restrictions (UNWTO 2021). When the pandemic will be over, world tourism will increase and expand, increasing its impact on the environment and economic and social development of hosting countries (UNWTO 2019). Emphasis on sustainability may be a relevant strategy, as safety, cleanliness, and responsible attitudes toward clients will be in high demand.

\section{Sustainability Communications}

Increased awareness on sustainable development has led to the implementation of different instruments for measuring and communicating sustainability (Proto, Malandrino, and Supino 2007). While prevailing practices and legal norms are not applicable across industries, businesses and governments are using so called "soft policy instruments" (Cohen, Potchter, and Schnell 2014), such as eco- or sustainability labels, or symbols that disclose "attributes related to the sustainability practices embraced by a company" (Melo and Farias 2018, p. 37). These instruments may range from detailed certification standards to self-reported environmental claims based on ethical codes of conduct (Proto, Malandrino, and Supino 2007).

Some readers may question the difference between eco and sustainability terms. While there is an overlap and, in some cases, the terms are used interchangeably, for purposes of this dissertation we will use the term "sustainable" as it is a broader concept that, in addition to an eco- or environmental component, includes other components of sustainable development, such as economic and social development (United Nations 2016).

Sustainability labels are widely used in many industries. An Ecolabel Index (http://www.ecolabelindex.com), the largest global directory of ecolabels, today includes 465 ecolabels in 199 countries, and 25 industry sectors. The variety of labels represents global, 
regional, and local initiatives in agriculture, food industry, energy consumption, cosmetics, tourism, etc. (see Appendix A).

Sustainability labels are viewed as cues (Verbeke and Ward 2006) that signal certain quality and ethical characteristics of sustainable products to consumers (e.g., De Pelsmacker et al. 2005; Howard and Allen 2006; Zadek, Lingayah, and Forstater 1998) and, as a result, increase consumption of these products. For example, according to "Global Organic Food Market By Product Type (Organic Meat, Poultry and Dairy; Organic Fruits and Vegetables; Organic Processed Food; etc.), By Region (Europe, North America, Asia-Pacific, etc.), Competition Forecast and Opportunities, 2012 - 2022” report, global organic food market, where labels are widely used, will demonstrate over 16 percent growth during 2017-2022 (TechSci Research 2017). Use of eco-labels was also found effective in energy sector (Banerjee and Solomon 2003). However, these communications may not be equally effective across different industries and products (Ketron and Naletelich 2019), so companies need to adapt these messages to increase their effectiveness.

\section{Communicating Sustainability in Tourism}

Tourism is one of the industries where sustainability messages are often avoided even though it is a competitive advantage. Booking.com, one of the largest world travel e-commerce platforms, in their Sustainable Travel Report, indicate that $87 \%$ of global travelers want to travel sustainably and $39 \%$ often or always do that (Booking.com 2018). The most recent report conducted by Virtuoso, a large global network of travel agencies, found that conservation and sustainable interactions with wildlife is one of the top trends for tourists (Virtuoso 2018). 
At the same time, 32 percent of tourists reported that the lack of information and/or certification was one of the obstacles to sustainable travel (Booking.com 2018). According to the global survey conducted by TUI Group, one of the largest world's tourism businesses which serves 20 million customers in 180 regions, 55 percent of respondents criticized travel operators for the lack of information and choice on sustainable offers (TUI 2017).

While the interest in sustainable tourism communication is high, travel marketers' response to this seems sparse and lacking. In tourism sector, there is no globally applied certification system that is familiar and understandable to customers. 128 tourism labels tracked by Ecolabel Index are either locally applied (e.g. Galapagos Quality or Tunisia Ecolabel) or sector-specific (e.g. Eco Hotels Certified). Destinations and travel companies rarely use these labels in their communications, e.g., on their websites or other types of advertisements. For example, EarthCheck is a company that positions itself as "the world's leading scientific benchmarking certification and advisory group for travel and tourism" that provides certification for sustainable destinations and travel companies since 1987 (http://www.ecolabelindex.com/ecolabel/earthcheck, https://earthcheck.org/) However, a quick search revealed that none of the EarthCheck members use its logo on the front pages of their websites or even mention that they are "EarthCheck certified." Even when the information about sustainable actions or offers is available on the travel websites, it is made less accessible to potential consumers, e.g. is hidden under the second- or third-level links and tabs.

This phenomenon of the intentional non-use of sustainability messages in companies' communications, is named "greenhushing." Greenhushing is "the deliberate withholding, from customers and stakeholders, of information about the sustainability practices that they employ" 
(Font, Elgammal, and Lamond 2017, p. 1007). Businesses, specifically, tourist companies report and communicate to consumers only $30 \%$ of their efforts (Font, Elgammal, and Lamond 2017).

The literature identifies several possible reasons for greenhushing. First, companies may perceive that their communication should not conflict with consumer rights of consumerism and hedonic shopping (Baker, Davis, and Weaver 2014; Font, Elgammal, and Lamond 2017). Tourism has been viewed as a totally hedonic, i.e., unnecessary and non-essential product consumed mostly for pleasure and emotional experiences (Alba and Williams 2013; Baker, Davis, and Weaver 2014; Melo and Farias 2018). Sustainability, on the other hand, involves behaviors based on ethical values and principles including responsible and reduced consumption and decreased impact on the environment (Font and McCabe 2017). Sustainable consumers are less focused on immediate satisfaction and their own benefits but care more about the long-term benefits for the planet (White, Habib, and Hardisty 2019). Consumers may perceive that sustainable travels are less convenient and less luxurious for them, for example, if they have to choose alternative transportation means, e.g., traveling by bus vs. by their own cars, or walking (Baker, Davis, and Weaver 2014). Thus, tourists seeking for pleasure and positive emotions may perceive sustainable travel offers as incompatible with their personal goals.

Second, to positively respond to a message, consumers must view this message as accurate and credible (Lutz, MacKenzie, and Belch 1983; MacKenzie and Lutz 1989). However, making universal truthful and credible claims about sustainable tourism is not always possible due to the complexity of tourism product compared to other product categories, e.g., food products. While consumers easily make connections between sustainable features of the food product and their own benefits (e.g., "organic" = "healthy"), their perception of benefits of sustainable tourism products may vary because their effects are spread across society (Buckley 2013). Informational 
asymmetry (i.e., consumers hold less information about the labels than manufacturers/sellers do) and misinterpretation of labels (i.e., consumers have different levels of awareness about the information used on the labels) were mentioned as the most common reasons why such labels were ineffective (e.g. Atkinson and Rosenthal 2014; Font and McCabe 2017). For example, in Gössling and Buckley's (2016) study of carbon labels, only 5\% of respondents reported that labels containing numerical indicators, such as the amount of $\mathrm{CO}_{2}$ emissions (" $\mathrm{kg} \mathrm{CO}_{2}$ "), helped in travel decision-making, while $2 \%$ reported strong influence and $26 \%$ - some influence on their decisions when more simple color-coded carbon labels were used. Moreover, when consumers are unable to understand sustainability messages, they may think that companies act for their own benefit of cost cutting (e.g., a hotel introduced towel reuse programs to cut laundry cost rather than to save the environment) and do not provide any benefits for consumers (e.g., Baker, Davis, and Weaver 2014; Robinot and Giannelloni 2010).

Finally, there might be other reasons that originate from consumers' individual barriers to positive evaluations of the green products, e.g., higher prices, lower quality, low/no trust in greenness, apathy (low or no environmental awareness), brand loyalty (loyal to other non-green brands) (Gleim et al. 2013).

Another concern for marketers that promote sustainable products is the discrepancy between intentions and behaviors of consumers. Consumers state high sustainable attitudes and understanding of the environmental problems but demonstrate less actual behaviors in support of those attitudes (Budeanu 2007). Also, consumers may demonstrate different levels of environmental responsibility under certain conditions, for example, environmental responsibility may be higher at home than in a hotel (Baker, Davis, and Weaver 2014). 
Sustainable consumption is often viewed as a preference of a specific narrow group of consumers, the "green consumer" segment (e.g., Akehurst, Afonso, and Gonçalves 2012; Laroche, Bergeron, and Barbaro-Forleo 2001; Roberts 1996). However, as sustainability grows in importance, marketers now must consider targeting sustainable communication to a broader audience (Wehrli et al. 2017; White, Habib, and Hardisty 2019).

\section{Brand Anthropomorphism and Sustainability}

Anthropomorphism or imbuing an inanimate object with humanlike characteristics has been shown to increase the liking, attitudes, and purchasing intentions of products. Turning to this research, credibility and emotionality of sustainable messages can be enhanced by anthropomorphism (Epley, Waytz, and Cacioppo 2007).

The term "anthropomorphism" is derived from the two Greek words, anthropos ("human") and morphe ("shape" or "form"). Anthropomorphism goes beyond just a description of observed humanlike behaviors; it is a "process of inference about unobservable characteristics of a nonhuman agent" (Epley, Waytz, and Cacioppo 2007; p. 865).

Humans anthropomorphize non-human objects, such as supernatural beings (Niemyjska and Drat-Ruszczak 2013), natural phenomena (Waytz, Epley, and Cacioppo 2010), technical objects (Eyssel and Kuchenbrandt 2012), and companies, brands and products (Aggarwal and McGill 2012; Stinnett, Hardy, and Waters 2013), even if humanlike features of these objects are less directly observable.

People assign human characteristics to nonhuman objects to address the following needs. First, they need to effectively interact with the world (White 1959). Thus, in uncertainty situations, when the information about a nonhuman object is unavailable, anthropomorphism 
helps understanding the nonhuman agent's actions and predicting its future behaviors. The reason people apply their knowledge about humans is that it is readily accessible because people acquire knowledge about themselves or other people's behaviors from their early childhood throughout their lives (Epley, Waytz, and Cacioppo 2007). Second, people tend to establish social connections with other people. In the absence of connections with humans, they may satisfy this need establishing connections with nonhuman objects (Epley, Waytz, and Cacioppo 2007).

Epley et al. (2008) described the following consequences of anthropomorphism. First, when an agent is assigned human characteristics, it is perceived to have a mind and is treated as a moral agent. As a result, people automatically respond to anthropomorphized agents as they would respond to human beings (Chartrand, Fitzsimons, and Fitzsimons 2008).

Second, anthropomorphism increases the likelihood of interactions with non-human agents, and, according to social exchange theory (Blau 1964), interacting parties evaluate the extent to which they are associated with each other and what rewards they may expect from this exchange. When an agent has a mind and morale, it is perceived to hold certain values and can exhibit a normative social influence on a human (Waytz, Cacioppo, and Epley 2010) increasing empathy and connectedness with objects (Tam, Lee, and Chao 2013), avoidance to harm an object, desire to save it from destruction and make it happy (Gray, Gray, and Wegner 2007). Anthropomorphism can also predict such specific behaviors as concern for the environment and trust in decisions made by technological agents (Waytz, Cacioppo, and Epley 2010) and increase willingness to volunteer and donate to nonprofits (Stinnett, Hardy, and Waters 2013).

Marketers take advantages of anthropomorphism, employing and activating anthropomorphic characteristics of products and brands (Aggarwal and McGill 2007, 2012; 
Chandler and Schwarz 2010). Brand personalities as well as the anthropomorphic characteristics of a product, such as smiling faces (Aggarwal and McGill 2007; Labroo, Dhar, and Schwarz 2008) and textual personifications (Ahn, Kim, and Aggarwal 2014; Letheren, Martin, and Jin 2017), increase the liking of these products, positive attitudes, and purchasing intentions.

In tourism marketing, anthropomorphism is mainly used in the form of a country's or an event's mascot, e.g., in the Paris 2024 Olympics logo, one can see the image of a French national symbol Marianne (Wharton 2019). To the best of our knowledge, little research has been conducted on utilization of anthropomorphized messages in sustainable tourism promotion. Yet this begs the obvious question — can anthropomorphism be used to help effect tourism marketing communications, specifically in the tourism sector?

Based on the previous findings from marketing literature, we propose that anthropomorphized sustainability communications will increase consumer positive behavioral intentions toward the sustainable destination brands. Specifically, anthropomorphism will reduce uncertainty that may be caused by unfamiliarity with a sustainability label and will increase connectedness with a brand.

\section{Conclusion}

This dissertation aims to understand the effects of sustainability labels on consumer behavioral outcomes. In this chapter, a theoretical background for this study is presented. The first section of this chapter defines sustainability, describes guiding principles of sustainable development, and explains the importance of sustainable development in tourism industry. 
Further, this chapter discusses challenges in communicating sustainability messages in tourism industry. Specifically, in this literature review, the phenomenon of greenhushing and possible reasons for it were explored. Finally, the anthropomorphism framework was discussed in this chapter. This framework provides a foundation to addressing the issue for greenhushing in tourism industry.

In the next chapter, we will present the conceptual model and hypotheses that will help understanding the mechanisms through which sustainability messages increase intention to visit a sustainable travel destination, intention to recommend it to someone else, and willingness to pay price premium for the sustainable offer.

\section{CHAPTER 3}

\section{CONCEPTUAL MODEL AND HYPOTHESES}

In the previous chapter, we have identified possible reasons for greenhushing, such as incompatibility of sustainability with hedonic purpose of tourism and broad meaning of sustainability in tourism that leads to misunderstanding of sustainability messages presented in a label format.

In this dissertation, we apply the social exchange theory (Blau 1964; Emerson 1976) and the theory of anthropomorphism (Epley, Waytz, and Cacioppo 2007) to address the issue of greenhushing and to develop mechanisms that will lead to positive acceptance of sustainability messages and corresponding behavioral outcomes.

Figure 1 represents the conceptual model. We propose that presence (vs. absence) of a sustainabiliy label in sustainable tourism communications will increase consumer positive 
behavioral intentions, specifically, intention to visit a travel destinaiton, intention to recommend it to someone else (word of mouth), and willingness to pay price premium. These effects will occur through the mediating mechanisms of goal congruence and connectedness. We further propose that inclusion of anthropomorphic elements in sustainable tourism communications will positively influence consumer positive behavioral intentions. These effects will be moderated by consumer environmental awareness and emotional framing (positive vs. neutral). The hypothesized relationships are explained in the subsequent sections. The construct definitions in this dissertation are based on previous literature (see Table 1). 
Figure 3. 1 Research model.

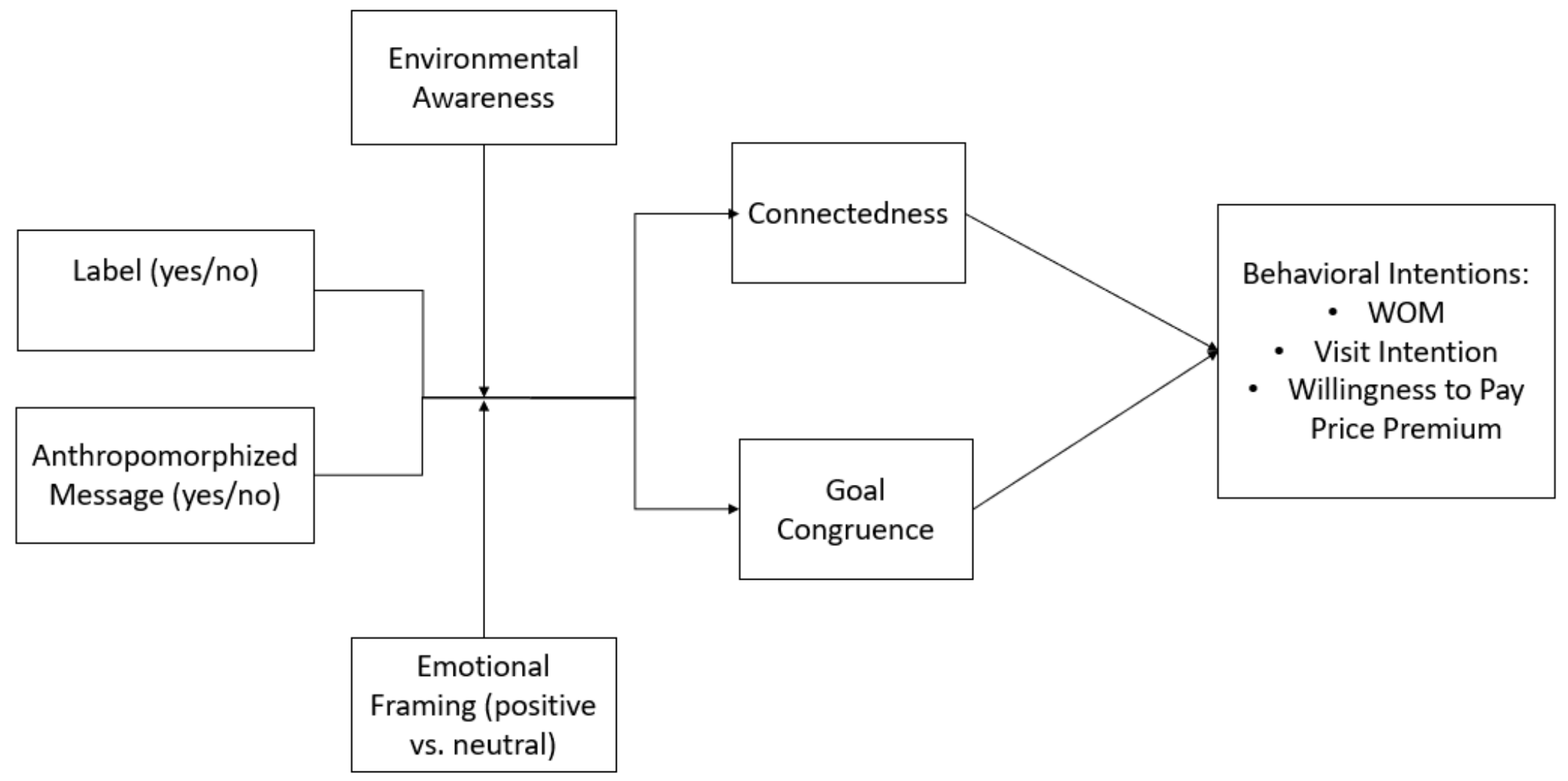


Table 3. 1 Definitions of Key Constructs

\begin{tabular}{|l|l|}
\hline Construct & Definition \\
\hline Visit intention & $\begin{array}{l}\text { Visit intention is a measure of purchase intention which is a consumer's } \\
\text { intention to buy a product or a brand in a certain condition (e.g., Salisbury } \\
\text { et al. 2001; Saad et al. 2012). }\end{array}$ \\
\hline Word of mouth & $\begin{array}{l}\text { Word of mouth is the likelihood of customer positively referring the seller } \\
\text { to another potential customer (Hennig-Thurau, Gwinner, and Gremler } \\
\text { 2002) }\end{array}$ \\
\hline $\begin{array}{l}\text { Willingness to } \\
\text { pay } \\
\text { premium }\end{array}$ & $\begin{array}{l}\text { Willingness to pay price premium is reservation price, or the maximum } \\
\text { amount a customer is willing to pay for a good, or, stated differently, the } \\
\text { price at which a consumer is indifferent between buying and not buying the } \\
\text { product (Jedidi and Zhang 2002). }\end{array}$ \\
\hline $\begin{array}{l}\text { Consumer } \\
\text { connectedness to } \\
\text { the brand }\end{array}$ & $\begin{array}{l}\text { Connectedness to the brand reflects the extent to which the brand is linked } \\
\text { to the self, given its essentiality in facilitating utilitarian, experiential and/or } \\
\text { symbolic needs (goals) (Park, Macinnis, and Priester 2006) }\end{array}$ \\
\hline Goal congruence & $\begin{array}{l}\text { Goal congruence is defined as the extent to which a transaction is consistent } \\
\text { or inconsistent with what the person wants-that is, it either thwarts or } \\
\text { facilitates personal goals (Lazarus 1991,p. 150, cited in Soscia 2007). }\end{array}$ \\
\hline $\begin{array}{l}\text { Environmental } \\
\text { awareness }\end{array}$ & $\begin{array}{l}\text { Environmental awareness is the knowledge "of the impact of human } \\
\text { behavior on the environment" (Kollmuss and Agyeman 2002, p. 253). }\end{array}$ \\
\hline $\begin{array}{l}\text { Anthropomorphic } \\
\text { tendency }\end{array}$ & $\begin{array}{l}\text { Anthropomorphic tendency is the tendency to anthropomorphize nonhuman } \\
\text { agents (Waytz, Cacioppo, and Epley 2010). }\end{array}$ \\
\hline
\end{tabular}




\section{Label Presence $\rightarrow$ Behavioral Outcomes}

Sustainable tourism development is a complex phenomenon that involves the optimal use of various types of resources - economic, natural, cultural, etc. - of travel destinations (UNEP and UNWTO 2005). However, sustainable tourism literature is mostly focused on the preservation and conservation of natural resources (Liu 2003), and sustainable tourism is often misrepresented with eco, environmental, or green tourism with the emphasis on nature and wildlife. This notion of sustainable tourism conflicts with actual sustainability messages. Tourists seeking for pleasure and satisfaction of their hedonic motivations may perceive that traveling to a sustainable destination will limit their experiences and perceptions of luxury and convenience (Baker, Davis, and Weaver 2014).

In addition, a broad meaning of the concept of sustainable tourism - optimal utilization of all types of resources for creating benefits for all stakeholders (UNEP and UNWTO 2005) creates a lot of uncertainty about sustainable travel offers. These broad claims also do not allow creating rigorous and uniform certification and quality-rating systems for sustainable tourist products that would be communicated in a form of a label (symbol or pictogram) understandable for consumers. As a result, tourist companies avoid communicating their sustainable efforts and rarely or never use sustainable messages in their communications (Font, Elgammal, and Lamond 2017).

Existing academic literature on sustainability in tourism provides mixed findings regarding the effect of sustainability labels on consumer behaviors and intentions. For example, Wehrli et al. (2017) empirically examined in four countries that emotional communication elements (symbols, images, key words, emotional connotations, etc.) best address sustainability issues both for sustainability-experienced and non-experienced tourists. In contrast, Vicente and Melo (2014) did 
not find any significant impact of sustainability elements placed on destination websites on formation of a positive destination image and visit intentions.

However, marketing literature provides evidence regarding the utility of sustainability labels in other industries. In food industry, labels are viewed as cues that signal certain quality and ethical characteristics of sustainable products to consumers (e.g., Howard and Allen 2006; De Pelsmacker et al. 2005;) and, as a result, increase consumption of these products. For example, use of food sustainability labels increases purchase or consumption of sustainable food and drink products (Potter et al. 2021). Such labels also increase consumption of sustainable products in energy sector (Banerjee and Solomon 2003).

Thus, we hypothesize that, when exposed to sustainability labels placed on tourism marketing materials, consumers will be more likely to positively evaluate the message and to respond to it. These positive responses may take the form of positive word of mouth (WOM), or positively referring the destination to other potential customers (Hennig-Thurau, Gwinner, and Gremler 2002); purchase intention, or intention to visit the destination (Aggarwal and McGill 2007; Labroo, Dhar, and Schwarz 2008), and willingness to pay price premium (Laroche, Bergeron, and Barbaro-Forleo 2001; Okada and Mais 2010).

H1: Presence (vs. absence) of a sustainability label in a sustainable tourism communication will increase a) intention to visit a destination, b) intention to spread positive word-of-mouth about the destination (WOM), and c) willingness to pay price premium (WTP).

\section{Anthropomorphism $\rightarrow$ Behavioral Outcomes}

Informational asymmetry (i.e., consumers hold less information about the labels than manufacturers/sellers do) and misinterpretation of labels (i.e., consumers have different levels of 
awareness about the sustainability concept) are mentioned as the most common obstacles to label adoption and use (e.g. Atkinson and Rosenthal 2014; Font and McCabe 2017).

As it was mentioned in the previous section of this dissertation, a broad meaning of the concept of sustainable tourism may create difficulties in designing uniform labels that would be easily understood and interpreted by consumers. The proposed anthropomorphism framework aims to reduce uncertainties related to miscommunication of sustainable tourism offers. Anthropomorphism reduces uncertainty and helps understanding and predicting the nonhuman objects' behaviors. Moreover, when people humanize non-human objects, they are more likely to treat them as agents having a mind and morale (Epley et al. 2008) and to interact with them as with human beings (Chartrand, Fitzsimons, and Fitzsimons 2008).

According to social exchange theory (e.g. Blau 1964; Emerson 1976), interactions between two parties are viewed as a social exchange (Homans 1961, p.13; c.f. Cook and Rice 2013). According to Blau (1964, p. 91), social exchange "refers to voluntary actions of individuals that are motivated by the returns they are expected to bring and typically do in fact bring from others." In other words, in social exchanges under uncertainty conditions, parties are evaluating the extent to which they are associated with each other and what rewards they may expect from this exchange (Blau 1964). Anthropomorphism increases these positive associations between a consumer and a brand and leads to expectations of positive exchange outcomes.

H2: Embedding anthropomorphic stimuli in sustainable messages will increase a) intention to visit a destination, b) intention to spread positive word-of-mouth about the destination, and c) willingness to pay price premium. 


\section{Mediating Effects of Connectedness and Goal Congruence}

Interactions between tourists and destinations can start long before the actual visit. Tourism product is hedonic by its nature (Font and McCabe 2017; Vinerean 2013) and, for many people, it may become a unique lifetime experience. As a result, consumers may start being connected with a destination before they actually book or purchase a trip. Relationship marketing theory predicts that the seller and the buyer (Morgan and Hunt 1994) or the brand and the customer (Fournier 1998) establish relationships based on the similarity or congruence of lifestyle, goals, and values. Vice versa, when feeling connected with a destination, consumers will perceive that their goals are congruent with a destination's goals.

Goal congruence is defined as "the extent to which a transaction is consistent or inconsistent with what the person wants - that is, it either thwarts or facilitates personal goals" (Lazarus 1991, p. 150, cited in Soscia 2007). It is a concept widely used in organizational and business-to-business marketing research to explain relationship formation between organizations (Cuevas, Julkunen, and Gabrielsson 2015), an employee and an organization (Coote, Price, and Ackfeldt 2004), or a buyer and a supplier (Yan and Dooley 2013). Goal congruence occurs when a relational party perceives a fit between his/her beliefs and values and beliefs values of the other party in this relationship (Coote, Price, and Ackfeldt 2004) especially under uncertainty situations (Yan and Dooley 2013). Goal congruence is associated with perception of fairness (Coote, Price, and Ackfeldt 2004) and equal power (Cuevas, Julkunen, and Gabrielsson 2015) and is considered a predictor of numerous positive relational outcomes, such as project performance (Yan and Dooley 2013), trust (Cuevas, Julkunen, and Gabrielsson 2015), and partnership (Scott and Gable 1997). It was also found that goal congruence elicit positive emotions, such as happiness (Soscia 2007). 
In sustainable tourism promotion, perception of goal congruence will reduce consumption barriers related to perceived lack of benefits, convenience, and comfort (Baker, Davis, and Weaver 2014; Font, Elgammal, and Lamond 2017; Robinot and Giannelloni 2010). In other words, if consumers perceive that, with a sustainable message, a destination is not pursuing its own benefits but the understanding of benefits (e.g., a pleasurable vacation) is shared between a destination and a consumer, they will be more likely to save this destination as an option for a future travel in a mental "shopping basket" (visit intention) and will support the destination's sustainable initiatives (via word-of-mouth).

Also, sustainable travels are perceived to be more costly for tourists because of the nature of the experience. Eating at the authentic local restaurant is more expensive compared to a fastfood chain, and using alternative transportation (e.g., riding a bicycle or walking instead of driving a car) can take more time. Higher price (in a combination with lower quality) was identified as one of the top barriers to sustainable consumption (Gleim et al. 2013). Thus, paying price premium for sustainable products/services is an important goal of sustainable communication. Laroche, Bergeron, and Barbaro-Forleo (2001) consider willingness to pay a higher price to be an evidence supporting increasing sustainable consumer behavior. Consumers are willing to pay a higher value for "green" products and services both when they are environmentally concerned and value the benefits of sustainable offer (Kang et al. 2012) and when they are less environmentally conscious but want to avoid the negative effects of consuming non-sustainable products (Okada and Mais 2010).

\section{H3: Consumer connectedness with a travel destination will mediate the effects of} sustainability label on a) intention to visit a destination, b) intention to spread positive word-ofmouth about the destination, and c) willingness to pay price premium. 
$\mathbf{H}_{4}$ : Perceived congruence between the consumer's and travel destination's goals will mediate the effects of sustainability label on a) intention to visit a destination, b) intention to spread positive word-of-mouth about the destination, and c) willingness to pay price premium.

\section{Moderating Effect of Emotional Framing}

Emotionality (vs. rationality) is the appeal that may trigger positive consumer attitudes toward sustainable offer. Emotional communications are addressing consumers' emotions and feelings (Albers-Miller and Royne Stafford 1999; Bagozzi, Gopinath, and Nyer 1999) while rational communications employ cognitive appeals and factual information (Batra and Ray 1986). Rational communications are more effective in advertising utilitarian products (Bagozzi, Gopinath, and Nyer 1999) and were considered least effective for sustainable products (Wehrli et al. 2017). Emotional appeals are more effective for advertising hedonic (vs. utilitarian) products (e.g., Johar and Sirgy 1991; Tsao 2010; Wehrli et al. 2017) and services (Pang, Keh, and Peng 2009).

Turning to the tourism industry, emotional communications were most effective for advertising sustainable tourism products (Wehrli et al. 2017). Wehrli et al. (2014) also found that emotional communication elements (symbols, images, key words, emotional connotations, etc.) best address sustainability issues both for sustainability-experienced and non-experienced tourists.

Research has also found that emotional communications are more effective and persuasive when the message is delivered by an anthropomorphic object (e.g., (Aggarwal and McGill 2007). However, it is unclear from the literature, what emotions are effective in communicating sustainable tourism. The present research on anthropomorphic sustainability messages has 
focused on the actions driven by negative emotions. For example, Ketron and Naletelich (2019) found that, when an anthropomorphic messenger (e.g., a logo) had a sad facial expression, it was viewed as a victim, and consumers were more willing to help the victim due to the evoked feeling of sympathy. Ahn, Kim, and Aggarwal (2014) also used anthropomorphic stimuli with negative (sad) face expression in their study of effects of an anthropomorphized social cause on compliance with the message. They found that this effect was mediated by feelings of anticipatory guilt.

However, the hedonic nature of tourism suggests that negatively framed emotions may deter consumers from sustainable travel activities. The hedonic consumption perspective suggests that the main driver of hedonic consumption is the unique consumption experience (Hudson and Murray 1986) that allows consumers to avoid and escape from negative and unpleasant realities and to fulfil their fantasies (Hirschman 1983). Thus, a sustainable message should cause a reaction and an action that is compatible with the hedonic purpose of consumption. Such emotions as guilt or sympathy, previously viewed as mediators in sustainable communications, may conflict with the consumer's positive expectations (he or she wants to have a pleasurable and enjoyable experience rather than become a savior). Moreover, strong feelings of distress, guilt, or helplessness do not lead to action because, if the person feels that (s)she cannot change the situation, (s)he will less likely take any pro-environmental action (Kollmuss and Agyeman 2002).

Miao, Lehto, and Wei (2014) found that customer experience with consumption starts before the actual consumption occurs. The authors looked at three different types of experiences: predicted (consumer expectations about the future interactions with a product), experienced (at the moment of purchase), and remembered (after the purchase). Their findings suggest that 
hedonic value was the highest for the predicted experience, e.g. vacation planning. Hence, it is very important that on this stage consumers have positive emotions and feelings toward sustainable brand. These positive emotions may be triggered by using positive (vs. negative) framing of sustainable communication message.

\section{H5a: Emotional framing will moderate the effects of anthropomorphized sustainability} message on consumer connectedness with a travel destination.

\section{H5b: Emotional framing will moderate the effects of anthropomorphized sustainability} message on perceived congruence between the consumer's and travel destination's goals.

\section{Moderating Effect of Environmental Awareness}

The extent to which a consumer is influenced by sustainability communications depends on the levels of his/her environmental awareness and perceived fit between sustainability values and consumer's own values and lifestyle.

Over the last 40 years, researchers have explored the antecedents to environmental attitudes and behaviors and the factors that explain the gap between those two. Research has shown that, despite the increased body of information on sustainable consumption, only a small segment of consumers fully understands the impact of consumption on environment (Rettie, Burchell, and Barnham 2014). This small segment is characterized by higher level of environmental awareness, or the knowledge "of the impact of human behavior on the environment" (Kollmuss and Agyeman 2002, p. 253).

However, the findings regarding the role of consumer awareness in positive reactions to sustainability messages are conflicting. Environmental concern of consumers generally has a positive impact on their behavioral intentions (Lee and Holden 1999; Robinot and Giannelloni 
2010; Pagiaslis and Krontalis 2014) and their ecological lifestyle is positively associated with the behavioral intentions (Chen 2014). Okada and Mais (2010) found that positive framing (focusing on the advantages of green product) functions better for the environmentally aware consumers, while negative framing (focusing on avoiding the disadvantages of the non-green product) functions better for the less aware consumers. In the contrary, Melo and Farias (2018) found that people with low ecological awareness demonstrated more positive emotions towards a travel destination and a higher intention to visit it when presented with hedonic (vs. utilitarian) sustainability stimuli.

Following Kollmuss and Agyeman (2002), we propose that environmentally aware consumers are more likely to be guided by sustainable messages and are more likely to experience emotions that lead to actions, specifically, to bonding with a destination and aligning consumer own goals with the destination's goals. Thus, we hypothesize that:

H6a: Consumer's environmental awareness will moderate the effects of sustainability label on consumer connectedness with a travel destination.

H6b: Consumer's environmental awareness will moderate the effects of sustainability label on perceived congruence between the consumer's and travel destination's goals.

\section{Control variables}

In testing the effects of anthropomorphized sustainability messages on consumer behavioral outcomes, three relevant control variables will be included in the model: anthropomorphic tendency, familiarity with a brand (destination), and age. The rationale for each variable is discussed briefly. 
First, people humanize brands in various ways and the process is highly subjective and depends on the levels of anthropomorphic tendency - the individual propensity to anthropomorphize (Waytz, Cacioppo, and Epley 2010). Different people anthropomorphize to a different extent. For example, some people argue with their devices, give them names, or assign certain intentions (e.g., "My car betrayed me and did not start this morning") while for others such behaviors do not make any sense and look ridiculous. Therefore, anthropomorphic tendency is likely to affect perception of connectedness and goal congruence.

Second, research has found that attitudes toward sustainable products varies among various age groups. Specifically, younger generational cohorts (gen $\mathrm{Y}$ and $\mathrm{Z}$ ) have shown greater interest in the topic than prior generations (Ketron and Naletelich 2019).

Finally, although we will use a fictitious travel destination in our studies, consumers may still have individual biases if the destination's name sounds familiar to them. As such, controlling for anthropomorphic tendency, age and familiarity with the brand will help to eliminate possible alternative explanations of findings.

In the next chapter, we will present the methodology to empirically test the hypotheses developed in this chapter. 


\section{CHAPTER 4}

\section{METHODS}

\section{Introduction}

This chapter describes methods that were applied to empirically test the conceptual model developed in Chapter 3. This chapter is divided into two sections: Pretests and Main Study.

To make our empirical research more realistic and to ensure that research participants did not have any previous associations, we designed a mock website of a fictitious travel destination and asked participants to spend on the website as much time as they needed to decide about visiting this destination. We also designed three different types of sustainability labels using content analysis and topic modeling. In the "Pretests" section, we discuss the pretests of the stimuli, statistical methods used to analyze the data, and the results.

We tested our hypotheses with a controlled between-subjects online experiment using a sample form Amazon Mechanical Turk CloudResearch panel. In the Main Study section, we discuss research design, sampling procedures, measurement, data collection, and statistical analyses that we used to test our conceptual model.

\section{Pretests}

Content analysis. To design the labels that include anthropomorphized elements, it is necessary to identify the key topics that are used to describe and promote sustainable tourism initiatives. "Topic modeling" technique is a tool that helps discovering topical patterns that are 
present across the large collection of text documents using a defined algorithm (e.g., Latent Dirichlet Allocation, or LDA).

1. The first step in the analysis is scraping data from the English versions of the official country's travel websites. Out of 195 countries, 17 did not have official tourism website leaving $\mathrm{n}=178$ (see complete list of the websites in Appendix B). Text scraping was based on the two keywords: "sustainability" and "sustainable tourism." Scraping resulted in 7387 web pages containing either of the two keywords (to obtain the full list of web pages please contact the author).

2. Next, we randomly selected 500 web pages and read their content as text objects including html, css, and javascript elements and recorded the text as a dataframe object (see Python code for this and further operations in Appendix C).

3. Then we identified javascript and css scripts $(<$ javascript $><$ javascript $>$ and $<$ style $><$ style $>$ ) and deleted them from the object containing selected files.

4. We removed the following stop words:

'item', 'href', 'www', 'px', 'com', 'type', 'id', 'width', 'text', 'en', 'quot', 'icon', 'height', 'color', 'js', 'top', 'value', 'image', 'src', 'css', 'jpg', 'api', 'rel', 'hidden', 'size', 'page', 'margin', 'hover', 'name', 'images', 'weight', 'target', 'min', 'container', 'background', 'true', 'left', 'url', 'important', 'navbar', 'block', 'right', 'settings', 'alt', 'padding', 'border', 'display', 'wrapper', 'files', 'png', 'javascript', 'jpeg', 'max', 'bottom', 'styles', 'widget', 'svg', 'none', 'dropdown', 'components', 'box', 'slide', 'position', 'jquery', 'assets', 'sections', 'format', 'children', 'dark', 'srcset', 'links', 'list', 'document', 'wrap', 'submenu', 'transform', 'visible', 'row', 'megamenu', 'top_bar', 'toggle', 'window', 'lang', 'plugins', 'webkit', 'responsive', 'click', 'logo', 'grid', 'items', 'overlay', 'screen', 'stylesheet', 'slider', 'uploads', 'attributes', 'align', 'slideshow', 'homepage', 'navigation', 'inner', 'parent', 'php', 'opacity', 'uid', 'inline', 'uuid', 'absolute', 'metadata', 'field_folder', 'rgba', 'cache', 'relative', 'autocomplete', 'placeholder', 'field_menu_link', 'float', 'flex', 'child', 'name_key', 'json', 'vertical', 'visibility', 'txt', 'overflow', 'scroll', 'xmins', 'cacheid', 'scale', 'angle', 'animation', 'btn', 'tag', 'modal', 'ajax', 'submit', 'bold', 'checkbox', 'tourism', 'travel', 'sustainable', 'region', 'destination', 'http', 'https', 'from', 'subject', 're', 'edu', 'use', 
"!important;", ".panel-row-style", "li", "ul", "menu", "\});,",

"we", "our", "ours", "ourselves", "you", "your",

"yours", "yourself", "yourselves", "he", "him", "his", "himself", "she", "her",

"hers", "herself", "it", "its", "itself", "they", "them", "their", "theirs",

"themselves", "what", "which", "who", "whom", "this", "that", "these", "those", "am", "is", "are", "was", "were", "be", "been", "being", "have", "has", "had", "having", "do", "does", "did", "doing", "a", "an", "the", "and", "but", "if", "or", "because", "as", "until", "while", "of", "at", "by", "for", "with", "about", "against", "between", "into", "through", "during", "before", "after", "above", "below", "to", "from", "up", "down", "in", "out", "on", "off", "over", "under", "again", "further", "then", "once", "here", "there", "when", "where", "why", "how", "all", "any", "both", "each", "few", "more", "most", "other", "some", "such", "no", "nor", "not", "only", "own", "same", "so", "than", "too", "very", "s", "t", "can", "will", "just", "don't", "should", "now", "the", "a", "an", "australia", "australian", "zealand", "melbourn", "sydney", "also", "queensland", "said", "one", "well", "costa", "lenard", 'amp', 'ver', 'arrow', 'af', 'bar', 'fetch', 'family', 'mice', 'mod', 'clearfix', 'resources', 'und', 'post_type', 'noopener', 'description', 'fid', 'noreferrer', 'property', 'ba', 'options', 'status', 'dc', 'event', 'close', 'transition', 'mk', 'banner',

'fa', 'sf', 'fff', 'external', 'callback', 'media', 'central', 'mobile', 'events', 'search', 'aria', 'category', 'moz', 'ee', 'site', 'ed', 'df', 'ui', 'zm', 'wp', 'themes', 'date', 'auto', 'fb', 'timestamp', 'index', 'related', 'normal', 'cc', 'sticky', 'widgets', 'ff', 'es', 'el', 'fluid', 'thumbnail', 'alternate', 'st', 'global', 'mp', 'init', 'first', 'md', 'cookies', 'trigger', 'theme', 'aa', 'get', 'nbsp', 'flag', 'ac', 'de', 'post', 'bf', 'ab', 'filter', 'heading', 'sites', 'safe_value', 'sm', 'visitestonia', 'rica', 'estonia', 'lt', 'org', 'xs', 'elementor', 'estonia', 'file', 'org', 'visitlaos', 'slovenia', 'targettype',

'filename', 'uri', 'rdf_mapping', 'guanacaste', 'tid', 'fusion', 'ubermenu', 'malawitourism', 'filesize', 'sp', 'filemime',

'filesize', 'pcp', 'path', 'visitdenmark', 'taxonomy_term', 'visittheusa', 'modules', 'field', 'ict', 'fr', 'column', 'visitfinland',

'ffffff', 'caribbean', 'visit', 'gtm', 'puntarenas', 'sv', 'gt', 'cp', 'myswitzerland', 'mega', 'lg', 'us', 'dexp', 'ss', 'consent', 'gdlr', 'gtm', 'ca',

We also removed stop words related to html, css, and javascript commands.

5. We used frequency analysis to identify and remove leftovers of html, css, and javascript commands. 
6. Finally, we created a dictionary for each text document and analyzed each dictionary with LDA algorithm that produced a model which identified the key topics within sustainable tourism domain, the words occurring in each topic, and their corresponding weights.

LDA analysis identified five latent topics and corresponding words related to these topics. The results of the LDA analysis are presented in Table 4.1.

\section{Table 4. 1 Results of LDA Analysis}

\begin{tabular}{|l|l|l|l|l|}
\hline \multicolumn{1}{|c|}{ Topic A } & \multicolumn{1}{c|}{ Topic B } & \multicolumn{1}{c|}{ Topic C } & \multicolumn{1}{c|}{ Topic D } & \multicolumn{1}{c|}{ Topic E } \\
\hline tie & pacific & see & pacific & pacific \\
\hline see & cultural & pacific & valley & northern \\
\hline custom & south & south & south & cultural \\
\hline social & activities & level & predicates & activities \\
\hline pacific & areas & plains & cultural & valley \\
\hline showreel & northern & tie & northern & south \\
\hline go & node & social & plains & areas \\
\hline line & line & cultural & attractions & attractions \\
\hline rem & valley & activities & activities & predicates \\
\hline active & predicates & attractions & tie & plains \\
\hline
\end{tabular}

We further examined each topic and found that some words appeared in more than one topic and all five topics could be grouped under a higher-order construct "General geography terms" (see Figure 4.2). 
Figure 4. 1 Results of LDA Analysis

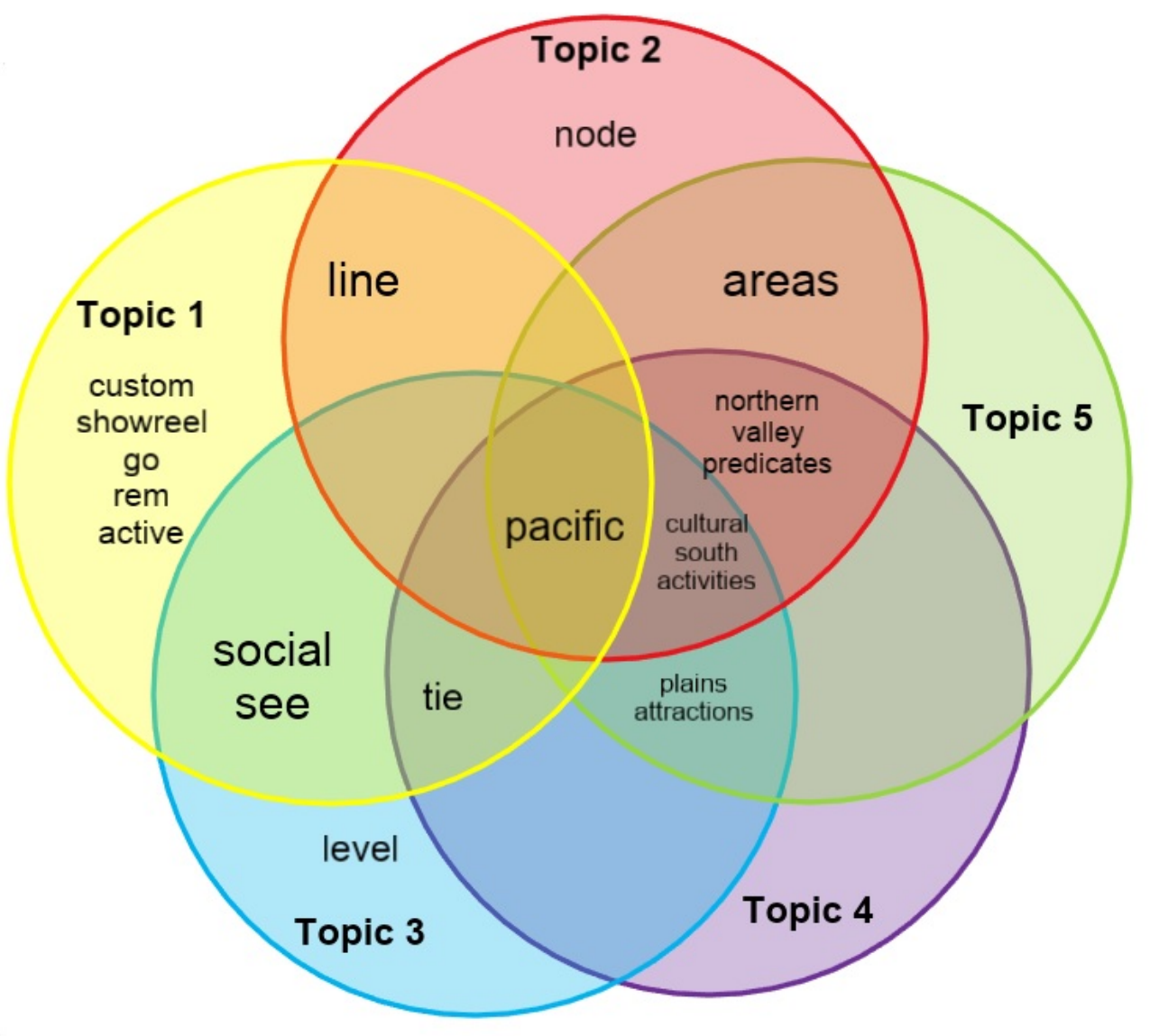




\section{Pretest 1 - Label Design and Validation}

Based on the construct "General geography terms" identified with the text modeling

analysis we designed a sustainability label (see Appendix D). To get empirical validation for the stimulus, the label was pretested to examine how it was understood and perceived by consumers. A pretest was conducted using Amazon's Mechanical Turk (mTurk) CloudResearch sample.

The participants were asked to evaluate familiarity with the label, its realism, and the message that it communicated to consumers, and were asked about their attitudes to the logo.

\section{Measures:}

Familiarity: a one-item 5-point Likert-type scale with endpoints "definitely not" and “definitely yes."

Realism: a one-item 5-point Likert-type scale (endpoints "strongly disagree" and "strongly agree").

Attitudes toward the logo: a five-item 5-point semantic differential scale, Chronbach's alpha $=.93$. The example is: "Now think about how the present logo would make you feel. To what extent would you feel: negative - positive?"

Logo meaning: the participants were asked to describe what the logo was communicating to them in an open-response question. Their responses were further coded as follows:

0 - does not communicate anything/does not communicate sustainability or sustainable tourism

1 - communicates sustainability

2 - communicates sustainable tourism. 
Finally, the participants were asked to evaluate the overall design of the logo on a oneitem 5-point Likert-type measure (endpoints "poor" and "excellent").

Sample and procedures. 29 participants were recruited via Amazon's Mechanical Turk (mTurk) CloudResearch panel. The following mandatory qualifications were included for mTurk participants: (1) Only individuals eighteen years of age or older were invited to participate; and (2) all participants needed a prior mTurk job-approval rate (i.e., indicating superior performance) of 90 percent or higher (the complete Qualtrics questionnaire is presented in Appendix E).

To ensure the quality of responses, one attention check was used across the study. For the question "From what sources do you get your news?" participants were asked to select "none of the above." One participant failed the attention check and was excluded from the study leaving $\mathrm{n}=28(39.3 \%$ female $)$.

The mean age of the respondents was $37(\mathrm{SD}=11)$. Seven percent had at least some college; and $67.8 \%$ percent had a completed college degree. The participants reported median income between $\$ 50,000$ and $\$ 69,999$.

Results. The results reveal that participants were not familiar with the $\log (\mathrm{M}=1.11$, $\mathrm{SD}=.57)$. The logo was evaluated as realistic $(\mathrm{M}=3.36, \mathrm{SD}=1.25)$. Overall design of the logo scored 3.32 on a 5-point scale $(\mathrm{SD}=1.31)$. Participants also demonstrated positive attitudes toward the logo $(\mathrm{M}=3.89, \mathrm{SD}=.88)$.

Thirty-two percent of respondents were able to correctly identify what the logo was intended to communicate (sustainable or environmentally friendly tourism services and operations) and $46 \%$ of respondents understood the logo message to some extent (sustainable or environmentally friendly product or service). 


\section{Pretest 2 - Travel Destination Name Design and Validation}

To avoid potential confounds, we created a fictitious travel destination "Grinamonte." This name was searched on Google and no associations with this name were found. To get empirical validation for the destination name, we conducted a pretest to examine how it was understood and perceived by consumers. A pretest was conducted using student sample (the complete Qualtrics questionnaire is presented in Appendix F).

Sample and procedures. 71 undergraduate students $(53.5 \%$ females, mean age $=22)$ participated in this study in exchange for an extra credit. They were asked to respond to a familiarity measure (a two-item 5-point Likert-type scale with endpoints "definitely not" and "definitely yes", r=.84).

Items:

1. Have you ever heard of this travel destination before?

2. Does this name sound like a travel destination you are familiar with?

Results. The results reveal that the name "Grinamonte" was not familiar to the participants $(\mathrm{M}=1.35, \mathrm{SD}=.85)$.

\section{Pretest 3 - Website Design and Validation}

To test main effects, the mock website of a fictitious travel destination Grinamonte was designed. The website had a design similar to other travel destinations websites (see Appendix G) and was used as a research stimulus to add realism to the study. A pretest was conducted using Amazon's Mechanical Turk (mTurk) CloudResearch sample (the complete Qualtrics questionnaire is presented in Appendix H). 
The participants were asked to evaluate familiarity with the website, its navigability, ease of use, realism, and visual attractiveness of the website.

Measures. Familiarity: a two-item 5-point Likert-type scale with endpoints "definitely not" and "definitely yes", r=.73). Items:

1. Have you ever seen this website before?

2. Does this website look familiar?

Realism: a three-item 5-point Likert-type measure (endpoints "strongly disagree" and "strongly agree"), Cronbach's alpha $=.77$. Items:

1. I think this website is realistic.

2. The website seems like the kind of websites travel destinations often make.

3. The website looks professionally designed.

Attitudes toward the website: a five-item 5-point semantic differential scale, Cronbach's alpha $=.91$.

Now think about how you felt viewing the website. Did you feel:

1. Negative - positive

2. Sad - happy

3. Angry - upbeat

4. Annoyed - pleased

5. Disappointed - satisfied.

Finally, the participants were asked to evaluate the overall design of the website on a one-item 5point Likert-type measure (endpoints “poor” and "excellent”). 
Sample and procedures. 50 participants (36\% female) were recruited via Amazon's Mechanical Turk (mTurk) CloudResearch panel. The mean age of the respondents was $41(\mathrm{SD}=12)$. Twenty-four percent had at least some college; and $64 \%$ percent had a completed college degree. The following mandatory qualifications were included for mTurk participants: (1) Only individuals eighteen years of age or older were invited to participate; and (2) all participants needed a prior mTurk job-approval rate (i.e., indicating superior performance) of 90 percent or higher. Also, embedded measures within the survey (e.g., mobile-device usage) guaranteed that only participants on a laptop or desktop computer were able to participate and that participants did not take the same survey twice.

To address the problem of inattentiveness, one attention check was used across the study. One of the scale's items was worded as "This is an attention check. The answer is "Disagree". All participants passed the attention check.

The participants were instructed to browse the website of a hypothetical travel destination located 2-3-hour drive from where they live. After viewing the website, they were asked to return to the survey and complete the survey questions.

Results. The results reveal that participants were not familiar with the website $(\mathrm{M}=1.24$, $\mathrm{SD}=.60)$. The website was evaluated as realistic and professionally designed $(\mathrm{M}=3.87, \mathrm{SD}=.75)$. Overall design of the website scored 3.92 on a 5-point scale ( $\mathrm{SD}=.88)$. Participants also demonstrated positive attitudes toward website $(\mathrm{M}=4.06, \mathrm{SD}=.75)$.

\section{Main Study}

A controlled experiment was implemented to explore five primary research questions: (1) Do sustainability labels increase consumer connectedness with a travel destination and 
perception of goal congruence? (2) Do sustainability labels increase consumer positive behavioral intentions (word of mouth, intention to visit a travel destination, and willingness to pay price premium)? (3) Is connectedness with a travel destination and perception of goal congruence higher for consumers with higher levels of environmental awareness? (4) Does inclusion of anthropomorphic elements in sustainability label design increase connectedness with a travel destination and perception of goal congruence? and (5) Does positive emotional message framing increase connectedness with a travel destination and perception of goal congruence?

The proposed research design is described below.

\section{Study Design}

The online study was a controlled between-subjects experiment. Participants were randomly assigned to one of the four experimental conditions through randomization function embedded in the Qualtrics survey.

In all conditions, participants were exposed to the mock travel destination's website. They were asked to explore the website spending at least two minutes on it and visiting at least five web pages. Finally, they were asked to report the likelihood of visiting the destination and recommending it to someone and to indicate how much they would be willing to pay for the trip. The survey was designed in a simple and clear manner and it took participants 15 minutes on average to complete it.

\section{Sample}

Two hundred fifty adult American consumers were recruited via Amazon's Mechanical Turk (mTurk) CloudResearch panel. We prescreened participants to ensure that we recruited only those respondents who were willing and able to travel outside of the United States within 
the next 12 months after the COVID-19 pandemic would be over and had some tourist experience (traveled at least once in the last 3 years). Prescreening allows ruling out alternative explanations in the study (e.g., low visit intention because of financial constraints or nonwillingness to travel in general).

In addition, the following mandatory qualifications were included for mTurk participants: (1) Only individuals eighteen years of age or older were invited to participate; and (2) all participants needed a prior mTurk job-approval rate (i.e., indicating superior performance) of 90 percent or higher. Also, embedded measures within the survey (e.g., mobile-device usage) guaranteed that only participants on a laptop or desktop computer were able to participate and that participants did not take the same survey twice.

To ensure that participants visited the website, they were asked to enter their mTurk ID in a special field on the website. Website activity statistics also allowed to track participants' activity on the website by their IP addresses that were further matched with their mTurk ID numbers.

To address the problem of inattentiveness, two attention checks were used across the study. For the first attention check, one of the scale's items was worded as "To make sure you are paying attention to the survey please check number 5 for this question." All participants passed this attention check.

For the second attention check, the participants were asked if they saw the TripAdvisor logo earlier in the study (the correct answer was "No"). Fifty-two participants did not pass this attention check, but we decided not to exclude them from the study.

Fifty-seven participants were excluded from the survey for not meeting the requirements (visiting just a home webpage and not browsing the website) and three participants were further 
excluded as multivariate outliers leaving final $n=190$ (the procedure of testing for multivariate outliers is described in the Statistical Analysis section of this dissertation). Cell sizes ranged from 46 to 49 participants per cell.

Fifty-eight percent of the sample were male; the mean age of the respondents was 39 (SD $=11$ ). Seventy-one percent had a completed college degree and $19.5 \%$ had at least some college. Eighty-six percent identified themselves as White/Caucasian, $6.3 \%$ as Black, and $4.7 \%$ as Latino. Twenty-five percent reported the income between 30,000 and 50,000.

\section{Manipulations and Procedures}

After the mTurk workers accepted the human intelligence task (HIT), they were told to carefully read the instructions, to explore the travel destination's website, and then to report their behavioral intentions. After that, all participants completed a survey with dependent measures and demographics (the complete Qualtrics questionnaire is presented in Appendix I).

For Manipulation 1 (Sustainability Label), we used stimuli designed as a result of content analysis and Pretest 1. In an "Anthropomorphized" condition, a label with an anthropomorphic characteristic was placed on every webpage of the website (in the first $1 / 3$ part of the page). In a "Non-Anthropomorphized" condition, correspondingly, the nonanthropomorphized label was placed on the website. In the control condition, the label was absent.

For Manipulation 2 (Emotion), in a "Positive" condition, the anthropomorphic character on the label had a smiley face. In a "Neutral" condition, the character had a neutral face expression. 


\section{Measures}

We addressed the following primary dependent measures: (1) intention to visit a destination (2) intention to recommend a destination (WOM) and (3) willingness to pay price premium (WTP).

Visit intention was measured on a single-item, 7-point Likert measure (endpoints "very unlikely" and "very likely"). The prompt was as follows: "Based on the travel destination's website you have seen, please indicate if you would consider visiting Grinamonte in future." The participants were also be asked to explain their choice in a further open-response question. Research has shown that single-item measures were more appropriate in measuring "doubly concrete" constructs, or constructs for which research subjects perceive the object of measurement and the attribute of measurement as clear and unambiguous (Bergkvist and Rossiter 2009). These constructs include attitude toward the ad, brand attitude, and brand purchase intention (Bergkvist and Rossiter 2009). Also, no difference was found in the predictive validity of the multiple-item and single-item measures for these constructs (Bergkvist 2015; Bergkvist and Rossiter 2007). Finally, single-item measures used for measuring concrete and unidimensional constructs help avoiding common method bias, shorten questionnaires, and increase response rates (Petrescu 2013).

Intention to recommend (word-of-mouth) was be measured on a three-item 7-point Likert scale (Cronbach's alpha $=.94)$ adapted from Babin et al. (2003). An example of the scale's item is "I will recommend Grinamonte as a vacation destination to someone who seeks my advice" (see complete list of measures in Table 4.1).

Willingness to pay price premium was be measured on a single-item measure (endpoints “\$1,000” and “\$3,000”). Miller et al. (2011) found that such WTP measure is suitable for most 
marketing research. It also outperforms other WTP measures (e.g., conjoint based and incentive aligned measures) in predicting pricing decisions (Miller et al. 2011).

The participants were told that weekly all-inclusive tours to Grinamonte were typically priced between $\$ 1,000$ and $\$ 3,000$ per person and were asked to indicate how much they would be willing to pay for such a tour using a slide bar. There were also price ques on the website: the "Pricing" page included three options: an all-inclusive tour priced for $\$ 1,500$ per person (for a 5night stay) that included community visits and interactive activities, a guided all-inclusive tour priced for $\$ 1,300$ per person (for a 5-night stay), and a bed and breakfast self-guided option priced for $\$ 150$ per person per night. These price points were included to add realism to the website.

In addition, we measured connectedness with a travel destination brand, perceived goal congruence, and environmental awareness. The complete list of measures is presented in Table 4.1. 
Table 4.1. Established Measures of Key Constructs

\begin{tabular}{|c|c|}
\hline Construct & Measurement items \\
\hline Visit intention & $\begin{array}{l}\text { A single-item, 7-point Likert-type measure (endpoints "very unlikely" and } \\
\text { "very likely"): } \\
\text { - Based on the travel destination's website you have seen, please } \\
\text { indicate if you would consider visiting Grinamonte in future. }\end{array}$ \\
\hline Word of mouth & $\begin{array}{l}\text { A three-item, 7-point Likert-type measure (endpoints "very unlikely" and } \\
\text { "very likely"), Babin et al. (2003): } \\
\text { - How likely are you to say positive things about Grinamonte to other } \\
\text { people? } \\
\text { - I will recommend Grinamonte as a vacation destination to someone } \\
\text { who seeks my advice. } \\
\text { - I will encourage friends and relatives to visit Grinamonte. }\end{array}$ \\
\hline $\begin{array}{l}\text { Willingness to } \\
\text { pay price } \\
\text { premium }\end{array}$ & $\begin{array}{l}\text { A single-item slider-scale measure (endpoints " } \$ 1000 " \text { and " } \$ 3000 ") \text { : } \\
\text { - Weekly packaged tours to Grinamonte are typically priced between } \\
\$ 1,000 \text { and } \$ 3,000 \text { per person. How much would you be willing to } \\
\text { pay for your tour? }\end{array}$ \\
\hline $\begin{array}{l}\text { Consumer } \\
\text { connectedness to } \\
\text { the brand }\end{array}$ & $\begin{array}{l}\text { A four-item, 7-point Likert-type measure (endpoints "very unlikely" and } \\
\text { "very likely") (Tsao 2010): } \\
\text { As you think about Grinamonte, please rate the following statements: } \\
\text { - Grinamonte reflects who I am. } \\
\text { - Grinamonte is congruent with my lifestyle. } \\
\text { - It seems that the brand can speak for me. } \\
\text { - I identify with the image of Grinamonte. }\end{array}$ \\
\hline Goal congruence & $\begin{array}{l}\text { A four-item 7-point Likert-type measure adapted from Jap (1999): } \\
\text { As you think about Grinamonte, please rate the following statements: } \\
\text { - I and Grinamonte have different goals. (R) } \\
\text { - I and Grinamonte have compatible goals. } \\
\text { - I and Grinamonte support each other's objectives. } \\
\text { - I and Grinamonte share the same goals in the relationship. }\end{array}$ \\
\hline $\begin{array}{l}\text { Environmental } \\
\text { awareness }\end{array}$ & $\begin{array}{l}\text { A 13-item 7-point Likert-type scale adapted from Banerjee and McKeage } \\
\text { (1994): } \\
\text { - I often think about the harm we are doing to our environment. } \\
\text { - The whole environmental issue is very important to me. } \\
\text { - I am a person who cares about the environment. } \\
\text { - I really don't spend much time thinking about the environment. }\end{array}$ \\
\hline
\end{tabular}




\begin{tabular}{|c|c|}
\hline & $\begin{array}{l}\text { - I think of myself as an environmentalist. } \\
\text { - I often worry about the effects of pollution on myself and my family. } \\
\text { - I am really not interested in environmental issues. } \\
\text { - The following problems are extremely serious and need to be } \\
\text { addressed immediately: } \\
\text { o Water pollution } \\
\text { o Air pollution } \\
\text { ○ Ozone depletion } \\
\quad \text { Deforestation } \\
\text { O Wildlife Extinction } \\
\text { o Global warming } \\
\text { - Pollution control measures have created unfair burdens on industry. } \\
\text { - Let future generations solve their own problems. } \\
\text { - The benefits of modem consumer products are more important than } \\
\text { the pollution that results from their production and use. } \\
\text { - The positive benefits of economic growth far outweigh any negative } \\
\text { environmental impact. } \\
\text { The current attention to the environment is basically raised by the } \\
\text { media and we don't really need to do anything about it. }\end{array}$ \\
\hline $\begin{array}{l}\text { Anthropomorphic } \\
\text { tendency }\end{array}$ & $\begin{array}{l}\text { Waytz, Cacioppo, and Epley (2010): } \\
\text { - To what extent is the desert lethargic? } \\
\text { - To what extent is the average computer active } \\
\text { - To what extent does technology-devices and machines for } \\
\text { manufacturing, entertainment, and productive processes (e.g., cars, } \\
\text { - Tomputers, television sets)-have intentions? } \\
\text { - To what extent is the average cloud good-looking? } \\
\text { - To what extent are pets useful? } \\
\text { - To what extent does the average mountain have free will? } \\
\text { - To what extent is the average amphibian lethargic? } \\
\text { - To what extent does a television set experience emotions? } \\
\text { - To what extent is the average robot good-looking? } \\
\text { - To what extent does the average robot have consciousness? } \\
\text { - To what extent do cows have intentions? } \\
\text { - To what extent does a car have free will? } \\
\text { - To what extent does the ocean have consciousness? } \\
\text { - To what extent is the average camera lethargic? } \\
\text { - To what extent is a river useful? } \\
\text { - To what extent does the average computer have a mind of its own? } \\
\text { - To what extent is a tree active? } \\
\text { - To what extent is the average kitchen appliance useful? } \\
\text { - To what extent does a cheetah experience emotions? } \\
\text { - Toxtent does the environment experience emotions? }\end{array}$ \\
\hline
\end{tabular}




\begin{tabular}{|l|l|}
\hline - To what extent does the average insect have a mind of its own? \\
- To what extent does a tree have a mind of its own? \\
To what extent is technology - devices and machines for \\
manufacturing, entertainment, and productive processes (e.g., cars, \\
- Tomputers, television sets) - durable? \\
- To what extent is the average cat active? \\
- To what extent is the forest durable? \\
- To what extent is a tortoise durable? \\
- To what extent does the average reptile have consciousness? To what \\
extent is the average dog good-looking?
\end{tabular}




\section{Statistical Analysis}

All data analyses were conducted using the statistical package IBM SPSS Statistics 27.0 for Windows. After performing data quality control procedures, i.e., assessing response time and response consistency (Meade and Craig 2012), outcome and predictor variables were examined for missing values and univariate and multivariate outliers.

Little's MCAR (missing completely at random) test (Little 1998) was performed to test for missing data. The Little's MCAR's $\chi 2=79.617, \mathrm{DF}=61, \mathrm{p}=.055$ indicates that the values were missing completely at random. The percentage of the missing values did not exceed $5 \%$.

To test for univariate outliers in the continuous variables, box plots were created. No univariate outliers were detected using this procedure.

To check for the multivariate outliers and multicollinearity, a linear regression analysis was performed using participants' ID as dependent variable (Tabachnick and Fidell 2013). Multicollinearity was tested by checking VIFs and tolerance. All VIFs did not exceed 4, and tolerance values were between .261 and .802 for the variables, which indicates the absence of multicollinearity (Belsley, Kuh, and Welsch 1980). Correlations between dependent variables vary from .29 and .83 , which are moderate to high correlations. (Table 4.2). These criteria suggest that multicollinearity is not an issue for the data. 
Table 4. 2 Inter-Construct Correlations and Descriptive Statistics.

\begin{tabular}{|c|c|c|c|c|c|c|c|}
\hline & $\begin{array}{c}\text { Visit } \\
\text { Intention }\end{array}$ & WTP & WOM & Connectedness & $\begin{array}{c}\text { Goal } \\
\text { Congruence }\end{array}$ & $\begin{array}{c}\text { Environmental } \\
\text { Awareness }\end{array}$ & $\begin{array}{c}\text { Anthropomorphic } \\
\text { Tendency }\end{array}$ \\
\hline Visit Intention & 1 & & & & & & \\
\hline WTP & $.369^{* *}$ & 1 & & & & & \\
\hline WOM & $.736^{* *}$ & $.320^{* *}$ & 1 & & & & \\
\hline Connectedness & $.657^{* *}$ & $.300^{* *}$ & $.714^{* *}$ & 1 & & & \\
\hline Goal Congruence & $.612^{* *}$ & $.282^{* *}$ & $.665^{* *}$ & $.819^{* *}$ & 1 & & \\
\hline $\begin{array}{l}\text { Environmental } \\
\text { Awareness }\end{array}$ & $.226^{* *}$ & -.003 & $.222^{* *}$ & $.199^{* *}$ & $.234^{* *}$ & 1 & \\
\hline $\begin{array}{l}\text { Anthropomorphic } \\
\text { Tendency }\end{array}$ & $.253^{* *}$ & .130 & $.279^{* *}$ & $.302^{* *}$ & $.210^{* *}$ & $.143^{*}$ & 1 \\
\hline Number of Items & 1 & 1 & 3 & 4 & 4 & 13 & 30 \\
\hline Mean & 5.55 & 1460.54 & 5.64 & 4.86 & 5.21 & 5.56 & 3.80 \\
\hline $\mathrm{SD}$ & 1.26 & 404.74 & .99 & 1.37 & 1.14 & 1.17 & .68 \\
\hline Cronbach's $\alpha$ & - & - & .94 & .92 & .92 & .94 & .87 \\
\hline
\end{tabular}

**. Correlation is significant at the 0.01 level (2-tailed)

*. Correlation is significant at the 0.05 level (2-tailed). 
The Mahalanobis distance for each case was compared to a chi-square distribution with nine degrees of freedom with a .001 alpha level (chi-square $=24.322)$. The analysis revealed three multivariate outliers with the Mahalanobis distance higher than the determined chi-square value that were removed from the study leaving final $n=190$.

Using an alpha level of .001 to evaluate homogeneity assumptions, Levene's homogeneity of variance test was completed. It was not statistically significant for all dependent variables (all p-values were greater than .001) indicating that, although group sizes were unequal in "label" and "no label" conditions, the variances were equal.

\section{Results}

Manipulation checks. To ensure the effectiveness of the scenario, one self-report question was used to measure the effectiveness of each manipulation independent of the measures. This question was included after responses to the dependent measures had been recorded. Participants were asked what logo they have previously seen on the website (e.g., an anthropomorphic label with positive framing, an anthropomorphic label with neutral framing, a non-anthropomorphic label, no label, or "I don't remember"). A two-way contingency table analysis was conducted to determine the significance of those participants who correctly identified their experimental condition. Sixty-six percent correctly recalled their experimental condition: $\chi^{2}=77.326, p<$ .000 , Cramer's $V=.613$. The significant results and large effect size confirm the effectiveness of this experimental manipulations.

Direct main effects. A series of One-way ANCOVAs was conducted to examine effects of the presence (vs. absence) of sustainability label and anthropomorphized (vs. nonanthropomorphized) label on intention to visit a destination, WOM, and willingness to pay price premium, controlling for age, and familiarity with the brand and the product, and 
anthropomorphic tendency. There was no significant effect of label presence on visit intention, $\mathrm{F}(1,189)=.477, \mathrm{p}=.491$, WOM, $\mathrm{F}(1,189)=1.629, \mathrm{p}=.204$, and WTP, $\mathrm{F}(1,189)=.000, \mathrm{p}=1.000$ after controlling for age, and familiarity with the brand and the product, and anthropomorphic tendency. $\mathrm{H}_{1}$ was not supported.

The effects of anthropomorphized (vs. non-anthropomorphized) label on visit intention, $\mathrm{F}(1,189)=.492, \mathrm{p}=.484$, WOM, $\mathrm{F}(1,189)=.010, \mathrm{p}=.919$, and WTP, $\mathrm{F}(1,189)=.976, \mathrm{p}=.324$ after controlling for age, and familiarity with the brand and the product, and anthropomorphic tendency were also non-significant. $\mathrm{H}_{2}$ was not supported.

We further tested the effects of label presence on connectedness and goal congruence. There was no significant effect of label presence on connectedness, $F(1,189)=.049, \mathrm{p}=.825$, and goal congruence, $\mathrm{F}(1,189)=.234, \mathrm{p}=.629$ after controlling for age, familiarity with the brand and the product, and anthropomorphic tendency.

Finally, we tested direct effect of anthropomorphized (vs. non-anthropomorphized) label on connectedness and goal congruence. There was no significant effect of label presence on connectedness, $\mathrm{F}(1,189)=.856, \mathrm{p}=.356$, and goal congruence, $\mathrm{F}(1,189)=.734, \mathrm{p}=.393$ after controlling for age, familiarity with the brand and the product, and anthropomorphic tendency.

\section{Moderating effects of emotional framing. To test moderating effects of framing}

(Hypothesis 5), we filtered out the cases in anthropomorphic labeling condition ( $\mathrm{n}=93)$ and recoded emotional framing into a dummy variable (1 - "positive framing", 0 - "neutral framing") to avoid singularity between categorical variables. We further ran a series of One-way ANCOVAs to examine interaction effects of framing (positive vs. negative) and environmental awareness on consumer connectedness and goal congruence, controlling for age, and familiarity with the brand and the product, and anthropomorphic tendency. There was no significant 
interaction effect of framing and environmental awareness on connectedness, $F=.550, p=.902$, and goal congruence, $F=.961, p=.520$ after controlling for age, and familiarity with the brand and the product, and anthropomorphic tendency. $\mathrm{H}_{5}$ was not supported. We also tested a moderated-mediation model using PROCESS bootstrapping procedure (Model 7) with 5,000 resamples (Hayes 2018; Hayes and Matthes 2009) controlling for age, brand familiarity, product familiarity, and anthropomorphic tendency. Moderated mediation from framing to visit intention through both connectedness and goal congruence was not supported (all confidence intervals for Index of Moderated Mediation 95\% included a zero) thus not providing support for $\mathrm{H}_{5}$.

Mediating effects of connectedness. We tested a moderated-mediation model using PROCESS bootstrapping procedure (Model 7) with 5,000 resamples (Hayes 2018; Hayes and Matthes 2009). The same covariates (age, brand familiarity, product familiarity, and anthropomorphic tendency) were included in the model.

Label $\rightarrow$ Connectedness $\rightarrow$ Visit Intention. In the first indirect mediation stage, environmental awareness was expected to moderate the relationship between the presence/absence of the label and connectedness with a destination. The analysis shows that a person's environmental awareness directly influences how presence/absence of label affects their perception of connectedness. When the label was present on the website, higher levels of environmental awareness increased connectedness with the destination. In a no-label condition, higher levels of environmental awareness led to decreased perception of connectedness.

On the second stage of the indirect mediation to visit intention, connectedness $(b=.57, \mathrm{p}$ $<.001)$ mediated the relationship between the presence/absence of the sustainability label and visit intention. No direct effect of presence/absence of the sustainability label on visit intention 
was found $(b=.11, p=.489$, CI $[-.205 ; .427])$. The primary path relationships are shown in Figure 4.2 and full path results are reported in Table 4.3.

In summary, moderated mediation was supported from presence/absence of the sustainability label to visit intention through connectedness (Index of Moderated Mediation 95\% CI: -.034, -.388) thus supporting $\mathrm{H}_{3 \mathrm{a}}$ and $\mathrm{H}_{6 \mathrm{a}}$.

Figure 4. 2 Moderated Mediation - Label $\rightarrow$ Connectedness $\rightarrow$ Visit Intention.

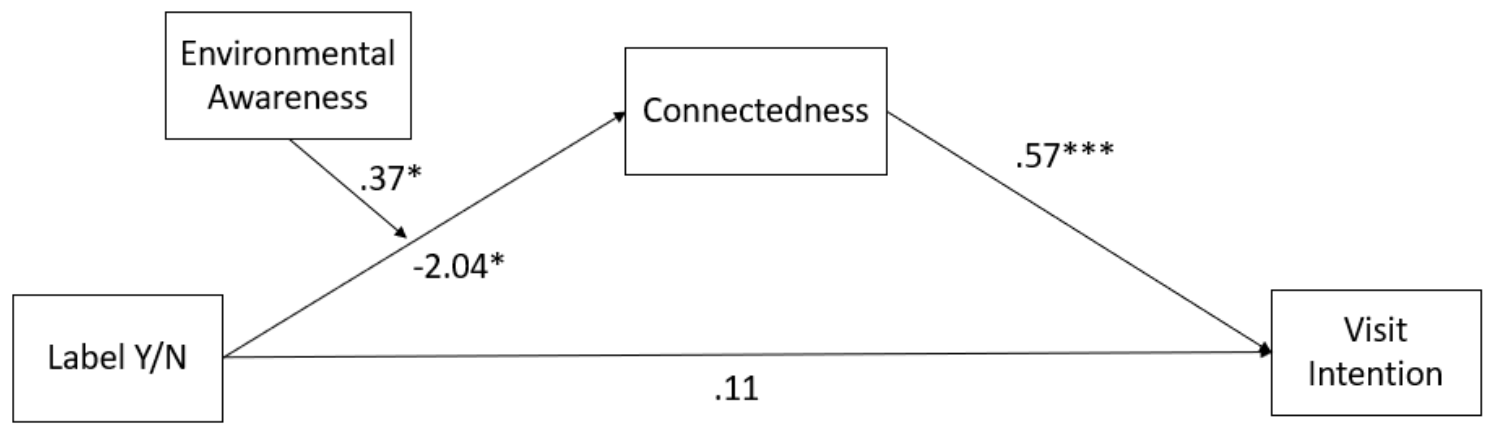

${ }^{*} p<.05 ; * * p<.01 ;{ }^{* * *} p<.001$

Label $\rightarrow$ Connectedness $\rightarrow$ WOM. Consistent with the previous model, in the first indirect mediation stage, environmental awareness moderates the relationship between the presence/absence of the label and connectedness with a destination. As in a previous model, in a label condition, higher levels of environmental awareness increased connectedness with the destination. In a no-label condition, higher levels of environmental awareness led to decreased perception of connectedness.

On the second stage of the indirect mediation to WOM, connectedness $(b=.48, p<.001)$ mediated the relationship between the presence/absence of the sustainability label and WOM. No 
direct effect of presence/absence of the sustainability label on visit intention was found $(b=.17$, $\mathrm{p}=.143$, CI $[-.059 ; .401])$. The primary path relationships are shown in Figure 4.3 and full path results are reported in Table 4.3.

In summary, moderated mediation was supported from presence/absence of the sustainability label to WOM through connectedness (Index of Moderated Mediation 95\% CI: $.026,-.332$ ) thus supporting $\mathrm{H}_{3 b}$ and $\mathrm{H}_{6 a}$.

Figure 4. 3 Moderated Mediation - Label $\rightarrow$ Connectedness $\rightarrow$ WOM.

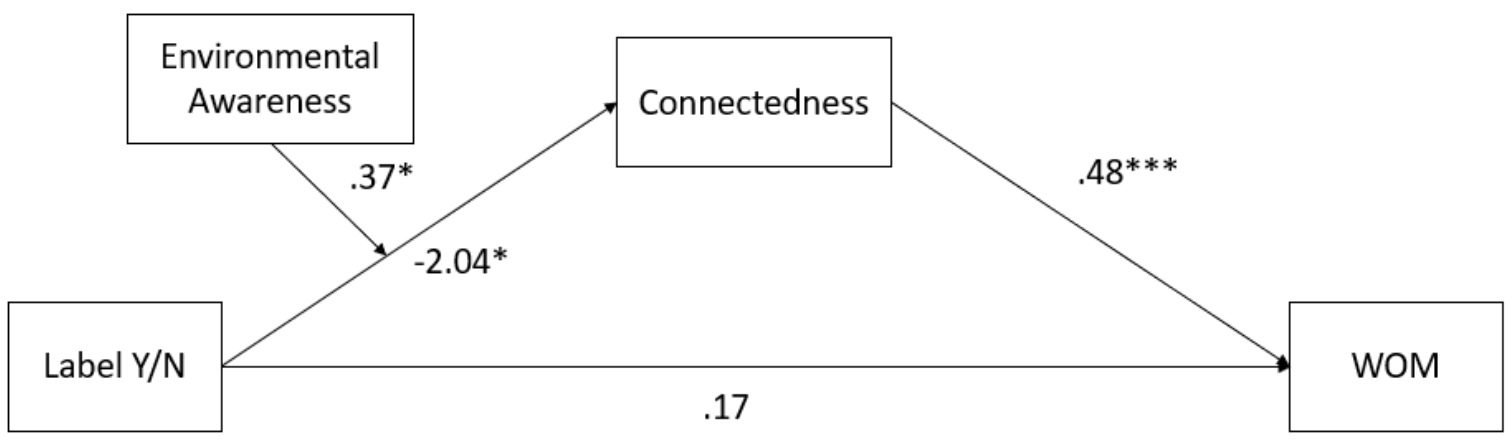

${ }^{*} p<.05 ; * * p .01 ; * * *<.001$

Label $\rightarrow$ Connectedness $\rightarrow$ WTP. In the first indirect mediation stage, environmental awareness moderates the relationship between the presence/absence of the label and connectedness with a destination following the patterns discovered in the previous analyses. In a label condition, higher levels of environmental awareness increased connectedness with the destination. In a no-label condition, higher levels of environmental awareness decreased perception of connectedness. 
On the second stage of the indirect mediation to WTP, connectedness $(b=52.223, p<.001)$ mediated the relationship between the presence/absence of the sustainability label and WOM. No direct effect of presence/absence of the sustainability label on visit intention was found $(b=-.962$, $\mathrm{p}=.1974$, CI $[-121.549 ; 117.624])$. The primary path relationships are shown in Figure 4.4 and full path results are reported in Table 4.3 .

However, moderated mediation from presence/absence of the sustainability label to WTP through connectedness was not supported (Index of Moderated Mediation 95\% CI: [-.405, 48.766]) thus supporting $\mathrm{H}_{6 \mathrm{a}}$ but providing no support for $\mathrm{H}_{3 \mathrm{c}}$.

Figure 4. 4 Moderated Mediation - Label $\rightarrow$ Connectedness $\rightarrow$ WTP.

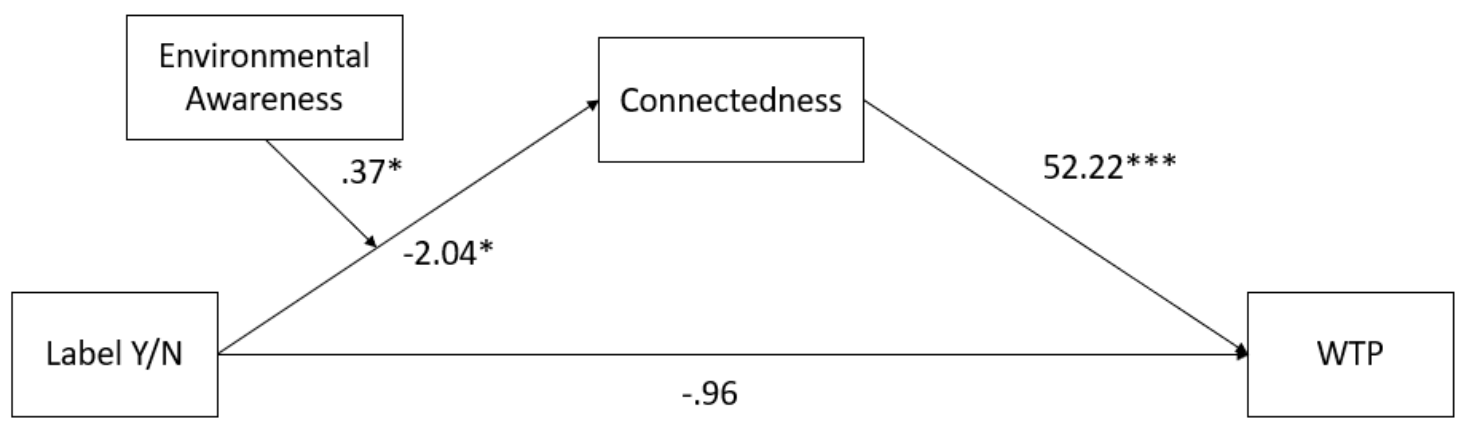

${ }^{*} p<.05 ; * * p<.01 ; * * * p<.001$ 
Figure 4. 5 Interaction Effects of Label Presence/Absence and Environmental Awareness on Connectedness

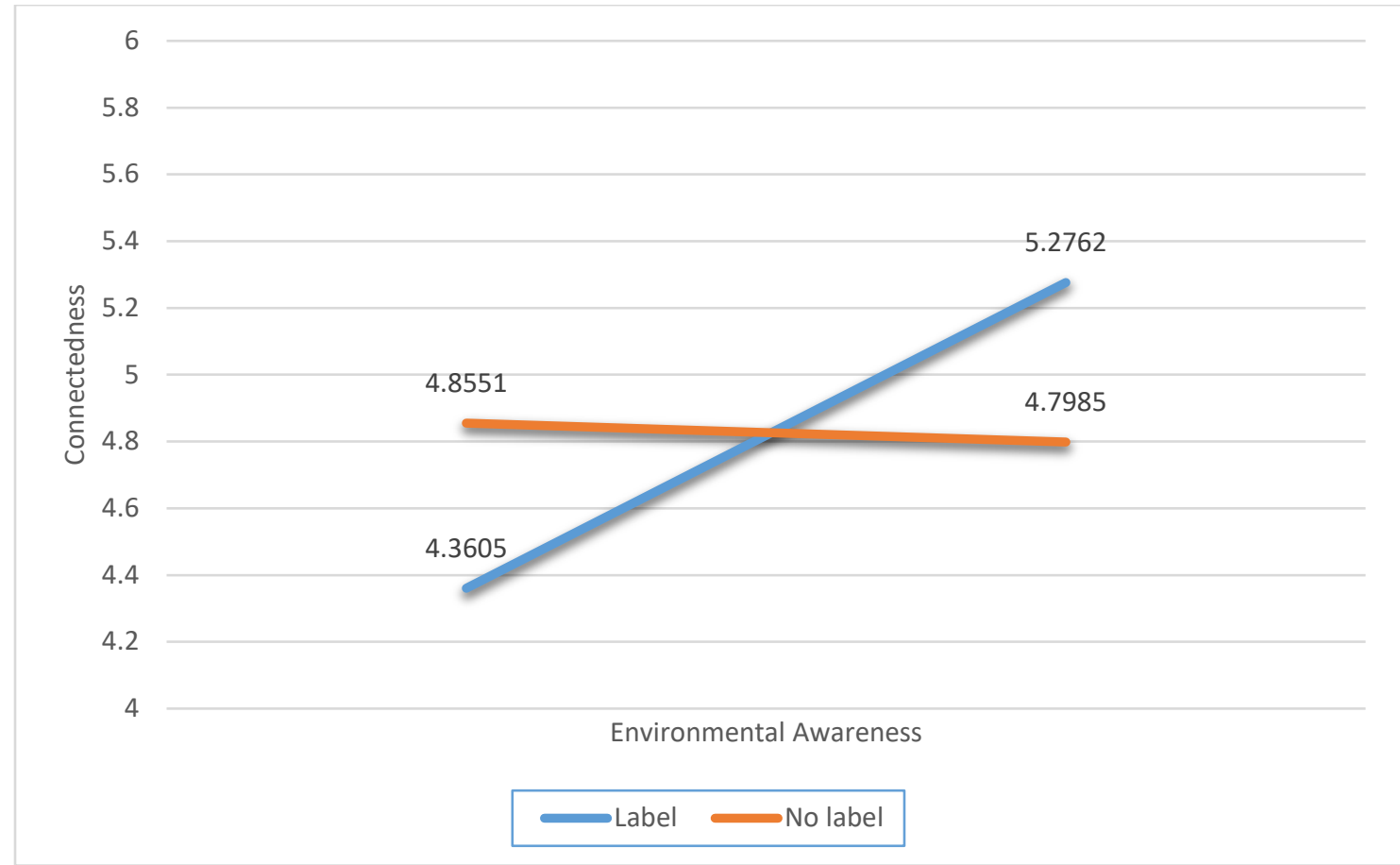


Table 4. 3 Moderated Mediation Results with Confidence Intervals - Connectedness

\begin{tabular}{|c|c|c|}
\hline & Coeff & $95 \% \mathrm{CI}$ \\
\hline \multicolumn{3}{|l|}{ Stage A - DV: Connectedness } \\
\hline (Constant) & $4.553 * * *(.999)$ & $2.582 ; \quad 6.523$ \\
\hline Label (yes/no) & $-2.039 *(.907)$ & $-.3 .830 ;-.249$ \\
\hline Environmental Awareness & $-.022(.130)$ & $-.279 ; .235$ \\
\hline Label (yes/no) x Environmental Awareness & $.372 *(.160)$ & $.057 ; .687$ \\
\hline \multicolumn{3}{|l|}{$F(8,180)=10.032, p<.001, R^{2}=.31$} \\
\hline \multicolumn{3}{|l|}{ Stage 1B - DV: Visit Intention } \\
\hline (Constant) & $2.855^{* * *}(.598)$ & $1.675 ; 4.035$ \\
\hline Label (yes/no) & $.111 \dagger(.160)$ & $-.205 ;-.427$ \\
\hline Connectedness & $.568 * * *(.059)$ & $.452 ; .684$ \\
\hline \multicolumn{3}{|l|}{$F(7,181)=21.215, p<.001, R^{2}=.67$} \\
\hline \multicolumn{3}{|l|}{ Stage 2B - DV: WOM } \\
\hline (Constant) & $2.900 * * *(.435)$ & $2.042 ; 3.758$ \\
\hline Label (yes/no) & $.171 \dagger(.116)$ & $-.059 ; .401$ \\
\hline Connectedness & $.476^{* * *}(.043)$ & $.392 ; .561$ \\
\hline \multicolumn{3}{|l|}{$F(7,181)=29.065, p<.001, R^{2}=.53$} \\
\hline \multicolumn{3}{|l|}{ Stage 2C-DV: WTP } \\
\hline (Constant) & $1357.746 * * *(226.273)$ & $911.273 ; 1804.219$ \\
\hline Label (yes/no) & $-.962 \dagger(60.606)$ & $-.121 .549 ; 117.624$ \\
\hline Connectedness & $52.223 *(22.245)$ & $8.335 ; 96.118$ \\
\hline$F(7,181)=6.941, p<.001, R^{2}=.21$ & & \\
\hline
\end{tabular}

$\dagger p<.10 ; * p<.05 ; * * p<.01 ; * * * p<.001$ 
We hypothesized that presence (vs. absence) of a sustainable label on a travel destination's website would increase consumer intention to visit a destination, to share positive information about it, and to pay a price premium, and that these effects would occur through connectedness with a destination $\left(\mathrm{H}_{3}\right)$. We also predicted that environmental awareness would increase perceptions of connectedness and goal congruence when the sustainability label is present $\left(\mathrm{H}_{6}\right)$. These hypotheses were partially supported: moderated mediation was supported for the relationship between the label presence/absence and visit intention and word of mouth but was not supported for willingness to pay price premium.

Mediating effects of goal congruence. We further tested mediating role of goal congruence with a moderated-mediation model using a bootstrapping procedure (PROCESS Model 7) with 5,000 resamples (Hayes 2018; Hayes and Matthes 2009). The same covariates (age, brand familiarity, product familiarity, and anthropomorphic tendency) were included in the model.

Label $\rightarrow$ Goal Congruence $\rightarrow$ Visit Intention. In the first indirect mediation stage, environmental awareness was predicted to moderate the relationship between the presence/absence of the label and goal congruence. The analysis shows that an individual's environmental awareness directly influences how presence/absence of label affects their perception congruence between their own goals and the destination's goals. When the label was present on the website, higher levels of environmental awareness increased goal congruence. In a no-label condition, higher levels of environmental awareness led to decreased perception of goal congruence.

On the second stage of the indirect mediation to visit intention, goal congruence $(b=.61$, $\mathrm{p}<.001)$ mediated the relationship between the presence/absence of the sustainability label and 
visit intention. No direct effect of presence/absence of the sustainability label on visit intention was found $(\mathrm{b}=.08, \mathrm{p}=.619, \mathrm{CI}[-.243 ; .408])$. The primary path relationships are shown in Figure 4.6 and full path results are reported in Table 4.4.

In summary, moderated mediation was supported from presence/absence of the sustainability label to visit intention through goal congruence (Index of Moderated Mediation $95 \%$ CI: .032, .389) thus supporting $\mathrm{H}_{4 a}$ and $\mathrm{H}_{6 \mathrm{~b}}$.

Figure 4. 6 Moderated Mediation - Label $\rightarrow$ Goal congruence $\rightarrow$ Visit intention.

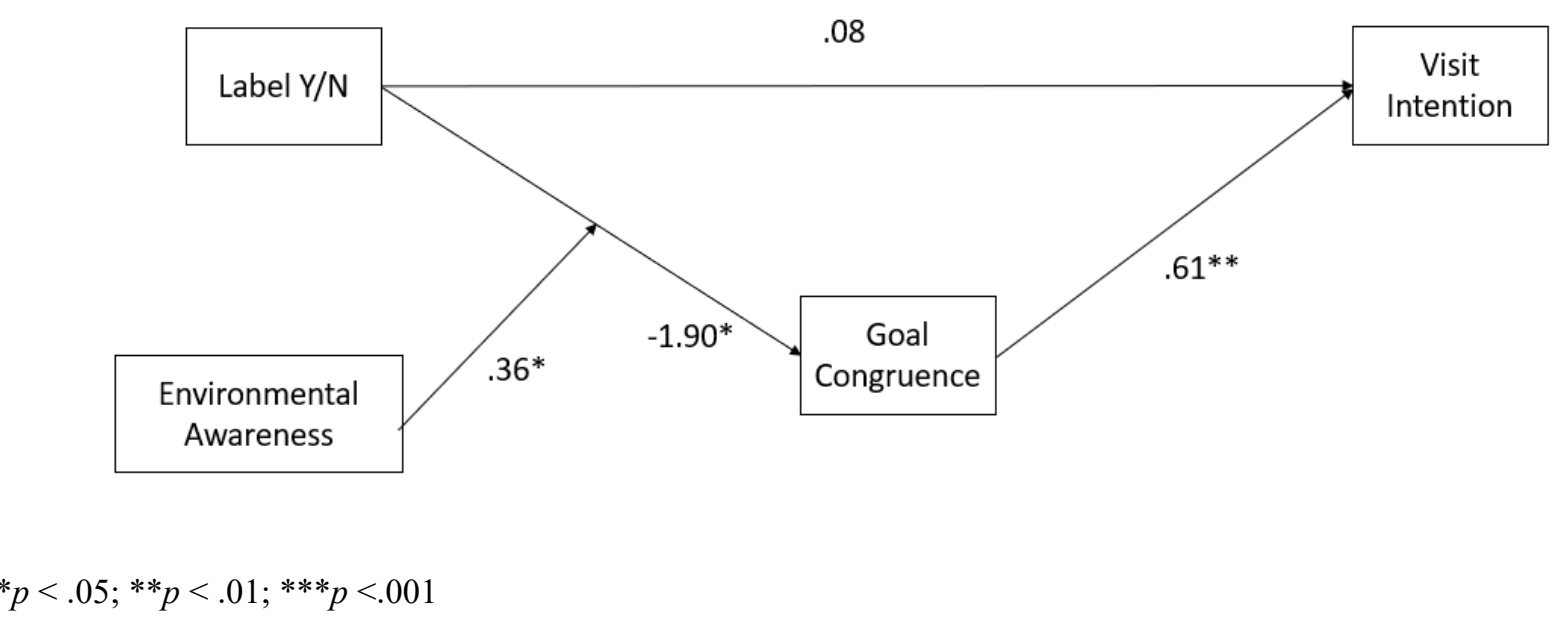

Label $\rightarrow$ Goal Congruence $\rightarrow$ WOM. The analysis shows that a person's environmental awareness directly influences how presence/absence of label affects their perception congruence between their own goals and the destination's goals replicating the results of the first model (Label $\rightarrow$ Goal Congruence $\rightarrow$ Visit Intention). Again, when the label was present on the website, higher levels of environmental awareness increased goal congruence. In a no-label condition, higher levels of environmental awareness led to decreased perception of goal congruence. 
On the second stage of the indirect mediation to visit intention, goal congruence $(b=.61$, $\mathrm{p}<.001)$ mediated the relationship between the presence/absence of the sustainability label and WOM. No direct effect of presence/absence of the sustainability label on WOM was found $(\mathrm{b}=.15, \mathrm{p}=.228$, CI $[-.093 ; .388])$. The primary path relationships are shown in Figure 4.7 and full path results are reported in Table 4.4.

In summary, moderated mediation was supported from presence/absence of the sustainability label to WOM through goal congruence (Index of Moderated Mediation 95\% CI: $.031, .326)$ supporting $\mathrm{H}_{4 b}$ and $\mathrm{H}_{6 b}$.

Figure 4. 7 Moderated Mediation - Label $\rightarrow$ Goal congruence $\rightarrow$ WOM.

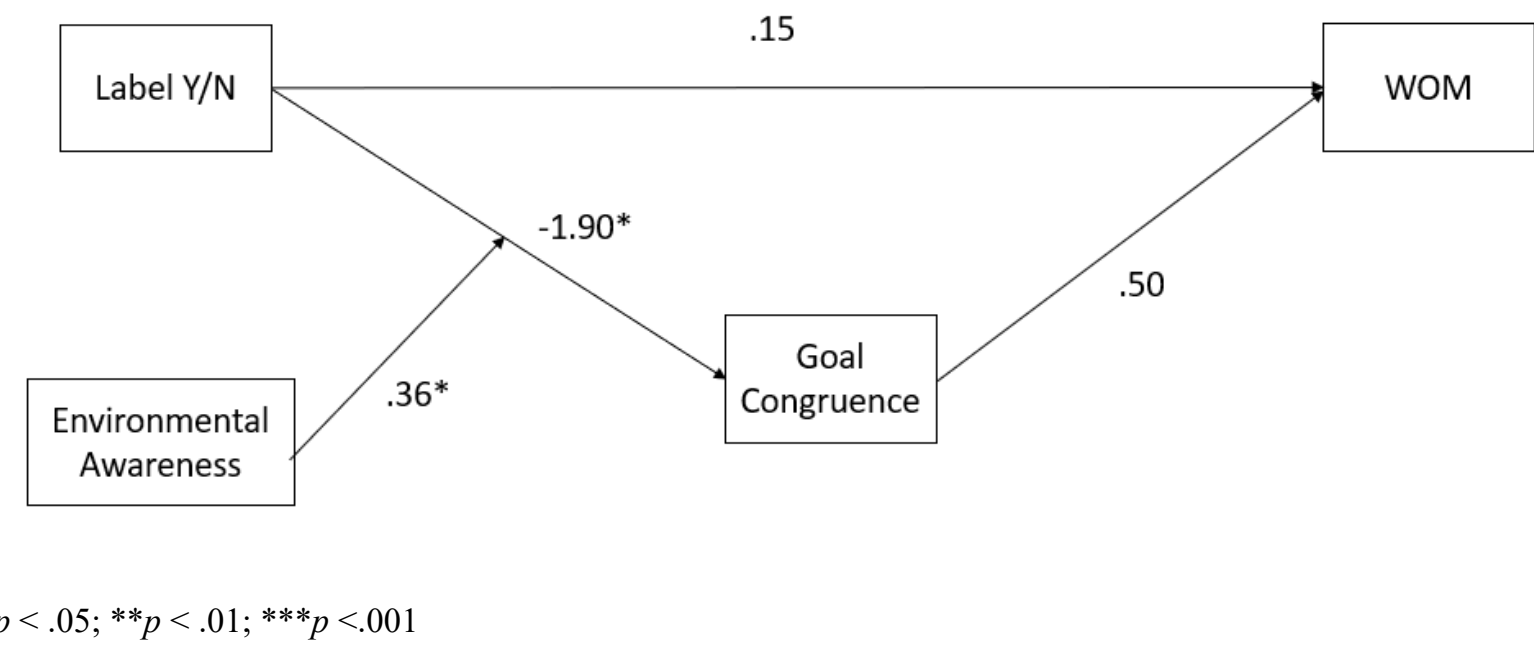

Label $\rightarrow$ Goal Congruence $\rightarrow$ WTP. Consistent with the previous analyses, individual's environmental awareness directly influences how presence/absence of label affects their perception congruence between their own goals and the destination's goals. Higher levels of environmental awareness increased perception of goal congruence in a label condition and slightly decreased it in a no-label condition. 
On the second stage of the indirect mediation to visit intention, goal congruence $(b=$ $68.67, \mathrm{p}<.05)$ mediated the relationship between the presence/absence of the sustainability label and WTP. No direct effect of presence/absence of the sustainability label on WTP was found $(b=-5.678, p=.925$, CI $[-124.716 ; 113.361])$.

The primary path relationships are shown in Figure 4.8 and full path results are reported in Table 4.4. In summary, moderated mediation was supported from presence/absence of the sustainability label to WTP through goal congruence (Index of Moderated Mediation 95\% CI: 1.783, 58.888) supporting $\mathrm{H}_{4 \mathrm{c}}$ and $\mathrm{H}_{6 \mathrm{~b}}$.

Figure 4. 8 Moderated Mediation - Label $\rightarrow$ Goal congruence $\rightarrow$ WTP.

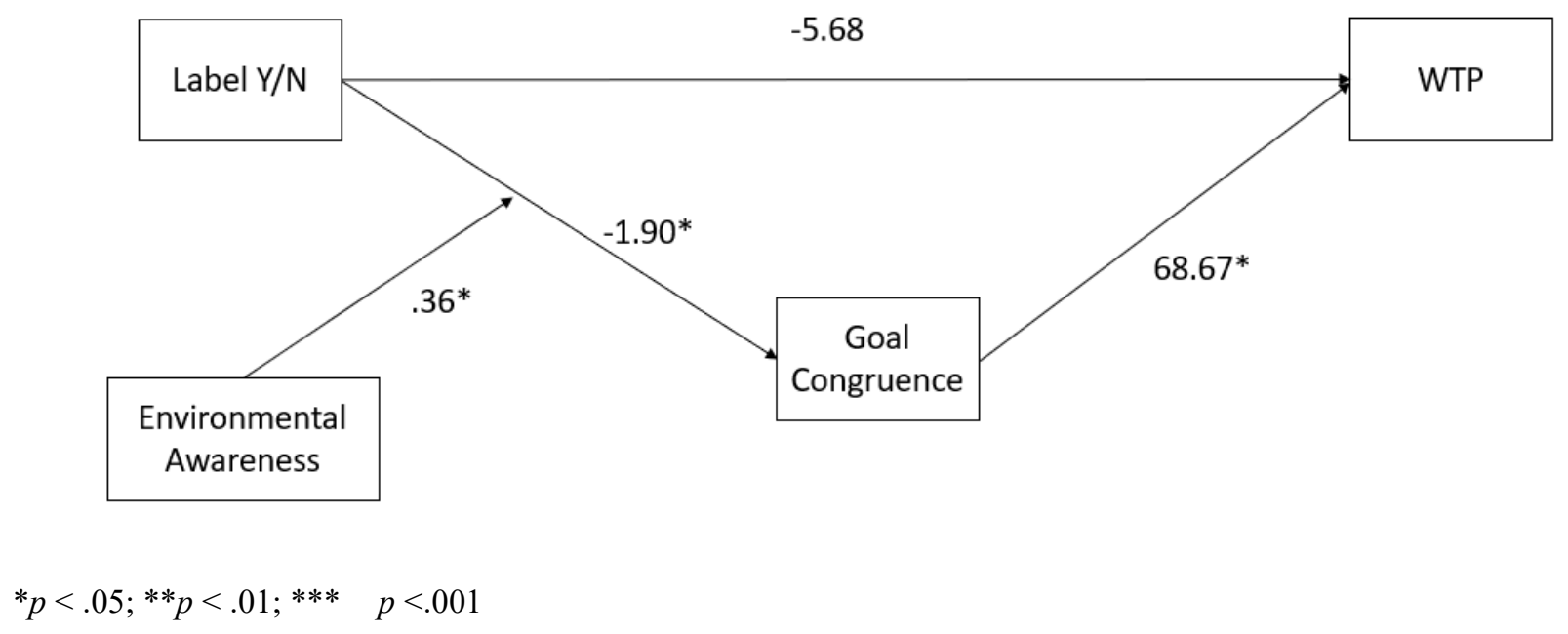


Figure 4. 9 Interaction Effects of Label Presence/Absence and Environmental Awareness on Goal Congruence

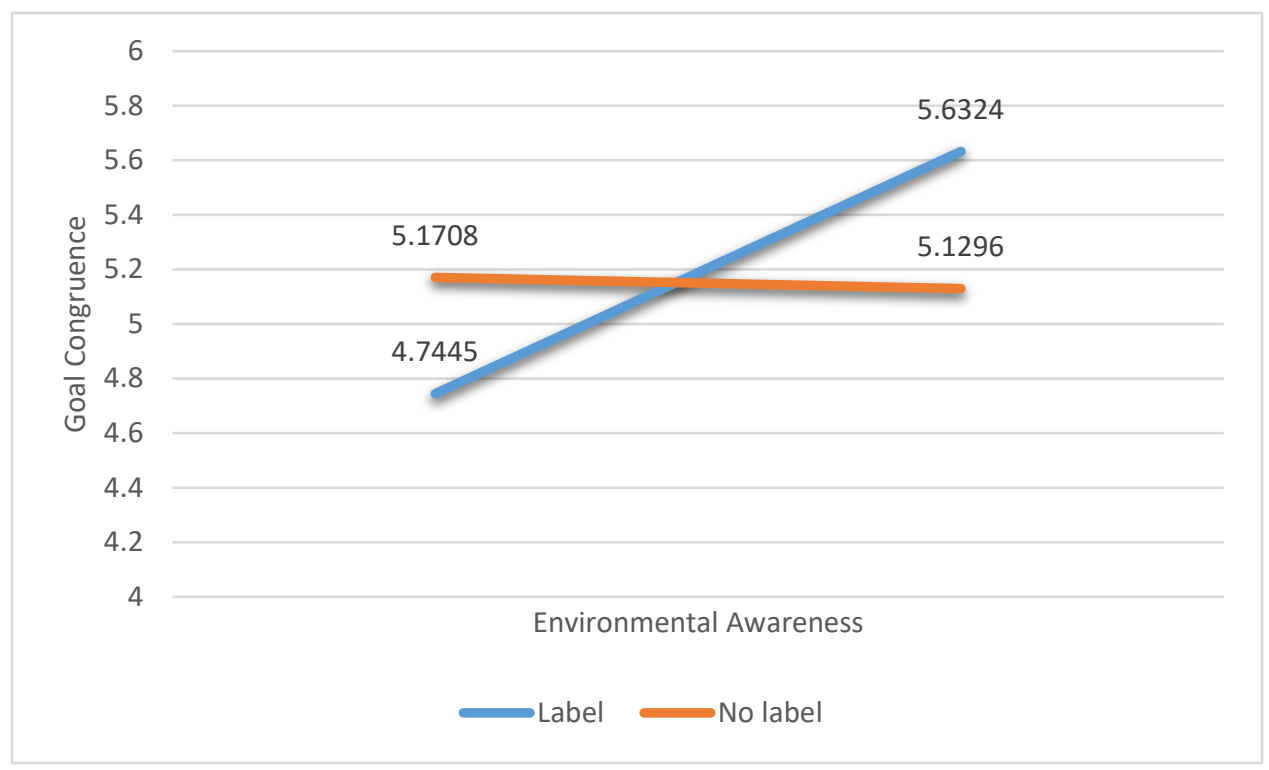


Table 4. 4 Moderated Mediation Results with Confidence Intervals - Goal Congruence

\begin{tabular}{|c|c|c|}
\hline & Coeff & $95 \% \mathrm{CI}$ \\
\hline \multicolumn{3}{|l|}{ Stage A - DV: Goal Congruence } \\
\hline (Constant) & $5.034^{* * *}(.870)$ & $3.318 ; 6.750$ \\
\hline Label (yes/no) & $-1.902 *(.790)$ & $-.3 .461 ;-.343$ \\
\hline Environmental Awareness & $-.016 \dagger(.113)$ & $-.239 ; .208$ \\
\hline Label (yes/no) x Environmental Awareness & $.355 *(.139)$ & $.081 ; .630$ \\
\hline \multicolumn{3}{|l|}{$F(8,180)=7.292, p<.001, R^{2}=.24$} \\
\hline \multicolumn{3}{|l|}{ Stage 1B - DV: Visit Intention } \\
\hline (Constant) & $2.374 * * *(.647)$ & $1.099 ; 3.650$ \\
\hline Label (yes/no) & $.082 \dagger(.165)$ & $-.243 ;-.408$ \\
\hline Goal Congruence & $.608 * * *(.069)$ & $.472 ; .744$ \\
\hline \multicolumn{3}{|l|}{$F(7,181)=18.534, p<.001, R^{2}=.42$} \\
\hline \multicolumn{3}{|l|}{ Stage 2B - DV: WOM } \\
\hline (Constant) & $2.525 * * *(.478)$ & $1.582 ; 3.467$ \\
\hline Label (yes/no) & $.148 \dagger(.122)$ & $-.093 ; .388$ \\
\hline Goal Congruence & $.504 * * *(.051)$ & $.403 ; .604$ \\
\hline \multicolumn{3}{|l|}{$F(7,181)=24.324, p<.001, R^{2}=.48$} \\
\hline \multicolumn{3}{|l|}{ Stage 2C-DV: WTP } \\
\hline (Constant) & $1255.692 * * *(236.377)$ & $789.283 ; 1722.101$ \\
\hline Label (yes/no) & $-5.678 \dagger(60.329)$ & $-.124 .716 ; 113.361$ \\
\hline Goal Congruence & $68.673 *(25.209)$ & $18.932 ; 118.415$ \\
\hline$F(7,181)=7.276, p<.001, R^{2}=.22$ & & \\
\hline
\end{tabular}

$\dagger p<.10 ; * p<.05 ; * * p<.01 ; * * * p<.001$ 
We hypothesized that presence (vs. absence) of a sustainable label on a travel destination's website would increase consumer intention to visit a destination, to share positive information about it, and to pay a price premium and that these effects would occur through perception of congruence of the traveler's and destination's goals $\left(\mathrm{H}_{4}\right)$. We also predicted that environmental awareness would increase perceptions of connectedness and goal congruence when the sustainability label is present $\left(\mathrm{H}_{6}\right)$. Both $\mathrm{H}_{4}$ and $\mathrm{H}_{6}$ were supported.

The summary of results of the main study are presented in Table 4.5 . 
Table 4. 5 Summarized Results of the Main Study

\begin{tabular}{|c|c|}
\hline Hypothesis & Results \\
\hline $\begin{array}{l}\text { H}_{1} \text { : Presence (vs. absence) of a sustainability label in a sustainable } \\
\text { tourism communication will increase } \\
\text { a) intention to visit a destination, } \\
\text { b) intention to spread positive word-of-mouth about the destination } \\
\text { (WOM), and } \\
\text { c) willingness to pay price premium (WTP). }\end{array}$ & $\mathrm{H}_{1}$ not supported \\
\hline $\begin{array}{l}\text { H}_{2} \text { : Embedding anthropomorphic stimuli in sustainable messages will } \\
\text { increase a) intention to visit a destination, b) intention to spread positive } \\
\text { word-of-mouth about the destination, and c) willingness to pay price } \\
\text { premium. }\end{array}$ & $\mathrm{H}_{2}$ not supported \\
\hline $\begin{array}{l}\text { H3: Consumer connectedness with a travel destination will mediate the } \\
\text { effects of sustainability label on } \\
\text { a) intention to visit a destination, } \\
\text { b) intention to spread positive word-of-mouth about the destination, and } \\
\text { c) willingness to pay price premium. }\end{array}$ & $\begin{array}{l}\mathrm{H}_{3 \mathrm{a}} \text { supported } \\
\mathrm{H}_{3 b} \text { supported } \\
\mathrm{H}_{3 \mathrm{c}} \text { not supported }\end{array}$ \\
\hline $\begin{array}{l}\text { H4: Perceived congruence between the consumer's and travel } \\
\text { destination's goals will mediate the effects of sustainability label on } \\
\text { a) intention to visit a destination, } \\
\text { b) intention to spread positive word-of-mouth about the destination, and } \\
\text { c) willingness to pay price premium. }\end{array}$ & $\begin{array}{l}\mathrm{H}_{4 \mathrm{a}} \text { supported } \\
\mathrm{H}_{4 \mathrm{~b}} \text { supported } \\
\mathrm{H}_{4 \mathrm{c}} \text { supported }\end{array}$ \\
\hline $\begin{array}{l}\text { H5: Emotional framing will moderate the effects of anthropomorphized } \\
\text { sustainability message on } \\
\text { a) consumer connectedness with a travel destination and } \\
\text { b) perceived congruence between the consumer's and travel destination's } \\
\text { goals. }\end{array}$ & $\begin{array}{l}\mathrm{H}_{5 \mathrm{a}} \text { not supported } \\
\mathrm{H}_{5 \mathrm{~b}} \text { not supported }\end{array}$ \\
\hline $\begin{array}{l}\text { H6: Consumer's environmental awareness will moderate the effects of } \\
\text { sustainability label on } \\
\text { a) consumer connectedness with a travel destination and } \\
\text { b) perceived congruence between the consumer's and travel destination's } \\
\text { goals. }\end{array}$ & $\begin{array}{l}\mathrm{H}_{6 \mathrm{a}} \text { supported } \\
\mathrm{H}_{6 \mathrm{~b}} \text { supported }\end{array}$ \\
\hline
\end{tabular}




\section{Discussion.}

Sustainability label was found to be an important determinant of consumer intentions to visit a destination, to share positive information about it and to recommend it to others, and to pay a price premium. However, these effects occur indirectly, when consumer goals are perceived to be congruent with the destination's goals and when consumers perceive connectedness with a destination. Effects of sustainability labels on connectedness and goal congruence depend on how much an individual is aware of environmental problems. Illustrating this effect, higher levels of environmental awareness increase connectedness and goal congruence. Moreover, moderated mediation appeared to have no effect in a relationship between connectedness and willingness to pay price premium.

However, the presence of anthropomorphic elements on the label had no effect on consumer behavioral intentions either directly or indirectly. We did not find any differences in consumer intentions between the group in a positive emotional framing condition and the group in a neutral framing condition. Our findings are relevant to the tourism industry and academia. As discussed in the next section, we reaffirmed the importance of sustainability labels in tourism communications. While our inquiry into anthropomorphism was inconclusive, there remains ample opportunity to explore boundary conditions of anthropomorphism. These findings and potential limitations of this research will be discussed in the next chapter. 


\section{CHAPTER 5}

\section{DISCUSSION}

The purpose of this chapter is to discuss the anticipated research implications. Following a discussion of theoretical and managerial contributions, the chapter concludes with the limitations and future research directions.

\section{Theoretical Contributions}

Sustainability has recently become a competitive advantage for many industries and a global trend (Lansing and De Vries 2007; Nidumolu, Ram, Coimbatore K. Prahalad 2009). In response to this trend, companies, including travel operators and destination marketing organizations, are shifting toward sustainable practices. However, unlike in many other sectors that use sustainability messages in their communications (e.g., food and energy sectors), tourism companies often avoid communicating their sustainable efforts to customers (Font, Elgammal, and Lamond 2017).

This dissertation adds to the sustainability tourism framework and identifies potential barriers to positive perception of sustainable tourism messages and seeks mechanisms that can increase consumer favorable acceptance of travel destinations advertised with sustainability messages. Specifically, we found that sustainability messages in tourism may be backfired if consumers view such offers as incompatible with their goals.

To address these issues, we proposed an anthropomorphism framework to increase consumer positive responses to sustainable destination ads. The reviewed literature suggests that anthropomorphized messages may positively affect consumer attitudes toward sustainability offers, but these studies only researched the negative emotional message framing and 
corresponding mechanisms, such as sympathy and guilt (Ahn, Kim, and Aggarwal 2014; Ketron and Naletelich 2019; Tam, Lee, and Chao 2013). These findings do not explain how anthropomorphism affects sustainability behaviors in tourism context since negative emotions are unlikely to be effective for hedonic products (e.g., Johar and Sirgy 1991; Tsao 2010; Wehrli et al. 2017). Thus, effects of anthropomorphism on consumer pro-sustainable behaviors remain underexplored in marketing research.

We found that the presence of sustainability label can positively influence consumer intentions to visit a destination, to recommend it to others, and to pay a price premium through the mechanisms of connectedness and goal congruence. These findings extend the knowledge on the effects of sustainability labels on consumer behavior to tourism context. We also contribute to the prior research by proposing that, based on social exchange theory (Blau 1964), connectedness to the brand and goal congruence are the underlying mechanisms that increase consumer pro-sustainable behaviors.

We also found that consumers who do not recognize the importance of environmental issues are less likely to make connections with a travel destination based on the sustainability label and do not feel that their goals will be met at the travel destination contributing to the literature that supports positive associations of environmental concern with consumer behavioral intentions (Chen 2014; Lee and Holden 1999; Robinot and Giannelloni 2010; Pagiaslis and Krontalis 2014).

However, our findings reveal that anthropomorphic (vs. non-anthropomorphic) messages had no effect on consumer behavioral intentions. More research is needed to uncover the reasons why anthropomorphic elements embedded in communication have no effect on consumers in 
tourism industry. One possible reason is that the design of experimental stimuli itself was flawed. The evaluations of the logo realism and overall design were acceptable ( 3 on a 5-point scale) but not ideal. Also, the logo was designed based on the analysis of content published on the official travel destination websites but not on the analysis of consumer perceptions of sustainability. Another possible reason is that consumers do not associate a more abstract travel package or a destination with humanlike characters.

\section{Managerial Implications}

Sustainable tourism becomes a priority for companies (Lansing and De Vries 2007) and a differentiating factor for tourists (Booking.com 2018; TUI 2017). Thus, destination marketers must seek for methods to communicate their offers for current and future customers. This dissertation suggests using sustainability labels that incorporate anthropomorphic elements to improve sustainability marketing communications.

From a practitioner's perspective, this dissertation has the following managerial implications. First, it demonstrates that sustainability labels are an important determinant of consumer intentions to visit a destination, to share positive information about the destination and to recommend it to others, and to pay a price premium. However, destination marketers should be aware of the fact that sustainability labels will attract only a small segment of consumers who are concerned about the environment. Sustainability label may withdraw people with low levels of environmental awareness from a destination as they may perceive that their goals may not be met.

Second, adding anthropomorphic elements in sustainability messages does not affect consumers' positive intentions toward sustainable tourism offers. Possible explanation of this non-significant effects will be provided in the "Limitations" section of this research. 
Third, connectedness does not result in willingness to pay price premium. Since $42.2 \%$ of our sample reported income less than $\$ 50,000$, this finding may signal that financial constraints may limit connectedness but not the goal congruence. In other words, when consumers think their goals and expectations will be met, they are more likely to pay more for their sustainable vacation.

Fourth, using MTurk sample and realistic experimental stimuli allows expanding generalizability of our research compared to studies that used undergraduate student samples (e.g., Ahn, Kim, and Aggarwal 2014; Melo and Farias 2018). Specifically, we were able to provide insights on behavioral intentions across different generations.

Finally, the present research provides strong empirical support of the UNWTO efforts on encouraging sustainability in tourism, and the ways how labeling systems for destinations will be effective in communicating their sustainable efforts.

\section{Limitations and future research}

This study has the following limitations. First, there might be other numerous factors, such as altruism/egoism, distrust in third party labels, and motivational factors (community vs. personal needs,) that affect various types of consumer attitudes and behaviors. In their open responses, participants mentioned that they would not consider Grinamonte because they already planned another trip, preferred other types of vacation (e.g., shopping or spending time in large cities with lots of entertainment), or because it was similar to their hometown and they wanted their holiday experience to be different. These factors may be further uncovered in future studies through focus groups or in-depth interviews.

Second, the label stimulus for the experimental study was designed based on content analysis that included only published sources (sustainability materials from travel destination 
websites). However, companies may use other methods to communicate with their customer, e.g., personalized emails and mailing materials that are not publicly available. Moreover, content analysis did not reveal any specific topics/words pertaining to advertisement of sustainable tourism. Thus, the design of the labels for the experiment may not communicate sustainable tourism and positive emotions well. For future studies, it may be advised to use other type of content, e.g., content obtained from the participants' open responses that reveals their perceptions of a sustainable vacation.

Third, the present research examines the attitudes and behavioral intentions of an average U.S. consumer. However, according to "The Guardian", U.S. falls behind the other developed countries in terms of recycling and other sustainable initiatives (Holden 2019). It would be interesting to compare U.S. consumers with consumers from other developed countries that widely implement sustainability programs and consumers from less developed countries. Also, it would be important to explore behaviors of specific groups of consumers, e.g., experienced vs. novice travelers. In addition, although use of mTurk samples has its potential benefits (e.g., over the use of student samples), it also has potential limitations. Sixty-five percent of our sample reported household income below $\$ 70,000$. Sustainable products are perceived as more expensive (Gleim et al. 2013) so future research is needed to identify if positive attitudes to a sustainable destination are higher for the consumers with higher levels of household income (\$100,000 and above).

Finally, we collected the data when the COVID-19 pandemic was not over yet. Although some destinations (e.g., China and Russia, UNWTO 2021) demonstrated growth of domestic tourism, tourism industries of most countries, including USA, were still severely affected by the 
pandemic. As most countries emerge from the pandemic, sustainability practices, promotion of such practices, and desired target populations will need to be reconceptualized.

\section{Conclusion}

This dissertation explored the effects of labels in communicating sustainability in tourism context. Using data from an online survey of the U.S. consumers, the present research examines underlying mechanisms (i.e., connectedness to the brand and goal congruence) that lead to increased pro-sustainable consumer behaviors. This is also one of the first empirical studies that attempted to explore the role of anthropomorphism in sustainable tourism communications using the data from the content analysis of the travel destination websites. This research provides important theoretical findings and managerial implications; however, additional research is needed to address potential limitations of this dissertation. 


\section{REFERENCES}

Aggarwal, Pankaj and Ann L. McGill (2007), "Is That Car Smiling at Me? Schema Congruity as a Basis for Evaluating Anthropomorphized Products," Journal of Consumer Research, 34 (4), $468-79$.

and - (2012), "When Brands Seem Human, Do Humans Act Like Brands? Automatic Behavioral Priming Effects of Brand Anthropomorphism," Journal of Consumer Research, 39 (2), 307-23.

Ahn, Hee Kyung, Hae Joo Kim, and Pankaj Aggarwal (2014), "Helping Fellow Beings: Anthropomorphized Social Causes and the Role of Anticipatory Guilt," Psychological Science, 25 (1), 224-29.

Akehurst, Gary, Carolina Afonso, and Helena Martins Gonçalves (2012), "Re-examining green purchase behaviour and the green consumer profile: New evidences," Management Decision, $50(5), 972-88$.

Alba, Joseph W and Elanor F Williams (2013), "Pleasure principles: A review of research on hedonic consumption," Journal of Consumer Psychology, 23 (1), 2-18.

Albers-Miller, Nancy D. and Marla Royne Stafford (1999), "International services advertising: An examination of variation in appeal use for experiential and utilitarian services," Journal of Services Marketing, 13 (4), 390-406.

Allsop, Dee T., Bryce R. Bassett, and James A. Hoskins (2007), "Word-of-mouth research: Principles and applications," Journal of Advertising Research, 47 (4), 398-411.

Atkinson, Lucy and Sonny Rosenthal (2014), "Signaling the green sell: The influence of eco-label source, argument specificity, and product involvement on consumer trust," Journal of Advertising, 43 (1), 33-45.

Babin, Barry J, Yong-ki Lee, Eun-ju Kim, and Mitch Griffin (2003), "Modeling consumer satisfaction and word-of-mouth : restaurant patronage in Korea."

Bagozzi, Richard P., Mahesh Gopinath, and Prashanth U. Nyer (1999), "The Role of Emotions in Marketing," Journal of the Academy of Marketing Science, 27 (2), 184-206.

Baker, Melissa A., Eric A. Davis, and Pamela A. Weaver (2014), "Eco-friendly Attitudes, Barriers to Participation, and Differences in Behavior at Green Hotels," Cornell Hospitality Quarterly, 55 (1), 89-99. 
Banerjee, Abhijit and Barry D. Solomon (2003), "Eco-labeling for energy efficiency and sustainability: A meta-evaluation of US programs," Energy Policy, 31 (2), 109-23.

Banerjee, Bobby and Kim McKeage (1994), "How green is my value: Exploring the relationship between environmentalism and materialism," Advances in consumer research, 21 (1), 14752.

Batra, Rajeev and Michael L. Ray (1986), "Affective Responses Mediating Acceptance of Advertising," Journal of Consumer Research, 13 (2), 234.

Belsley, D.A., E. Kuh, and R.E. Welsch (1980), Regression Diagnostics. Identifying Influential Data and Sources of Collinearity, New York: John Wiley \& Sons.

Bergkvist, Lars (2015), "Appropriate use of single-item measures is here to stay," Marketing Letters, 26 (3), 245-55.

and John Rossiter (2009), "Tailor-made single-item measures of doubly concrete constructs," International Journal of Advertising, 28 (4), 607-21.

— and John R. Rossiter (2007), "The predictive validity of multiple-item versus single-item measures of the same constructs," Journal of Marketing Research, 44 (2), 175-84.

Blau, Peter M. (1964), “Justice in Social Exchange,” Sociological Inquiry, 34 (2), 193-206.

Booking.com (2018), "Where Sustainable Travel is Headed in 2018," [available at https://globalnews.booking.com/where-sustainable-travel-is-headed-in-2018/].

Brown, Tom J. and Peter A. Dacin (1997), “The company and the product: Corporate associations and consumer product responses," Journal of Marketing, 61 (1), 68-84.

Budeanu, Adriana (2007), "Sustainable tourist behaviour - a discussion of opportunities for change," International Journal of Consumer Studies, 31 (5), 499-508.

Burch, James (2020), "The effect of coronavirus is so extreme you can see it from space," [available at https://thehill.com/changing-america/sustainability/climate-change/486085coronavirus-has-slashed-chinas-co2-emissions].

Chandler, Jesse and Norbert Schwarz (2010), "Use does not wear ragged the fabric of friendship: Thinking of objects as alive makes people less willing to replace them," Journal of Consumer Psychology, 20 (2), 138-45.

Chartrand, Tanya L., Gráinne M. Fitzsimons, and Gavan J. Fitzsimons (2008), “Automatic effects of anthropomorphized objects on behavior," Social Cognition, 26 (2), 198-209.

Chen, Kuo Kee (2014), “Assessing the effects of customer innovativeness, environmental value 
and ecological lifestyles on residential solar power systems install intention," Energy Policy, 67, 951-61.

Chow, Denise (2020), "Coronavirus shutdowns have unintended climate benefits: cleaner air, clearer water," [available at https://www.nbcnews.com/science/environment/coronavirusshutdowns-have-unintended-climate-benefits-n1161921].

Cohen, Pninit, Oded Potchter, and Izhak Schnell (2014), "The impact of an urban park on air pollution and noise levels in the Mediterranean city of Tel-Aviv, Israel," Environmental Pollution, 195, 73-83.

Cook, Karen S. and Eric Rice (2013), "Social Exchange Theory," in Handbook of Social Psychology, J. Delamater, ed., Dordrecht: Springer, 61-88.

Coote, Leonard V., Evan Price, and Anna Lena Ackfeldt (2004), "An investigation into the antecedents of goal congruence in retail-service settings," Journal of Services Marketing, 18 (7), 547-59.

Cuevas, Javier Marcos, Saara Julkunen, and Mika Gabrielsson (2015), "Power symmetry and the development of trust in interdependent relationships: The mediating role of goal congruence," Industrial Marketing Management, 48, 149-59.

d'Angella, Francesca and Manuela De Carlo (2016), "Orientation to sustainability and strategic positioning of destinations: an analysis of international tourism websites," Current Issues in Tourism, 19 (7), 624-33.

Emerson, Richard M. (1976), "Social exchange theory,” Annual Review of Psychology, 2 (1), 33562.

Epley, Nicholas, Adam Waytz, Scott Akalis, and John T Cacioppo (2008), "When We Need a Human: Motivational Determinants of Anthropomorphism," Social Cognition, 26 (2), 14355.

— - , and John T. Cacioppo (2007), “On Seeing Human: A Three-Factor Theory of Anthropomorphism," Psychological Review, 114 (4), 864-86.

Eyssel, Friederike and Dieta Kuchenbrandt (2012), "Social categorization of social robots: Anthropomorphism as a function of robot group membership," British Journal of Social Psychology, 51, 724-31.

Font, Xavier, Islam Elgammal, and Ian Lamond (2017), "Greenhushing: the deliberate under communicating of sustainability practices by tourism businesses," Journal of Sustainable 
Tourism, 25 (7), 1007-23.

and Scott McCabe (2017), "Sustainability and marketing in tourism: its contexts, paradoxes, approaches, challenges and potential," Journal of Sustainable Tourism, 25 (7), 869-83.

Fournier, Susan (1998), "Consumers and Their Brands: Developing Relationship Theory in Consumer Research," Journal of Consumer Research, 24 (4), 343-53.

Gleim, Mark R., Jeffery S. Smith, Demetra Andrews, and J. Joseph Cronin (2013), "Against the Green: A Multi-method Examination of the Barriers to Green Consumption," Journal of Retailing, 89 (1), 44-61.

Gössling, Stefan and Ralf Buckley (2016), "Carbon labels in tourism: Persuasive communication?," Journal of Cleaner Production, 111, 358-69.

Gray, Heather M., Kurt Gray, and Daniel M. Wegner (2007), "Dimensions of mind perception," Science, 315 (5812), 619.

Hayes, Andrew F (2018), "Partial, conditional , and moderated moderated mediation: Quantification, inference, and interpretation Quantification , inference, and interpretation," Communication Monographs, 85 (1), 4-40. and Jörg Matthes (2009), "Computational procedures for probing interactions in OLS and logistic regression : SPSS and SAS implementations," 41 (3), 924-36.

Hennig-Thurau, Thorsten, Kevin P Gwinner, and Dwayne D Gremler (2002), "Marketing Outcomes An Integration of Relational Benefits and Relationship Quality," Journal of Service Research, 4 (3), 230-47.

Hirschman, Elizabeth C (1983), "Predictors of Self-Projection, Fantasy Fulfillment, and Escapism," Journal of Social Psychology, 120 (1), 63-76.

Holden, Emily (2019), "US produces far more waste and recycles far less of it than other developed countries," Washington DC.

Howard, Philip H. and Patricia Allen (2006a), "Beyond organic: Consumer interest in new labelling schemes in the Central Coast of California," International Journal of Consumer Studies, 30 (5), 439-51.

and (2006b), "Beyond organic: Consumer interest in new labelling schemes in the Central Coast of California," International Journal of Consumer Studies, 30 (5), 439-51.

Hudson, Laurel A. and Jeff B. Murray (1986), "Methodological Limitations of the Hedonic 
Consumption Paradigm and a Possible Alternative: a Subjectivist Approach," in North American Advances in Consumer Research, R. J. Lutz, ed., Provo, UT: Association for Consumer Research, 343-48.

Jap, Sandy D. (1999), "Pie-expansion efforts: Collaboration processes in buyer-supplier relationships," Journal of Marketing Research, 36 (4), 461-75.

Jedidi, Kamel and Z. John Zhang (2002), "Augmenting conjoint analysis to estimate consumer reservation price," Management Science, 48 (10), 1350-68.

Johar, Author J S and M Joseph Sirgy (1991), "Value-Expressive versus Utilitarian Advertising Appeals: When and Why to Use Which Appeal Value-Expressive Versus Utilitarian Advertising Appeals: When And Why To Use Which Appeal," Journal of Advertising, 20 (3), 23-33.

Kang, Kyung Ho, Laura Stein, Cindy Yoonjoung Heo, and Seoki Lee (2012), “Consumers' willingness to pay for green initiatives of the hotel industry," International Journal of Hospitality Management, 31 (2), 564-72.

Ketron, Seth and Kelly Naletelich (2019), "Victim or beggar? Anthropomorphic messengers and the savior effect in consumer sustainability behavior," Journal of Business Research, 96 (October 2018), 73-84.

Kollmuss, Anja and Julian Agyeman (2002), "Experiential and Informational Knowledge, Architectural Marketing ...," Environmental Education Research, 8 (3), 239-60.

Labroo, Aparna A., Ravi Dhar, and Norbert Schwarz (2008), "Of Frog Wines and Frowning Watches: Semantic Priming, Perceptual Fluency, and Brand Evaluation," Journal of Consumer Research, 34 (6), 819-31.

Lansing, Paul and Paul De Vries (2007), "Sustainable tourism: Ethical alternative or marketing ploy?," Journal of Business Ethics, 72 (1), 77-85.

Lee, Julie Ann and Stephen J S Holden (1999), "Understanding the Determinants of Environmentally Conscious Behavior," Psychology \& Marketing, 16 (5), 373-92.

Letheren, Kate, Brett A.S. Martin, and Hyun Seung Jin (2017), "Effects of personification and anthropomorphic tendency on destination attitude and travel intentions," Tourism Management, 62, 65-75.

Little, Roderick J A (1998), “A Test of Missing Completely at Random for Multivariate Data with Missing Values A Test of Missing Completely at Random for Multivariate Data With Missing 
Values," Journal of the American Statistical Association, 83 (404), 1198-1202.

Liu, Zhenhua (2003), "Sustainable Tourism Development: A Critique Sustainable Tourism Development :," Journal of Sustainable Tourism, 11 (6), 459-75.

Luo, Xueming and C. B. Bhattacharya (2006), "Corporate social responsibility, customer Satisfaction, and market value," Journal of Marketing, 70 (4), 1-18.

Lutz, Richard J., Scott B. MacKenzie, and George E. Belch (1983), "Attitude toward the ad as a mediator of advertising effectiveness: Determinants and consequences," in CR North American Advances, R. P. Bagozzi and A. M. Tybout, eds., Ann Abor, MI : Association for Consumer Research, 532-39.

MacKenzie, Scott B. and Richard J. Lutz (1989), "An Empirical Examination of the Structural Antecedents of Attitude toward the Ad in an Advertising Pretesting Context," Journal of Marketing, 53 (2), 48-65.

Meade, Adam W and S Bartholomew Craig (2012), "Identifying Careless Responses in Survey Data," Psychological Methods, 17 (3), 437-55.

Melo, Francisco Vicente Sales and Salomão Alencar de Farias (2018), "Sustainability Communication and its Effect in Consumer Intention to Visit a Tourist Destination," Tourism \& Management Studies, 14 (2), 36-44.

Miao, Li, Xinran Lehto, and Wei Wei (2014), "he Hedonic Value of Hospitality Consumption: Evidence From Spring Break Experiences," Journal of Hospitality Marketing \& Management, 23 (2), 99-121.

Michel Laroche, Jasmin Bergeron, and Guido Barbaro-Forleo (2001), "Targeting consumers who are willing to pay more for environmentally friendly products.," Journal of consumer marketing, 18 (6), 503-20.

Miller, Klaus M., Reto Hofstetter, Harley Krohmer, and Z. John Zhang (2011), "How should consumers' willingness to pay be measured? an empirical comparison of state-of-the-art approaches," Journal of Marketing Research, 48 (1), 172-84.

Morgan, Robert M and Shelby D Hunt (1994), "The Commitment-Trust Theory of Relationship Marketing," Journal of Marketing, 58, 20-38.

Nidumolu, Ram, Coimbatore K. Prahalad, Madhavan R. Rangaswam (2009), "Why sustainability is the key driver of innovation," Harvard business review, 87 (9), 57-64.

Niemyjska, Aleksandra and Krystyna Drat-Ruszczak (2013), "When There Is Nobody , Angels 
Begin to Fly: Supernatural Imagery Elicited by a Loss of Social Connection," Social Cognition, 31 (1), 57-71.

Okada, Erica Mina and Eric L. Mais (2010), “Framing the 'Green' alternative for environmentally conscious consumers," Sustainability Accounting, Management and Policy Journal, 1 (2), 222-34.

Pagiaslis, Anastasios and Athanasios Krystallis Krontalis (2014), “Antecedents : Environmental Concern , Knowledge , and Beliefs," Psychology \& Marketing, 31 (5), 335-48.

Pang, Jun, Hean Tat Keh, and Siqing Peng (2009), "Effects of advertising strategy on consumerbrand relationships : A brand love perspective," Frontiers of Business Research in China, 3 (4), 599-620.

Park, C Whan, Deborah J Macinnis, and Joseph Priester (2006), "Beyond Attitudes : Attachment and Consumer Behavior," Seoul Journal of Business, 12 (2), 3-35.

Paton, Elizabeth (2018), "Burberry to stop burning clothing and Other Goods It Can't Sell," The New York Times.

De Pelsmacker, Patrick, Wim Janssens, Ellen Sterckx, and Caroline Mielants (2005), "Consumer preferences for the marketing of ethically labelled coffee," International Marketing Review, $22(5), 512-30$.

Petrescu, Maria (2013), "Marketing research using single-item indicators in structural equation models," Journal of Marketing Analytics, 1 (2), 99-117.

Potter, Christina, Anastasios Bastounis, Jamie Hartmann-Boyce, Cristina Stewart, Kerstin Frie, Kate Tudor, Filippo Bianchi, Emma Cartwright, Brian Cook, Mike Rayner, and Susan A. Jebb (2021), The Effects of Environmental Sustainability Labels on Selection, Purchase, and Consumption of Food and Drink Products: A Systematic Review, Environment and Behavior.

Proto, Maria, Ornella Malandrino, and Stefania Supino (2007), "Eco-labels: A sustainability performance in benchmarking?," Management of Environmental Quality: An International Journal, 18 (6), 669-83.

Rettie, Ruth, Kevin Burchell, and Chris Barnham (2014), "Social normalisation : Using marketing to make green normal," Journal of Consumer Behaviour, 13 (1), 9-17.

Rizzo, Cailey (2020), "Venice's Canals Are Beautifully Clear and Dolphins Are Swimming Through Its Ports As Italy's Coronavirus Lockdown Cuts Down on Water Traffic," [available at https:/www.travelandleisure.com/travel-news/coronavirus-cleared-venice-canals-swans- 
fish].

Roberts, James A. (1996), "Green consumers in the 1990s: Profile and implications for advertising," Journal of Business Research, 36 (3), 217-31.

Robinot, E and J Giannelloni (2010), "Do hotels ' ' green' attributes contribute to customer satisfaction ?," Journal of Services Marketing, 24 (2), 157-69.

Roy, Debashish, Md Gulam, Mokta Dhir, and Mohammad Kamrul Ahsan (2016), "Factors Affecting Tourist Satisfaction: A Study in Sylhet Region," ABC Research Alert, 4 (3), 9-20.

Saad, Syed, Hussain Shah, Jabran Aziz, Ahsan Jaffari, Sidra Waris, and Wasiq Ejaz (2012), "The Impact of Brands on Consumer Purchase Intentions," Asian Journal of Business Management, 4 (2), 105-10.

Salisbury, W David, Rodney A Pearson, Allison W Pearson, and David W Miller (2001), "Perceived security and World Wide Web purchase intention," Industrial Management \& Data Systems, 101 (4), 165-76.

Scott, Judy E. and Guy Gable (1997), "Goal congruence, trust, and organizational culture: Strengthening knowledge links," Proceedings of the 18th International Conference on Information Systems, ICIS 1997, 107-19.

Soscia, Isabella (2007), “Gratitude, delight, or guilt: The role of consumers' emotions in predicting postconsumption behaviors," Psychology and Marketing, 24 (10), 871-94.

Stinnett, Rachel C., Eva E. Hardy, and Richard D. Waters (2013), "Who are we? The impacts of anthropomorphism and the humanization of nonprofits on brand personality," International Review on Public and Nonprofit Marketing, 10 (1), 31-48.

Strauss, Karsten (2019), “The Most Sustainable Companies In 2019,” Forbes.

Tabachnick, Barbara G and Linda S. Fidell (2013), Using Multivariate Statistics, Pearson Education Limited.

Tam, Kim Pong, Sau Lai Lee, and Melody Manchi Chao (2013), "Saving Mr. Nature: Anthropomorphism enhances connectedness to and protectiveness toward nature," Journal of Experimental Social Psychology, 49 (3), 514-21.

TechSci Research (2017), “Global Organic Food Market By Product Type (Organic Meat, Poultry and Dairy; Organic Fruits and Vegetables; Organic Processed Food; etc.), By Region (Europe, North America, Asia-Pacific, etc.), Competition Forecast and Opportunities, 2012 2022." 
Tourism, World and Organization Unwto (2021), "UNWTO World Tourism Barometer and Statistical Annex, May 2021," UNWTO World Tourism Barometer, 19 (3), 1-42.

Tsao, Wen-Chin (2010), "Investigating Brand Attitude Changes toward High- Involved Hedonic Products via Optimal Ad Appeal Arrangements over Multiple Exposures," International Journal of Management, 27 (3), 511-80.

TUI (2017), “TUI Group: Sustainability Survey Global Insights 2017.”

UNEP and UNWTO (2005), Making Tourism More Sustainable - A Guide for Policy Makers.

United Nations (n.d.), "Stakeholders," [available at https://sustainabledevelopment.un.org/mgos]. (2016), “The 2030 Agenda for Sustainable Development," [available at https://sustainabledevelopment.un.org/post2015/transformingourworld].

UNWTO (n.d.), "Global and Regional Tourism Performance," (accessed September 7, 2021), [available at https://www.unwto.org/global-and-regional-tourism-performance].

(2018), "UNWTO Tourism Highlights."

(2019), "International Tourism Highlights International tourism continues to outpace the global economy," 1-24.

(2021), “Tourist Arrivals Down 87\% in January 2021 As UNWTO Calls for Stronger Coordination to Restart Tourism," [available at https://www.unwto.org/news/tourist-arrivalsdown-87-in-january-2021-as-unwto-calls-for-stronger-coordination-to-restart-tourism].

Verbeke, Wim and Ronald W. Ward (2006), "Consumer interest in information cues denoting quality, traceability and origin: An application of ordered probit models to beef labels," Food Quality and Preference, 17 (6), 453-67.

Vicente, Francisco and Sales Melo (2014), "Sustainability as an Identity Factor of Tourist Destinations at Websites : Does the Consumer Care?," (81), 135-58.

Vinerean, Alexandra (2013), “The Influence of Hedonic and Utilitarian Motivators on Likelihood to Buy a Tourism Package," Expert Journal of Marketing, 1, 28-37.

Virtuoso (2018), “2019 Is The Year Of Ultra-Personalized Travel According To The VIRTUOSO® LUXE REPORT,” New York.

Waytz, Adam, John T. Cacioppo, and Nicholas Epley (2010), "Who Sees Human? : The Stability and Importance of Individual Differences in Anthropomorphism," Perspectives on Psychological Science, 5 (3), 219-32.

, Nicholas Epley, and John T. Cacioppo (2010), "Social cognition unbound: Insights into 
anthropomorphism and dehumanization," Current Directions in Psychological Science, 19 (1), 58-62.

Wehrli, Roger, Julianna Priskin, Sascha Demarmels, Dorothea Schaffner, Jürg Schwarz, Fred Truniger, and Jürg Stettler (2017), "How to communicate sustainable tourism products to customers: results from a choice experiment," Current Issues in Tourism, 20 (13), 1375-94.

Wharton, David (2019), "Is it an Olympic logo? Or a coquettish scamp?," [available at https://www.latimes.com/sports/story/2019-10-24/paris-olympics-2024-logo].

White, Katherine, Rishad Habib, and David J. Hardisty (2019), "How to SHIFT consumer behaviors to be more sustainable: A literature review and guiding framework," Journal of Marketing, 83 (3), 22-49.

White, Robert W (1959), "Motivation Reconsidered: The Concept of Competence," Psychological Review, 66, 297-333.

World Commission on Environment and Development (1987), "Our Common Future," Oxford/New York.

Yan, Tingting and Kevin J. Dooley (2013), "Communication intensity, goal congruence, and uncertainty in buyer-supplier new product development," Journal of Operations Management, 31 (7-8), 523-42.

Zadek, Simon, Sanjiv Lingayah, and Maya Forstater (1998), "Social labels: Tools for ethical trade," Report prepared by the New Economics Foundation for the European Commission, 126. 


\section{Examples of Sustainability Labels in Different Industries}
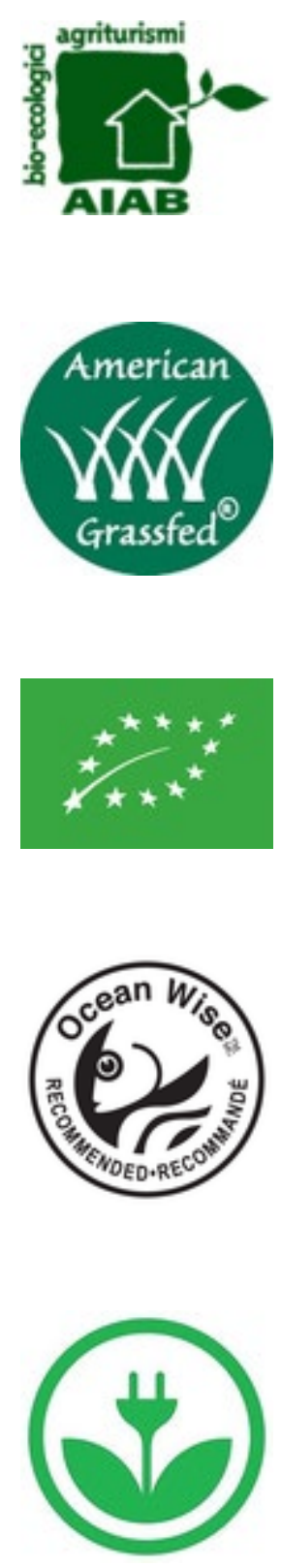

\section{Agriculture \& Food}

Italian Association for Organic Agriculture certifies organic products and companies in a broad range of categories, including food, detergents, farms, cosmetics, etc.

The American Grassfed Association (AGA) certifies food and agriculture products from animals that were fed by their mother's milk and fresh grass or grass-type hay only.

EU organic product label indicates that the product has been grown organically, i.e., if at least $95 \%$ of their agricultural ingredients are organic.

Ocean Wise is a global program that certifies market and restaurant seafood.

\section{Energy}

EKOenergy (Europe) is a label for electricity applied in more than 20 European countries. 

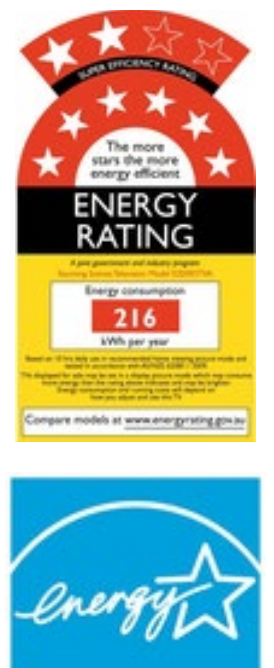

\section{ENERGYSTAR}

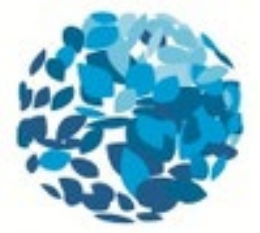

EARTHCHECK
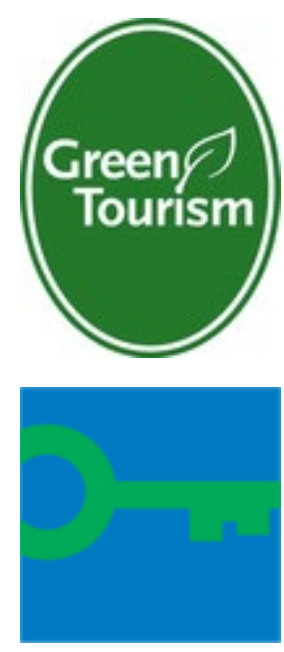

Viabono
Australian certification system that provides energy efficiency ratings of electrical appliances.

Energy Star is a world-wide program that certifies energy efficient equipment.

\section{Tourism}

EarthCheck is a global certification system for travel and tourism. They certify over 30 sectors including travel destinations and cities, parks and protected areas, travel businesses (e.g., hotels, restaurants, cruises), etc.

The Green Tourism Business Scheme is the national sustainable tourism certification scheme for the UK \& Ireland.

The Green Key is an award for excellence in the field of environmental responsibility and sustainable operation within the tourism industry. Green Key is given to hotels, hostels, small accommodations, campsites, holiday parks, conference centers, restaurants and attractions.

Viabono certifies destinations, accommodation facilities, and other tourism businesses in Germany. 


\section{Other}

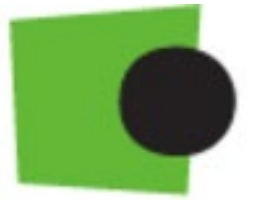

The BASTA system certifies construction and building products for hazardous substances in them.

BASTA

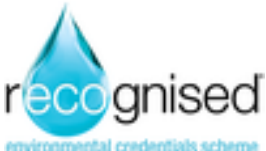

The Recognised $\AA$ eco-label program certifies environmentally friendly commercial cleaning products, such as hard surface cleaners, bathroom cleaners, carpet \& upholstery cleaners; hand hygiene products; sanitizers, etc..

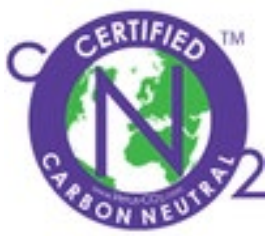

A Carbon Neutral Certification is a label given to businesses that offset their Scope 1 and 2 carbon footprint. 
APPENDIX B

\section{List of Travel Destination Websites}

\begin{tabular}{|c|c|c|}
\hline 1. & Afghanistan & https://tourism.gov.af/ \\
\hline 2 & Albania & http://albania.al/ \\
\hline 3 & Algeria & $\begin{array}{l}\text { https://www.algeria.com/ } \\
\text { https://www.tourismalgeria.com/index.html }\end{array}$ \\
\hline 4 & Andorra & https://visitandorra.com/en/ \\
\hline 5 & Angola & $\begin{array}{l}\text { https://www.southafrica.net/gl/en/trade/welcome/country/angola?gclid=Cj } \\
\text { OKCQjw9b 4BRCMARIsADMUlyrOJcPg5z N27R4zsfKwuDv93vlIXUEC udulVsh } \\
\text { H5-TyEG1b0QRakaArNkEALw wcB }\end{array}$ \\
\hline 6 & $\begin{array}{l}\text { Antigua and } \\
\text { Barbuda }\end{array}$ & https://visitantiguabarbuda.com/ \\
\hline 7 & Argentina & $\begin{array}{l}\text { https://www.argentina.travel/\#!/global/home?lang=en } \\
\text { https://www.welcomeargentina.com/index i.html }\end{array}$ \\
\hline 8 & Armenia & http://armenia.travel/en \\
\hline 9 & Australia & https://www.australia.com/en \\
\hline 10 & Austria & https://www.austria.info/en \\
\hline 11 & Azerbaijan & https://azerbaijan.travel/ \\
\hline 12 & Bahamas & https://www.bahamas.com/ \\
\hline
\end{tabular}




\begin{tabular}{|c|c|c|}
\hline 13 & Bahrain & https://visitbahrain.bh/ \\
\hline 14 & Bangladesh & http://www.tourismboard.gov.bd/ \\
\hline 15 & Barbados & https://www.visitbarbados.org/ \\
\hline 16 & Belarus & $\begin{array}{l}\text { https://www.belarustourism.by/en/ } \\
\text { https://www.visit-belarus.com/en/home/ }\end{array}$ \\
\hline 17 & Belgium & https://www.belgium.be/en/about belgium/tourism \\
\hline 18 & Belize & https://www.travelbelize.org/ \\
\hline 19 & Benin & No website \\
\hline 20 & Bhutan & https://www.bhutan.travel/ \\
\hline 21 & Bolivia & https://boliviatravelsite.com/ \\
\hline 22 & $\begin{array}{l}\text { Bosnia and } \\
\text { Herzegovina }\end{array}$ & http://www.discoverbosnia.com/ \\
\hline 23 & Botswana & https://www.botswanatourism.co.bw/ \\
\hline 24 & Brazil & https://www.visitbrasil.com/ \\
\hline 25 & Brunei & https://www.bruneitourism.com/ \\
\hline 26 & Bulgaria & https://bulgariatravel.org/en/ \\
\hline 27 & Burkina Faso & http://www.burkina.com/ \\
\hline 28 & Burundi & No website \\
\hline
\end{tabular}




\begin{tabular}{|c|c|c|}
\hline 29 & Côte d'Ivoire & No website \\
\hline 30 & Cabo Verde & No website \\
\hline 31 & Cambodia & http://cambodia-tourism.org/ \\
\hline 32 & Cameroon & https://www.tourisminformationcameroon.net/ \\
\hline 33 & Canada & $\begin{array}{l}\text { https://us-keepexploring.canada.travel/experience-canada-virtually-from- } \\
\text { home?oref=https://www.google.com/ (international version) }\end{array}$ \\
\hline 34 & $\begin{array}{l}\text { Central African } \\
\text { Republic }\end{array}$ & No website \\
\hline 35 & Chad & No website \\
\hline 36 & Chile & https://www.visitchile.org/ \\
\hline 37 & China & $\begin{array}{l}\text { http://www.travelchina.gov.cn/en/ } \\
\text { http://www.china.org.cn/travel/ }\end{array}$ \\
\hline 38 & Colombia & https://colombia.travel/en \\
\hline 39 & Comoros & http://www.willgoto.com/1/004582/liens.aspx \\
\hline 40 & $\begin{array}{l}\text { Congo (Congo- } \\
\text { Brazzaville) }\end{array}$ & https://congotravelandtours.com/ \\
\hline 41 & Costa Rica & https://www.visitcostarica.com/en \\
\hline 42 & Croatia & https://croatia.hr/en-GB \\
\hline 43 & Cuba & https://www.cubatravel.cu/en/destinations/havana-cuba \\
\hline
\end{tabular}




\begin{tabular}{|l|l|l|}
\hline 44 & Cyprus & http://media.visitcyprus.com/wps/portal \\
\hline 45 & $\begin{array}{l}\text { Czechia (Czech } \\
\text { Republic) }\end{array}$ & https://www.czechtourism.com/home/ \\
\hline 46 & $\begin{array}{l}\text { Democratic } \\
\text { Republic of the } \\
\text { Congo }\end{array}$ & \\
\hline 47 & Denmark & https://www.visitdenmark.com/ \\
\hline 48 & Djibouti & https://guide.visitdiibouti.dj/ \\
\hline 49 & Dominica & https://discoverdominica.com/en/home \\
\hline 50 & $\begin{array}{l}\text { Dominican } \\
\text { Republic }\end{array}$ & https://www.visitdominicanrepublic.org/dominican-republic-tourims \\
& & https://www.godominicanrepublic.com/ \\
\hline 51 & Ecuador & https://vivecuador.com/html2/eng/home.htm \\
\hline 52 & Egypt & http://egypt.travel/ \\
\hline 53 & El Salvador & https://elsalvador.travel/ \\
\hline 54 & $\begin{array}{l}\text { Equatorial } \\
\text { Guinea }\end{array}$ & $\begin{array}{l}\text { Website is marked as a phishing site } \\
\text { Estp://www.eritrea.be/ }\end{array}$ \\
\hline Swaziland") & https://www.thekingdomofeswatini.com/ \\
\hline 56 & Estonia & \\
\hline
\end{tabular}




\begin{tabular}{|c|c|c|}
\hline 58 & Ethiopia & http://www.moct.gov.et/ \\
\hline 59 & Fiji & https://www.fiji.travel/en-us \\
\hline 60 & Finland & https://www.visitfinland.com/ \\
\hline 61 & France & http://ee.france.fr/ \\
\hline 62 & Gabon & No website \\
\hline 63 & Gambia & http://www.visitthegambia.gm/ \\
\hline 64 & Georgia & https://gnta.ge/ \\
\hline 65 & Germany & $\begin{array}{l}\text { https://www.germany.travel/en/index.html } \\
\text { https://germantourismboard.com/ }\end{array}$ \\
\hline 66 & Ghana & https://visitghana.com/ \\
\hline 67 & Greece & http://www.visitgreece.gr/ \\
\hline 68 & Grenada & https://www.puregrenada.com/ \\
\hline 69 & Guatemala & https://visitguatemala.com/?lang=en \\
\hline 70 & Guinea & https://www.papuanewguinea.travel/ \\
\hline 71 & Guinea-Bissau & http://www.guinebissaurepublic.com/tourism/ \\
\hline 72 & Guyana & https://guyanatourism.com/ \\
\hline 73 & Haiti & https://visithaiti.com/ \\
\hline
\end{tabular}




\begin{tabular}{|c|c|c|}
\hline 74 & Holy See & \\
\hline 75 & Honduras & https://www.honduras.travel/en/ \\
\hline 76 & Hungary & https://wowhungary.com/en \\
\hline 77 & Iceland & https://visiticeland.com/ \\
\hline 78 & India & https://www.incredibleindia.org/content/incredible-india-v2/en.html \\
\hline 79 & Indonesia & https://www.indonesia.travel/gb/en/home \\
\hline 80 & Iran & https://www.visitiran.ir/ \\
\hline 81 & Iraq & $\begin{array}{l}\text { http://bot.gov.krd/ } \\
\text { https://tourisminiraq.weebly.com/ }\end{array}$ \\
\hline 82 & Ireland & https://www.ireland.com/en-us/ \\
\hline 83 & Israel & https://info.goisrael.com/en/ \\
\hline 84 & Italy & http://www.italia.it/en/home.html \\
\hline 85 & Jamaica & https://www.visitjamaica.com/ \\
\hline 86 & Japan & https://www.japan.travel/en/ \\
\hline 87 & Jordan & http://www.visitjordan.com/ \\
\hline 88 & Kazakhstan & https://visitkazakhstan.kz/en/ \\
\hline 89 & Kenya & https://magicalkenya.com/ \\
\hline
\end{tabular}




\begin{tabular}{|l|l|l|}
\hline 90 & Kiribati & https://www.visit-kiribati.com/ \\
\hline 91 & Kuwait & https://www.visit-kuwait.com/ \\
\hline 92 & Kyrgyzstan & http://www.discoverkyrgyzstan.org/ \\
\hline 93 & Laos & https://www.visitlaos.org/ \\
\hline 94 & Latvia & https://www.latvia.travel/en \\
\hline 95 & Lebanon & http://www.destinationlebanon.gov.lb// \\
\hline 96 & Lesotho & https://www.visitlesotho.travel/ \\
\hline 97 & Liberia & https://visitliberia.net/ \\
\hline 98 & Libya & http://www.libyan-tourism.org/ \\
\hline 99 & Liechtenstein & https://tourismus.li/en/ \\
\hline 100 & Lithuania & https://www.tourism.gov.my/ \\
\hline 101 & Luxembourg & https://lithuania.travel/en/ \\
\hline https://www.visitluxembourg.com/en \\
\hline https://www.malaysia.travel/ \\
\hline 102 & Madagascar & https://madagascar-tourisme.com/en/ministry-of-tourism/ \\
\hline & & Malavavelmadagascar.org/ \\
\hline
\end{tabular}




\begin{tabular}{|c|c|c|}
\hline 105 & Maldives & https://visitmaldives.com/en \\
\hline 106 & Mali & https://officetourismemali.net/ \\
\hline 107 & Malta & https://www.visitmalta.com/en/home \\
\hline 108 & Marshall Islands & $\begin{array}{l}\text { https://www.infomarshallislands.com/resources-3/marshall-islands-visitors- } \\
\text { authority/ }\end{array}$ \\
\hline 109 & Mauritania & No website \\
\hline 110 & Mauritius & https://www.tourism-mauritius.mu/ \\
\hline 111 & Mexico & https://www.visitmexico.com/en/ \\
\hline 112 & Micronesia & https://www.micronesiatour.com/ \\
\hline 113 & Moldova & http://turism.gov.md/index.php?l=en \\
\hline 114 & Monaco & https://www.visitmonaco.com/en \\
\hline 115 & Mongolia & $\begin{array}{l}\text { https://www.visitmongolia.com/ } \\
\text { http://www.touristinfocenter.mn/en/home.aspx }\end{array}$ \\
\hline 116 & Montenegro & https://www.montenegro.travel/en \\
\hline 117 & Morocco & https://www.visitmorocco.com/en \\
\hline 118 & Mozambique & $\begin{array}{l}\text { https://www.visitmozambique.net/ } \\
\text { https://www.mozambiquetourism.co.za/ }\end{array}$ \\
\hline 119 & $\begin{array}{l}\text { Myanmar } \\
\text { (formerly Burma) }\end{array}$ & https://tourism.gov.mm/ \\
\hline
\end{tabular}




\begin{tabular}{|c|c|c|}
\hline & & https://www.tourismmyanmar.org/ \\
\hline 120 & Namibia & http://www.namibiatourism.com.na/ \\
\hline 121 & Nauru & http://www.naurugov.nr/about-nauru/visiting-nauru.aspx \\
\hline 122 & Nepal & https://www.welcomenepal.com/ \\
\hline 123 & Netherlands & https://www.holland.com/global/tourism.htm \\
\hline 124 & New Zealand & $\begin{array}{l}\text { https://www.tourismnewzealand.com/about// } \\
\text { https://www.newzealand.com/int/ }\end{array}$ \\
\hline 125 & Nicaragua & https://www.visitnicaragua.us/ \\
\hline 126 & Niger & No website \\
\hline 127 & Nigeria & $\begin{array}{l}\text { https://tournigeria.gov.ng/ } \\
\text { https://www.cometonigeria.com/ }\end{array}$ \\
\hline 128 & North Korea & https://www.visitthedprk.org/ \\
\hline 129 & North Macedonia & http://www.exploringmacedonia.com/ \\
\hline 130 & Norway & https://www.visitnorway.com/ \\
\hline 131 & Oman & $\begin{array}{l}\text { https://omantourism.gov.om/wps/portal/mot/tourism/oman/home/!ut/p/a } \\
\text { 1/04 Sj9CPykssy0xPLMnMzOvMAfGjzOLN Nx8AlxdDA38LQwNDDyDLXzNgoO } \\
\text { diQ38TYEKloEKDHAARwNC-oMTi TD9aPAypzdHT1MzH2A- } \\
\text { py8nQ08vVODvUOMfQONHAOxFJhYGBI4ujh5uJhb- } \\
\text { gJNNIMqwOOOgtylCs9MROUAhfPJgw!!/dl5/d5/LOIHSkovdORNQUprQUVnQS } \\
\text { EhLzRKUOUvZW4!/ }\end{array}$ \\
\hline 132 & Pakistan & http://www.tourism.gov.pk/ \\
\hline
\end{tabular}




\begin{tabular}{|c|c|c|}
\hline & & http://aroundpakistan.com/ \\
\hline 133 & Palau & https://www.pristineparadisepalau.com/ \\
\hline 134 & Palestine State & http://visitpalestine.ps/ \\
\hline 135 & Panama & https://www.visitpanama.com/ \\
\hline 136 & $\begin{array}{l}\text { Papua New } \\
\text { Guinea }\end{array}$ & https://www.papuanewguinea.travel/ \\
\hline 137 & Paraguay & https://www.visitparaguay.travel/ \\
\hline 138 & Peru & https://www.visitperu.com/visit-peruinfo/english/index.php \\
\hline 139 & Philippines & https://www.itsmorefuninthephilippines.com/ \\
\hline 140 & Poland & https://www.poland.travel/en \\
\hline 141 & Portugal & https://www.visitportugal.com/en \\
\hline 142 & Qatar & https://www.visitqatar.qa/ \\
\hline 143 & Romania & http://romaniatourism.com/ \\
\hline 144 & Russia & https://www.visitrussia.com/ \\
\hline 145 & Rwanda & https://www.visitrwanda.com/ \\
\hline 146 & $\begin{array}{l}\text { Saint Kitts and } \\
\text { Nevis }\end{array}$ & https://www.stkittstourism.kn/ \\
\hline 147 & Saint Lucia & https://www.stlucia.org/en/ \\
\hline
\end{tabular}




\begin{tabular}{|c|c|c|}
\hline 148 & $\begin{array}{l}\text { Saint Vincent and } \\
\text { the Grenadines }\end{array}$ & https://www.discoversvg.com/ \\
\hline 149 & Samoa & https://www.samoa.travel/ \\
\hline 150 & San Marino & https://www.sanmarinosite.com/en/ \\
\hline 151 & $\begin{array}{l}\text { Sao Tome and } \\
\text { Principe }\end{array}$ & $\begin{array}{l}\text { https://visitsaotomeprincipe.st/en/welcome/ } \\
\text { http://www.visitsaotome.com/ }\end{array}$ \\
\hline 152 & Saudi Arabia & https://www.visitsaudi.com/en \\
\hline 153 & Senegal & \\
\hline 154 & Serbia & https://www.serbia.travel/ \\
\hline 155 & Seychelles & https://www.seychelles.travel/en/ \\
\hline 156 & Sierra Leone & https://www.visitsierraleone.org/ \\
\hline 157 & Singapore & https://www.visitsingapore.com/en/ \\
\hline 158 & Slovakia & https://slovakia.travel/en \\
\hline 159 & Slovenia & https://www.slovenia.info/en \\
\hline 160 & Solomon Islands & https://www.visitsolomons.com.sb/ \\
\hline 161 & Somalia & http://somta.so/ \\
\hline 162 & South Africa & https://www.southafrica.net/us/en/ \\
\hline 163 & South Korea & http://english.visitkorea.or.kr/enu/index.kto\# \\
\hline
\end{tabular}




\begin{tabular}{|c|c|c|}
\hline 164 & South Sudan & No website \\
\hline 165 & Spain & https://www.spain.info/en/ \\
\hline 166 & Sri Lanka & https://www.srilanka.travel/essence \\
\hline 167 & Sudan & No website \\
\hline 168 & Suriname & https://www.surinametourism.sr/ \\
\hline 169 & Sweden & https://visitsweden.com/ \\
\hline 170 & Switzerland & https://www.myswitzerland.com/en-us/ \\
\hline 171 & Syria & http://www.syriatourism.org/en/ \\
\hline 172 & Tajikistan & https://traveltajikistan.ti/ \\
\hline 173 & Tanzania & https://www.tanzaniatourism.go.tz/en \\
\hline 174 & Thailand & https://www.tourismthailand.org/ \\
\hline 175 & Timor-Leste & https://www.timorleste.tl/ \\
\hline 176 & Togo & No website \\
\hline 177 & Tonga & http://www.tongaholiday.com/ \\
\hline 178 & $\begin{array}{l}\text { Trinidad and } \\
\text { Tobago }\end{array}$ & $\begin{array}{l}\text { https://www.gotrinidadandtobago.com/ } \\
\text { http://tourism.gov.tt/ }\end{array}$ \\
\hline 179 & Tunisia & https://www.discovertunisia.com/en/ \\
\hline
\end{tabular}




\begin{tabular}{|c|c|c|}
\hline 180 & Turkey & https://www.visitturkey.in/ \\
\hline 181 & Turkmenistan & http://tourism.gov.tm/ \\
\hline 182 & Tuvalu & https://www.timelesstuvalu.com/ \\
\hline 183 & Uganda & https://www.visituganda.com/ \\
\hline 184 & Ukraine & https://traveltoukraine.org/ \\
\hline 185 & $\begin{array}{l}\text { United Arab } \\
\text { Emirates }\end{array}$ & https://visitabudhabi.ae/us-en/default.aspx \\
\hline 186 & United Kingdom & https://www.visitbritain.com/gb/en \\
\hline 187 & $\begin{array}{l}\text { United States of } \\
\text { America }\end{array}$ & https://www.visittheusa.com/ \\
\hline 188 & Uruguay & https://www.welcomeuruguay.com/index i.html \\
\hline 189 & Uzbekistan & https://uzbekistan.travel/en/ \\
\hline 190 & Vanuatu & https://www.vanuatu.travel/en/ \\
\hline 191 & Venezuela & No website \\
\hline 192 & Vietnam & https://vietnam.travel/ \\
\hline 193 & Yemen & https://www.yementourism.com/ \\
\hline 194 & Zambia & $\begin{array}{l}\text { https://www.zambiatourism.com/ } \\
\text { https://www.zambia.travel/ }\end{array}$ \\
\hline
\end{tabular}


\begin{tabular}{l|l|l}
195 & Zimbabwe & https://www.zimbabwetourism.net/
\end{tabular} 


\section{APPENDIX C}

\section{Python Code for Text Scraping and LDA Analysis}

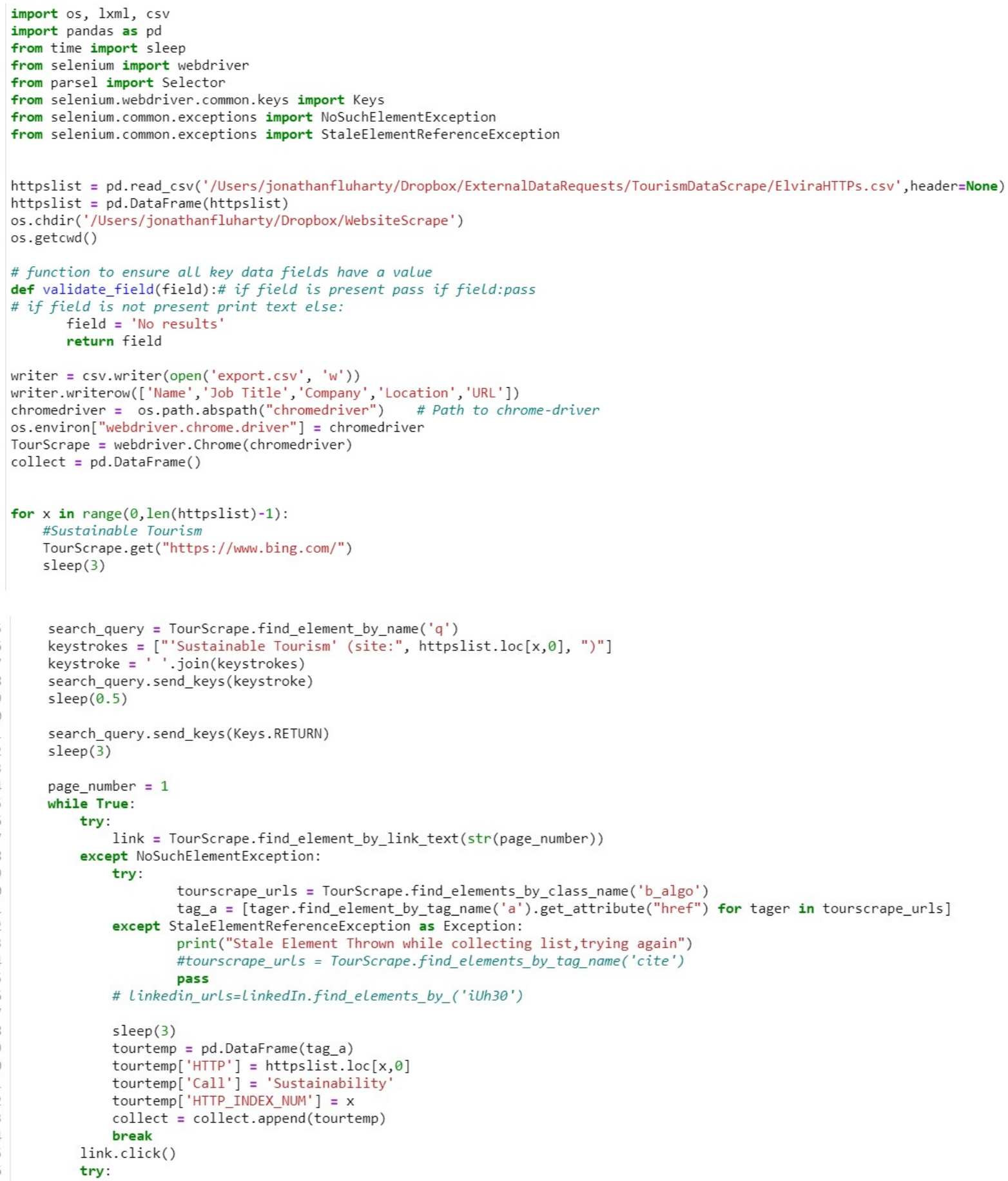




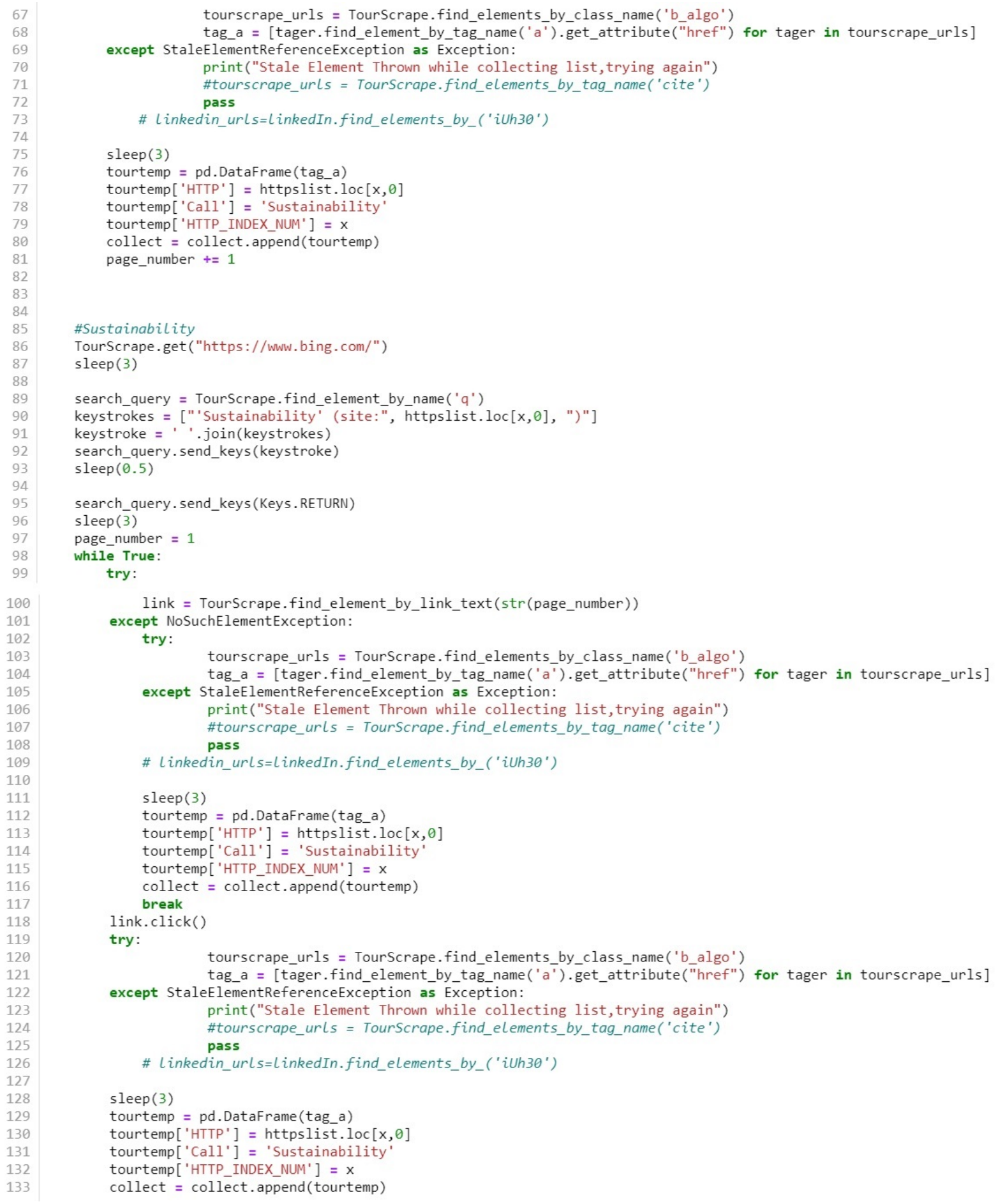




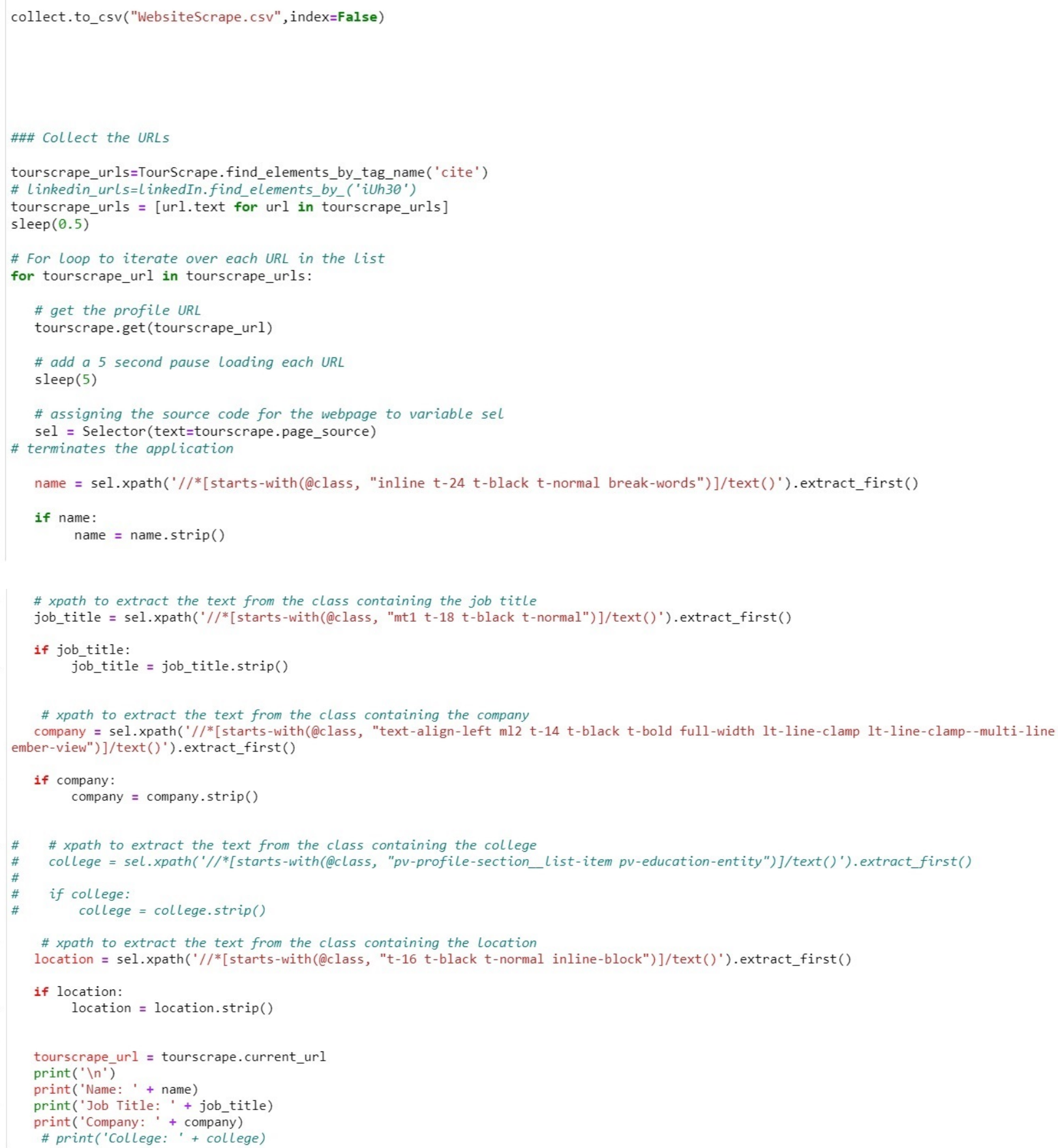




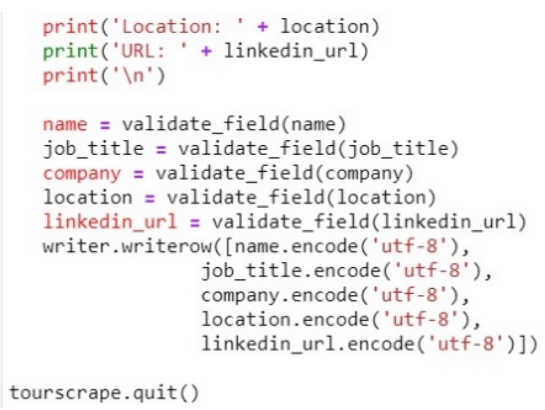




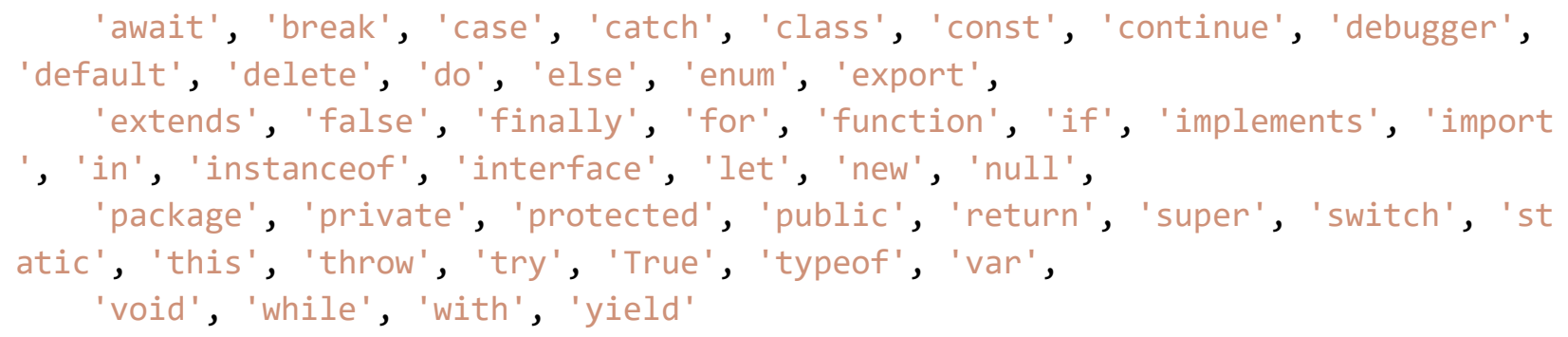




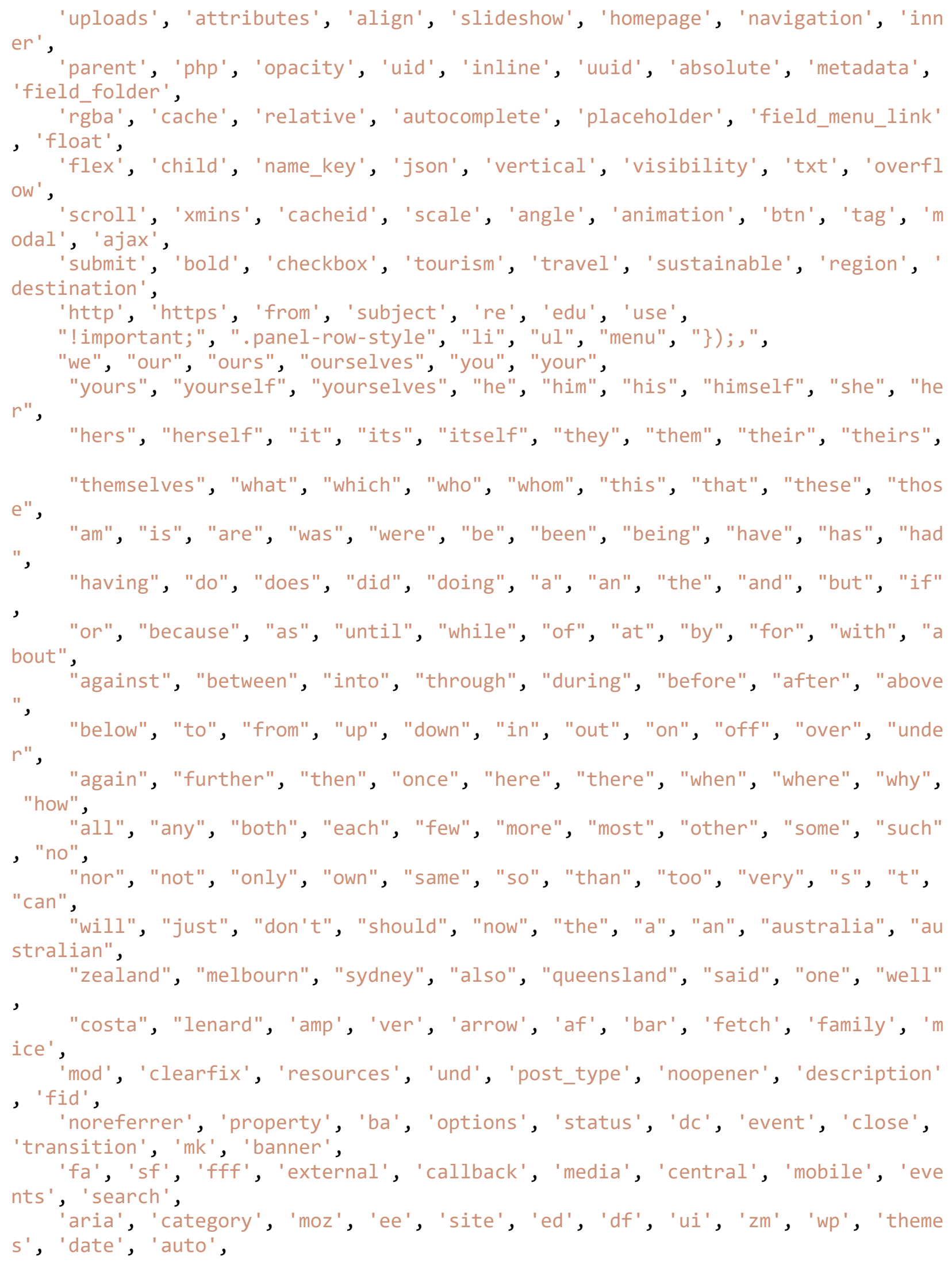




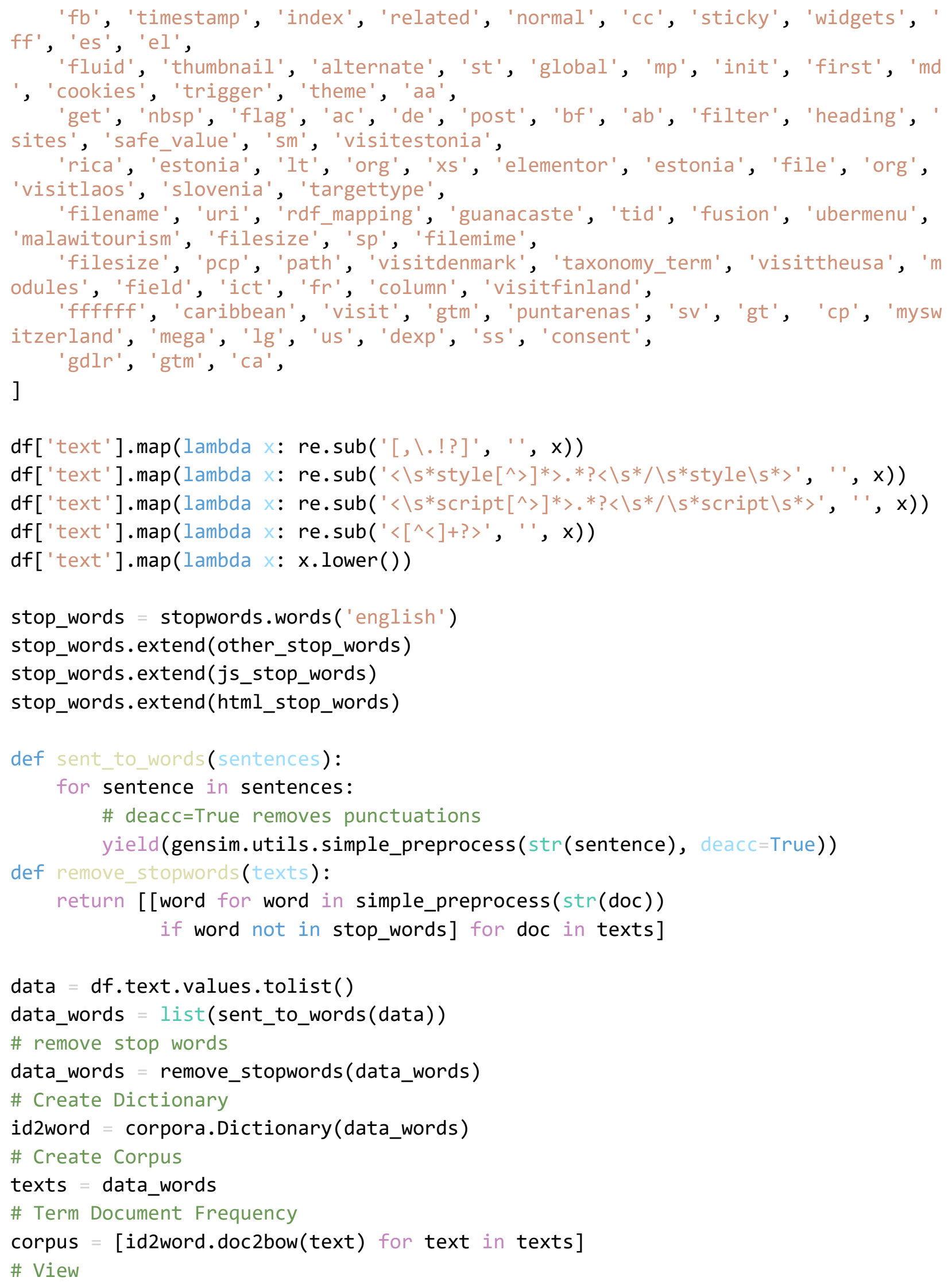




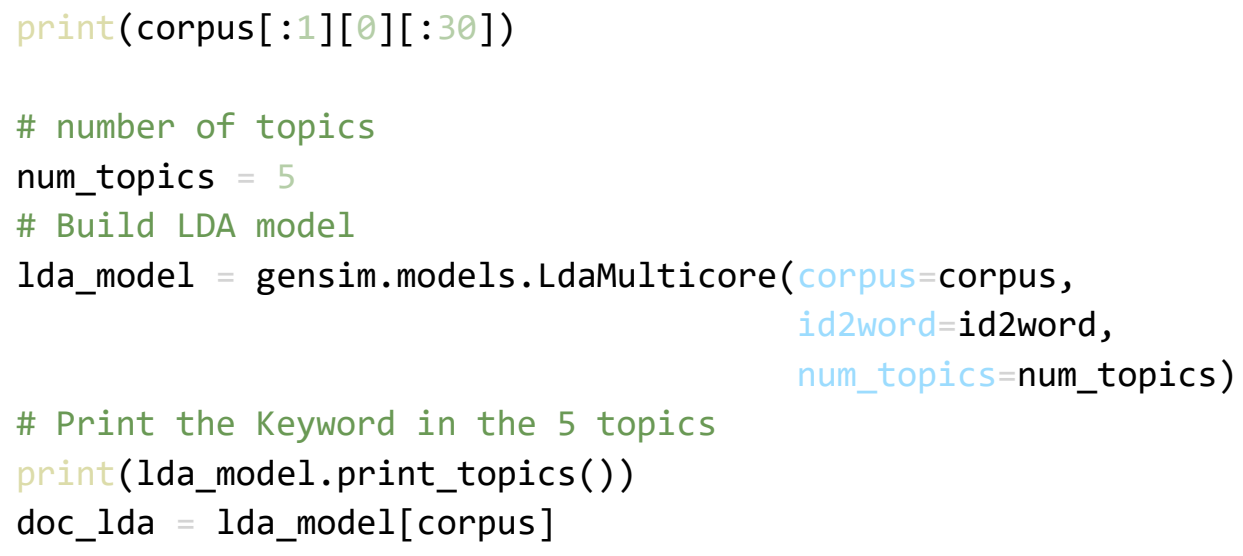




\section{Proposed Label Design}
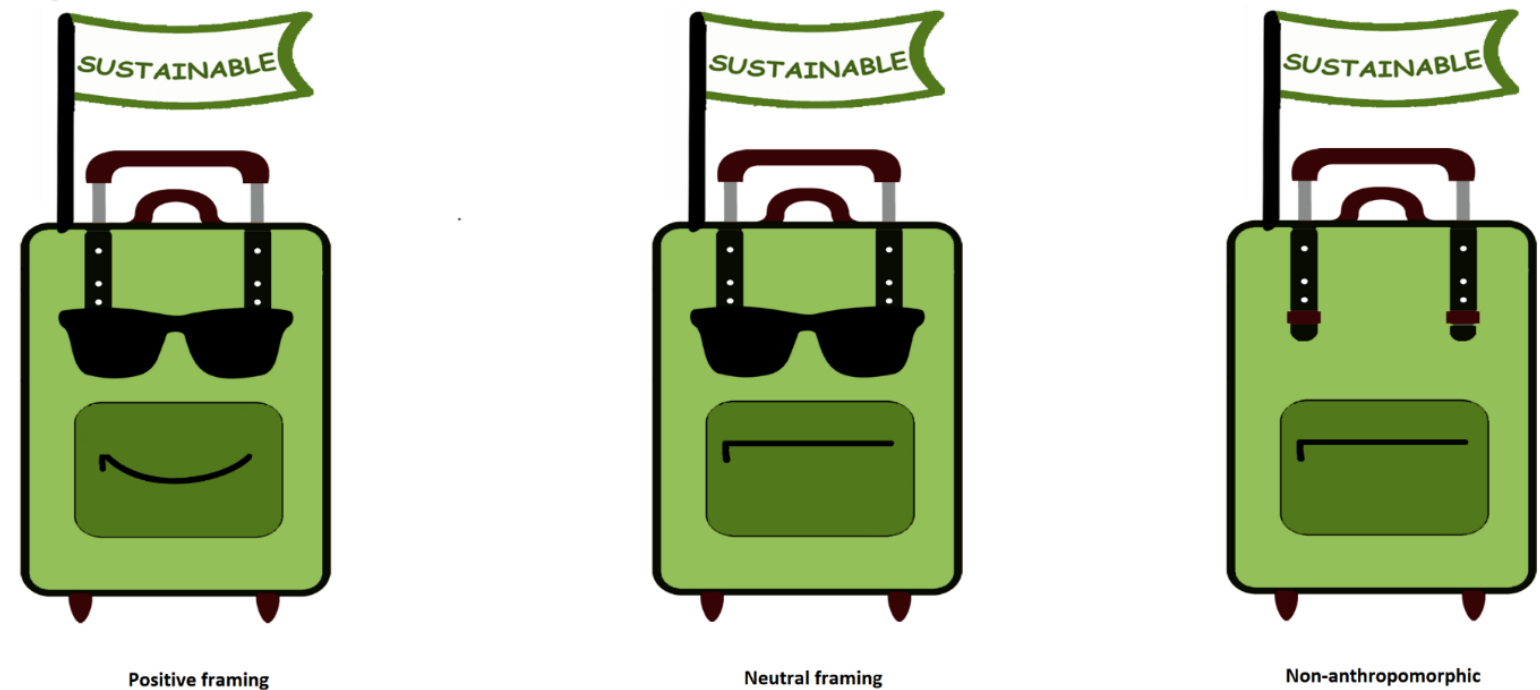


\title{
APPENDIX E
}

\section{Questionnaire - Label Pretest}

\author{
$5 / 24 / 2021$ \\ Qualtrics Survey Sofware \\ Intro \\ WestVirginiaUniversity. \\ COLLEGE OF BUSINESS AND ECONOMICS
}

Dear Participant,

This letter is a request for you to take part in a research project to assess consumer perceptions of a brand logo. This project is being conducted by Ms. Elvira Kizilova, a Marketing PhD Candidate at West Virginia University under the supervision of Dr. Michael F. Walsh. Your participation in this project is greatly appreciated and will take approximately 5 minutes to fill out the attached questionnaire.

To qualify for this study, you must be 18 years of age or older to participate.

Your involvement in this project will be kept as confidential as legally possible. All data will be reported in the aggregate. I will not ask any information that should lead back to your identity as a participant. Your participation is completely voluntary. You may skip any question that you do not wish to answer and you may discontinue at any time. West Virginia University's Institutional Review Board acknowledgment of this project is on file.

I hope that you will participate in this research project, as it could be beneficial in understanding the consumers' perceptions of a brand logo. Thank you very much for your time. Should you have any questions about this letter or the research project, please feel free to contact me at enk0001@mix.wvu.edu.

Thank you for your time and help with this project.

Sincerely,

Elvira Kizilova

PhD Candidate

Marketing Department

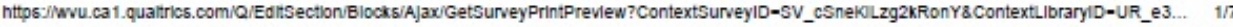


West Virginia University

I agree

I disagree

\section{Logo Evaluation}

Section 1. This is a logo that is used by companies and organizations who promote and practice sustainable tourism. The logo would appear in advertisements and brochures.

Please look at the logo. The questions in this study are related to this logo.

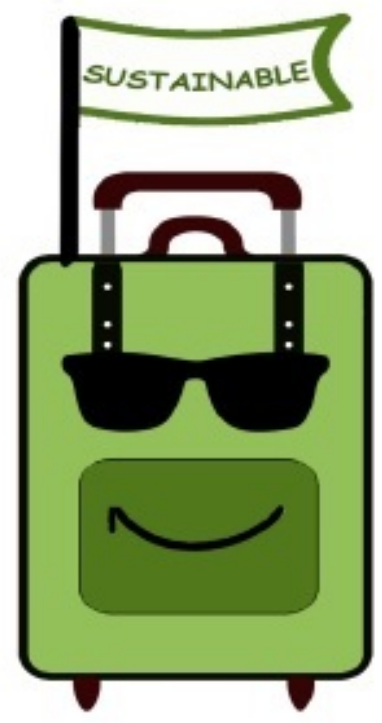

Have you ever seen this logo before? 
$5 / 24 / 2021$

Qualtrics Survey Software

Definitely not Probably not Might or might not Probably yes Definitely yes

Please write in your own words what does this logo communicate to you:

After 30 seconds, you may proceed. (The "NEXT" button will be on the lower right-hand side of your screen.)

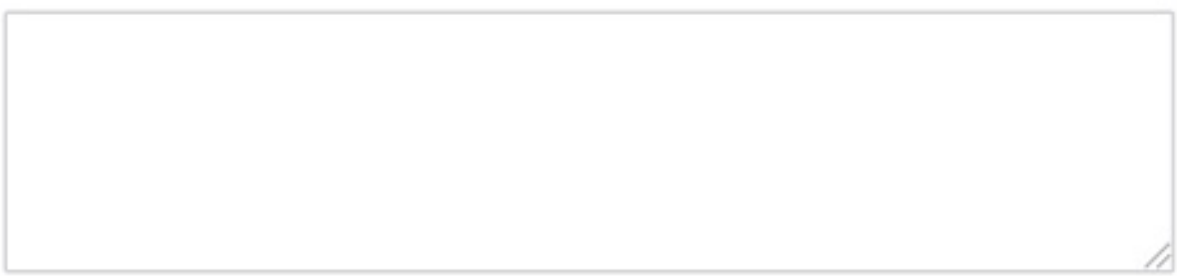

Please indicate your agreement with the following statements

$\begin{array}{lccccc} & \begin{array}{l}\text { Strongly } \\ \text { Disagree }\end{array} & \text { Disagree } & \begin{array}{c}\text { Neither } \\ \text { Agree Nor } \\ \text { Disagree }\end{array} & \text { Agree } & \begin{array}{c}\text { Strongly } \\ \text { Agree }\end{array} \\ \begin{array}{l}\text { I think this logo is } \\ \text { realistic }\end{array} & 0 & 0 & 0 & 0 & \bigcirc \\ \begin{array}{l}\text { The logo seems like } \\ \text { the kind of logo } \\ \text { designs companies } \\ \text { often make }\end{array} & 0 & 0 & 0 & 0 & 0 \\ \begin{array}{l}\text { The logo looks } \\ \text { professional }\end{array} & 0 & 0 & 0 & 0 & 0\end{array}$

Now think about how the present logo would make you feel. To what extent would you feel:

$\begin{array}{rllllll}\text { Negative } & \bigcirc & \bigcirc & \bigcirc & \bigcirc & \bigcirc & \text { Positive } \\ \text { Sad } & \bigcirc & \bigcirc & \bigcirc & \bigcirc & \bigcirc & \text { Happy } \\ \text { Angry } & \bigcirc & 0 & \bigcirc & \bigcirc & \bigcirc & \text { Upbeat } \\ \text { Annoyed } & \bigcirc & \bigcirc & \bigcirc & \bigcirc & \bigcirc & \text { Pleased } \\ \text { Disappointed } & \bigcirc & \bigcirc & \bigcirc & \bigcirc & \bigcirc & \text { Satisfied }\end{array}$

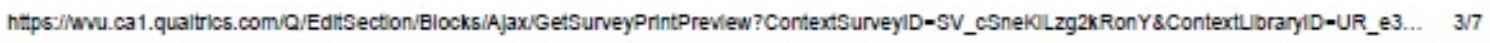


Please rate the overall design of this logo:

\section{Poor $\bigcirc \bigcirc \bigcirc \bigcirc \bigcirc$ Excellent}

\section{Demographics}

Section 2. These last questions are designed for classification purposes only.

Are you:

Male

Female

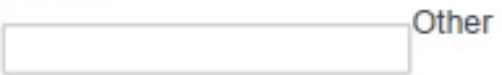

In what year were you born?

Please type the 4-digit year.

In order to insure that data is being collected correctly please disregard the following question and select "none of the above" below.

From what sources do you get your news?

Network TV

Cable TV

Radio

Newspapers

On-line news

On-line blogs
Podcasts

Magazines

Word of Mouth

Social networking sites

None of the above

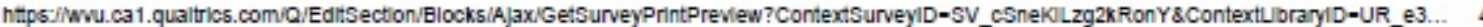


What is your combined annual household income (for 2020)?

less than $30 \mathrm{~K}$

$30,000-49,999$

$50,000-69,999$

$70,000-99,999$

$100 \mathrm{~K}$ or more

What is the highest level of education you have completed?

Less than 7 th grade

Less than High School

High School Graduate / GED

Some College

2-year College Degree

4-year College Degree

Completed Graduate Degree

What is your Mechanical Turk worker ID? single comment and greatly value your insight and opinions.

This is not a required question.

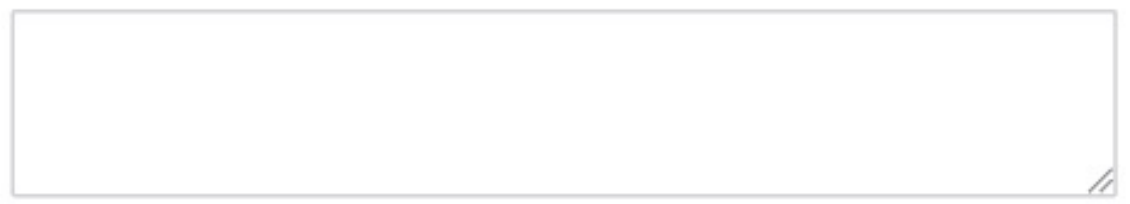

https:/Wwu_ca1.qualitric5.com/Q/EditSection/Blocks/Ajax/GetSurveyPrintPreview?ContextSurveyID-SV_cSnekILzg2kRonY8ContextLIbraryiD-UR_e3... 5/7 
IMPORTANT: In order for your responses to be recorded, you must click on the "SUBMIT" button (example shown below):

\section{$\gg$}

You have successfully submitted your responses when you see the following screen:

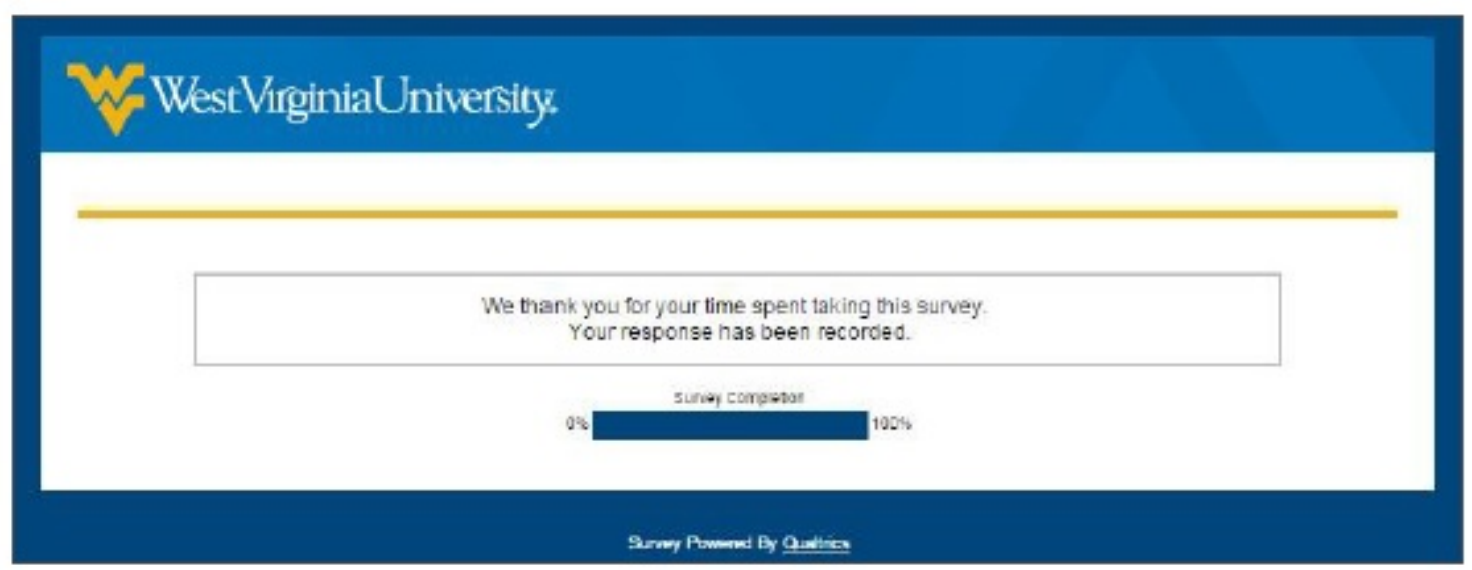

Again, in order for any. of your responses to be recorded you must click on the "SUBMIT" button on the next page.

Here is your completion code:

7562KEY 

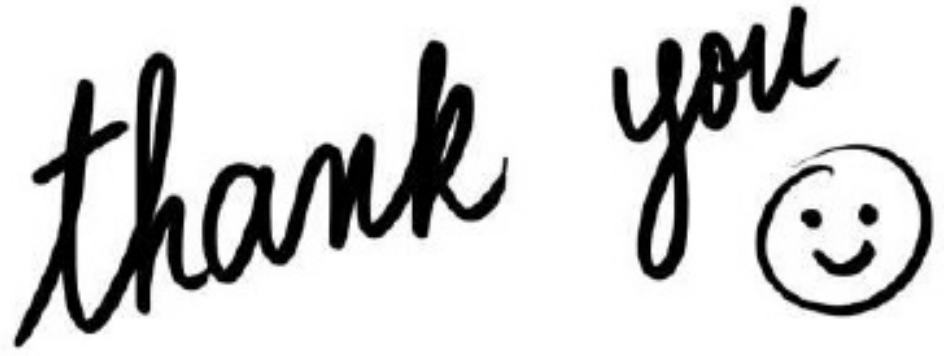

Thank you very much for your help with this survey.

We greatly appreciate your time and effort.

Please click on the "submit" button (lower right-hand side) to submit your answers.

Powered by Qualtrics 


\section{APPENDIX F}

\section{Questionnaire - Travel Destination Name Pretest}

$3 / 2 / 2021$

Qualtrics Survey Software

Intro

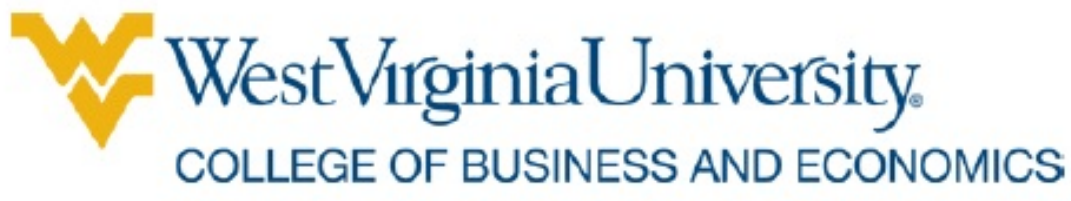

Dear Participant,

This letter is a request for you to take part in a research project to consumer perceptions of a travel destination. This project is being conducted by Ms. Elvira Kizilova, a Marketing PhD Candidate at West Virginia University under the supervision of Dr. Michael F. Walsh. Your participation in this project is greatly appreciated and will take approximately 5 minutes to fill out the attached questionnaire.

To qualify for this study, you must be 18 years of age or older to participate.

Your involvement in this project will be kept as confidential as legally possible. All data will be reported in the aggregate. I will not ask any information that should lead back to your identity as a participant. Your participation is completely voluntary. You may skip any question that you do not wish to answer and you may discontinue at any time. West Virginia University's Institutional Review Board acknowledgment of this project is on file.

Thank you very much for your time. Should you have any questions about this letter or the research project, please feel free to contact me at enk0001@mix.wvu.edu.

Thank you for your time and help with this project.

Sincerely,

Elvira Kizilova

$\mathrm{PhD}$ Candidate

Marketing Department

West Virginia University 
I agree

I disagree

Extra Credit

Thank you very much for your help with this survey.

We greatly appreciate your time and effort.

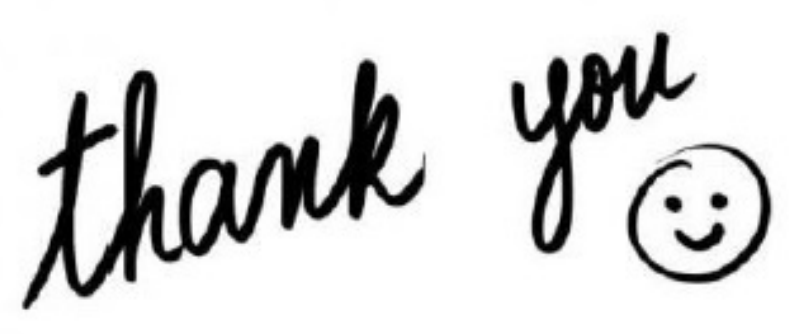

You will now be asked to complete the information needed to get your extra credit.

Please know that your personal information will not be associated with your responses to this survey.

Please click on the following link to proceed:

https://wvu.qualtrics.com/ffe/form/SV_8elYPKdfPyVBL7M

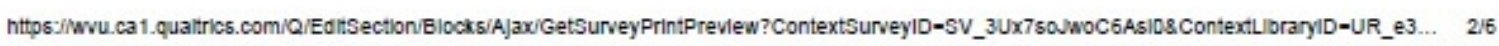




\section{Name Evaluation}

Section 1. This study is designed to measure attitudes to a potential travel destination within the United States.

The name of the destination is GRINAMONTE

As you contemplate the name GRINAMONTE, please answer the following questions:

Have you ever heard of this travel destination before?

Definitely yes Probably yes Might or might not Probably not Definitely not

Does this name sound like a travel destination you are familiar with?

Definitely yes Probably yes Might or might not Probably not Definitely not

Only knowing just the name of this travel destination, what other thoughts and associations come to your mind?

After 30 seconds, you may proceed. (The "NEXT" button will be on the lower right-hand side of your screen.)

\section{Demographics}

Section 2. These last questions are designed for classification purposes only.

Are you:

Male 
Female

Other

In what year were you born?

Please type the 4-digit year.

In order to insure that data is being collected correctly please disregard the following question and select "none of the above" below.

From what sources do you get your news?
Network TV
Podcasts
Cable TV
Magazines
Radio
Word of Mouth
Newspapers
Social networking sites
On-line news
None of the above
On-line blogs
What is your combined annual household income (for 2019)?
less than $30 \mathrm{~K}$
$30,000-39,999$
$40,000-49,9999$
$50,000-59,999$
$60,000-69,999$
$70,000-79,000$
$80,000-89,000$
$90,000-99,999$
$100 \mathrm{~K}$ or more 
What is the highest level of education you have completed?

Less than 7 th grade

Less than High School

High School Graduate / GED

Some College

2-year College Degree

4-year College Degree

Completed Graduate Degree

IMPORTANT: In order for your responses to be recorded, you must click on the "SUBMIT" button (example shown below):

Subrnit

You have successfully submitted your responses when you see the following screen:

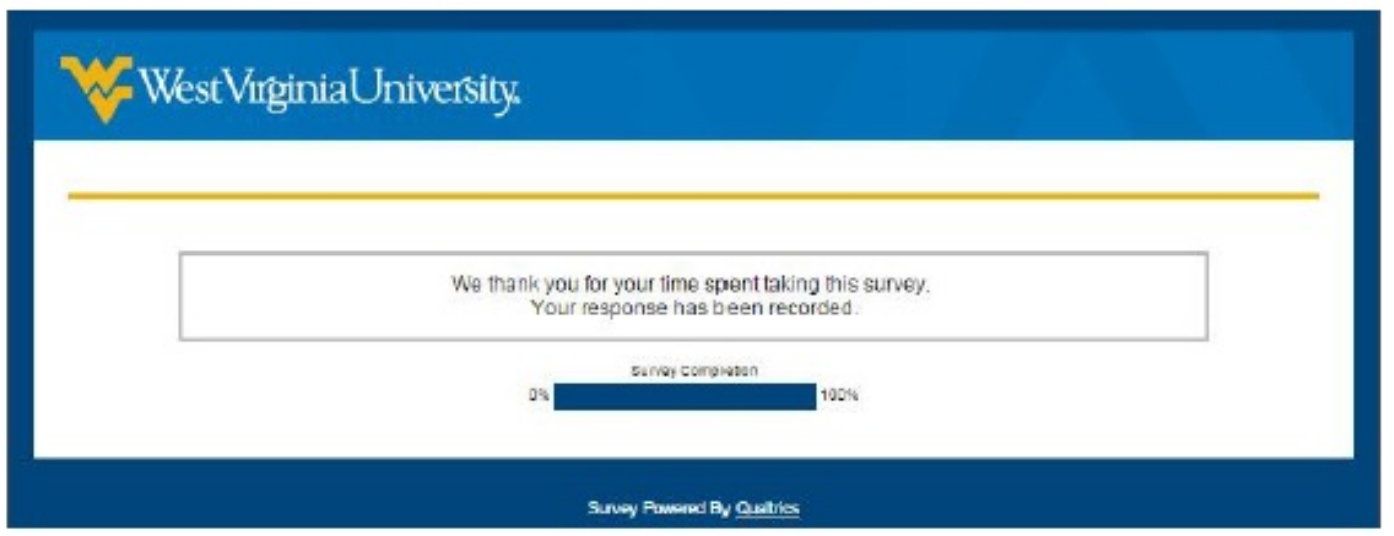

Again, in order for any of your responses to be recorded you must click on the "SUBMIT" button on the next page. 
APPENDIX G

\section{Proposed Website Design}

\section{GRINAMONTE}

A whole world in a single place

WELCOME TO

GRINAMONTE!

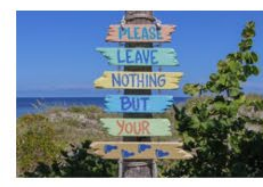

$\$ 1500.00$

per person $/ 5$ nights, all inclusive

HELPING HAND

Vistors are insooduced to the culture and

interoctive activities

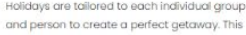

tour combines hilieng with comping in the

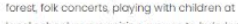

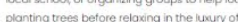

Pricing
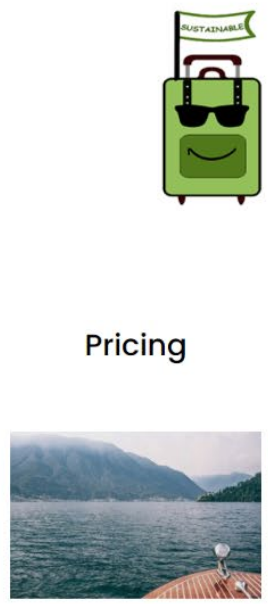

$\$ 1300.00$

per person/5 nights, all inclusive

SURF \& TURF

Hove tun and explore all types of water and
land activities with experienced local guides.

This tour combines boot and hiking tours

rou will be eintoging, bird and onimal wotching

endemic floro and touna and will retax ot the

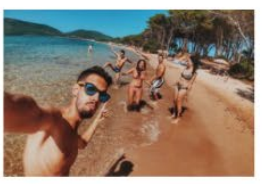

$\$ 150.00 /$ night

per person, Bed \& Breaktast

4 you prefere flexibility and do not want a

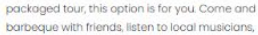

and enjoy the sceneries.

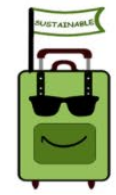




\title{
APPENDIX H
}

\section{Qualtrics Questionnaire - Website Pretest}

\author{
$3 / 18 / 2021$
}

Qualtrics Survey Sofware

Intro West VurginiaUniversity
COLLEGE OF BUSINESS AND ECONOMICS

Dear Participant,

This is an invitation to take part in a research project to assess consumer perceptions of a travel destination website. This project is being conducted by Ms. Elvira Kizilova, a Marketing PhD Candidate at West Virginia University with supervision of Dr. Michael F. Walsh. Your participation in this project is greatly appreciated and will take approximately 10-15 minutes to fill out the attached questionnaire.

To qualify for this study,

- You must be 18 years of age or older to participate.

- You must NOT take the survey on your smart phone.

Your involvement in this project will be kept as confidential as legally possible. All data will be reported in the aggregate. I will not ask any information that should lead back to your identity as a participant. Your participation is completely voluntary. You may skip any question that you do not wish to answer and you may discontinue at any time. West Virginia University's Institutional Review Board acknowledgment of this project is on file.

I hope that you will participate in this research project, as it could be beneficial in understanding the consumers' perceptions of a travel destination website. Thank you very much for your time. Should you have any questions about this letter or the research project, please feel free to contact me at enk0001@mix.wvu.edu.

Thank you for your time and help with this project.

Sincerely,

Elvira Kizilova

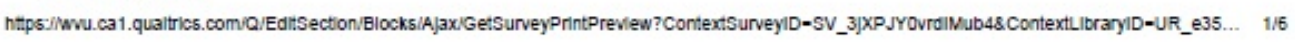


PhD Candidate

Marketing Department

West Virginia University

I agree

I disagree

\section{Website Evaluation}

Section 1. This is the website of a hypothetical travel destination that will be open for tourists after the COVID-19 pandemic. Please browse the website. While this place does not actually exist, we ask you to imagine you are considering this as a potential place to visit. Imagine that this destination is a 2-3 hour drive from where you live. The link below will take you to the website and you should spend several minutes viewing the pages. After viewing the website, please return to the survey and complete the survey questions.

When you click on the link below, it will open in a new tab. Please DO NOT close the Qualtrics tab. To get compensated, you will have to return to the Qualtrics survey and complete it.

https:/lgrinamonte squarespace.com/

Have you ever seen this website before?

$$
\text { Definitely not Probably not Might or might not Probably yes Definitely yes }
$$

Does this website familiar?

Strongly disagree Somewhat disagree Neither agree nor Somewhat agree Strongly agree disagree

Please indicate your agreement with the following statements 


\begin{tabular}{|c|c|c|c|c|c|}
\hline & $\begin{array}{l}\text { Strongly } \\
\text { Disagree }\end{array}$ & Disagree & $\begin{array}{l}\text { Neither } \\
\text { Agree Nor } \\
\text { Disagree }\end{array}$ & Agree & $\begin{array}{l}\text { Strongly } \\
\text { Agree }\end{array}$ \\
\hline $\begin{array}{l}\text { I think this website is } \\
\text { realistic }\end{array}$ & $\mathrm{O}$ & $\mathrm{O}$ & $\mathrm{O}$ & $\mathrm{O}$ & $\mathrm{O}$ \\
\hline $\begin{array}{l}\text { The website seems } \\
\text { like the kind of } \\
\text { websites travel } \\
\text { destinations often } \\
\text { make }\end{array}$ & $\mathrm{O}$ & $\mathrm{O}$ & $\bigcirc$ & $\mathrm{O}$ & $\mathrm{O}$ \\
\hline $\begin{array}{l}\text { The website looks } \\
\text { professionally } \\
\text { designed }\end{array}$ & $\mathrm{O}$ & $\mathrm{O}$ & O & $\mathrm{O}$ & $\mathrm{O}$ \\
\hline $\begin{array}{l}\text { This is an attention } \\
\text { check. The answer is } \\
\text { "Disagree" }\end{array}$ & $\mathrm{O}$ & 0 & $\bigcirc$ & $\mathrm{O}$ & $\mathrm{O}$ \\
\hline
\end{tabular}

Now think about how you felt viewing the website. Did you feel:

$\begin{array}{rllllll}\text { Negative } & 0 & 0 & 0 & 0 & 0 & \text { Positive } \\ \text { Sad } & 0 & 0 & 0 & 0 & 0 & \text { Happy } \\ \text { Angry } & \bigcirc & 0 & 0 & 0 & 0 & \text { Upbeat } \\ \text { Annoyed } & 0 & 0 & 0 & 0 & 0 & \text { Pleased } \\ \text { Disappointing } & \bigcirc & 0 & 0 & 0 & 0 & \text { Satisfactory }\end{array}$

Please rate the overall design of this website:

$$
\text { Poor } \bigcirc \bigcirc \bigcirc \bigcirc \bigcirc \text { Excellent }
$$

\section{Demographics}

Section 2. These last questions are designed for classification purposes only.

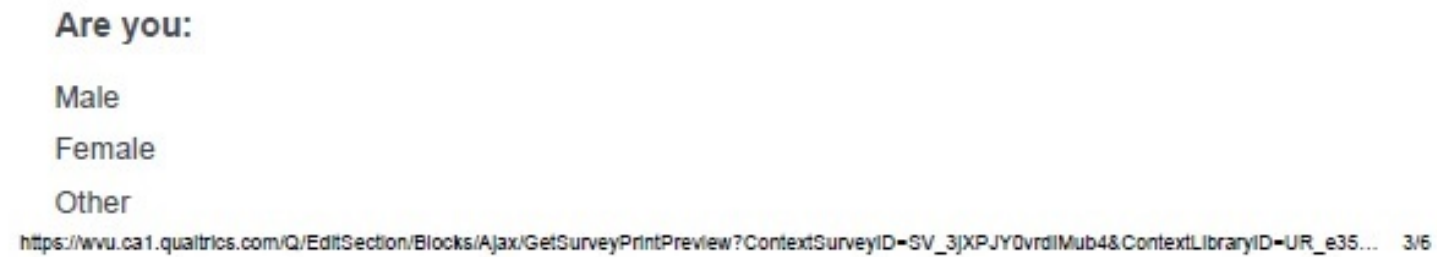


In what year were you born?

Please type the 4-digit year.

What is your combined annual household income (for 2020)?

less than $30 \mathrm{~K}$

$30,000-49,999$

$50,000-69,999$

$70,000-99,999$

$100 \mathrm{~K}$ or more

What is the highest level of education you have completed?

Less than 7 th grade

Less than High School

High School Graduate / GED

Some College

2-year College Degree

4-year College Degree

Completed Graduate Degree

What is your Mechanical Turk worker ID?

Are there any other thoughts or comments you would like to share with us? We read every single comment and greatly value your insight and opinions.

https/iwwu.ca 1.qualtrics.com/Q/Edisection/Elocks/AJax/GetSurveyPrintPrevlew?ContextSurveyID-SV_3JXPJYYovrdlMub48.ContextLIbraryID-UR_e35... 4/6 
This is not a required question.

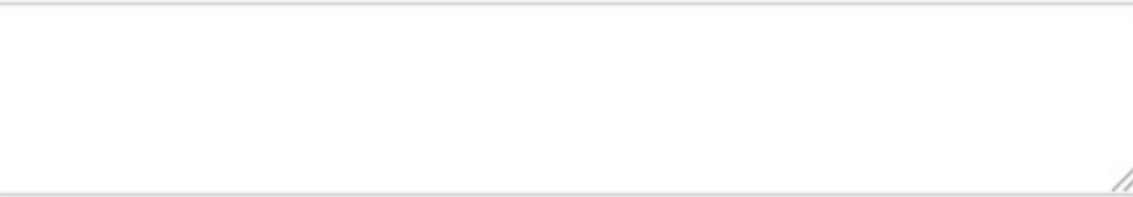

IMPORTANT: In order for your responses to be recorded, you must click on the "SUBMIT" button (example shown below):

You have successfully submitted your responses when you see the following screen:

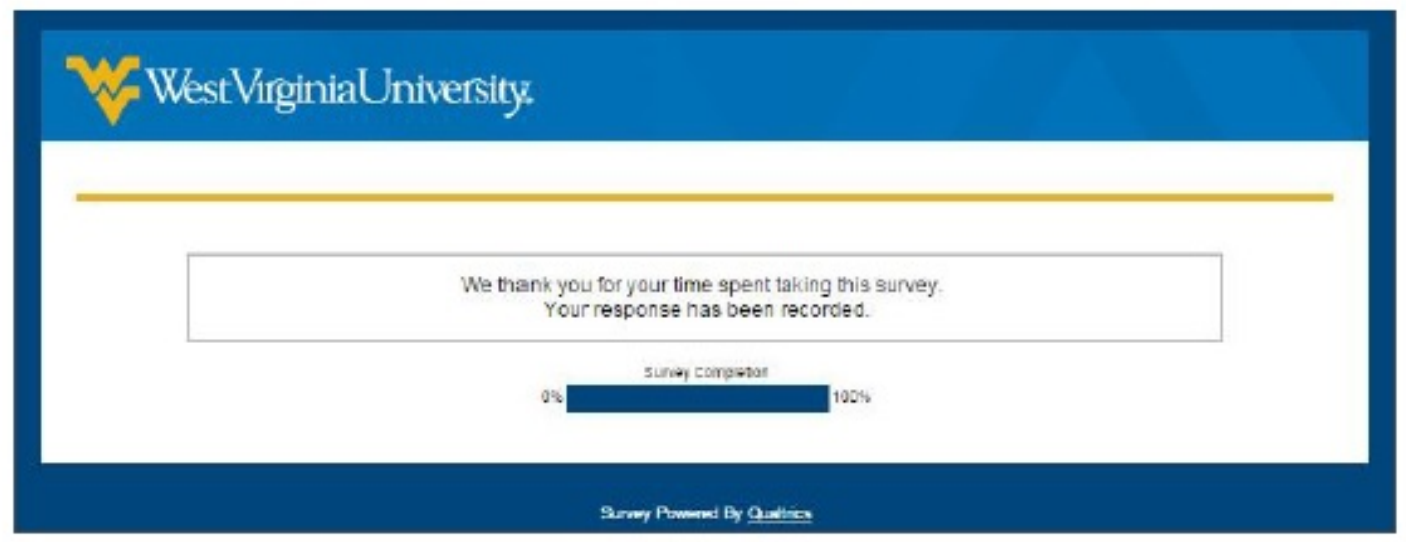

Again, in order for any of your responses to be recorded you must click on the "SUBMIT" button on the next page.

\section{Here is your completion code:}

ELL173 
Thank you very much for your help with this survey.

We greatly appreciate your time and effort.

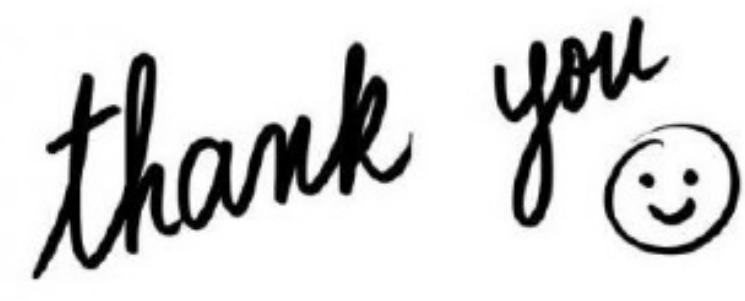

\section{Please click on the "submit" button (lower right-hand side) to submit your answers.}

Powered by Qualtrics 


\section{APPENDIX I}

\section{Qualtrics Questionnaire - Website Pretest}

6/1/2021 Qualtrics Survey sotware

Intro

\section{WestVirginiaUniversity. COLLEGE OF BUSINESS AND ECONOMICS}

Dear Participant,

This letter is a request for you to take part in a research project to assess consumer attitudes and choices of travel destinations. This project is being conducted by Ms. Elvira Kizilova, a Marketing PhD Candidate at West Virginia University with supervision of Dr. Michael F. Walsh. Your participation in this project is greatly appreciated and will take approximately 20 minutes to fill out the attached questionnaire.

To qualify for this study,

- You must be 18 years of age or older to participate.

- You must NOT take the survey on your smart phone.

- You must have some tourism experience in the past.

- You must be willing and able to travel within the next 12 months after the COVID-19 pandemic is over.

Your involvement in this project will be kept as confidential as legally possible. All data will be reported in the aggregate. You will not be asked any information that should lead back to your identity as a participant. Your participation is completely voluntary. You may skip any question that you do not wish to answer and you may discontinue at any time. West Virginia University's Institutional Review Board acknowledgment of this project is on file.

I hope that you will participate in this research project, as it could be beneficial in understanding consumer attitudes and choices of travel destinations. Thank you very much for your time. Should you have any questions about this letter or the research project, please feel free to contact me at enk0001@mix.wvu.edu.

Thank you for your time and help with this project.

hitps:/Wwu.ca 1.qualitics.com/Q/Editsection/Blocks/A]ax/GetSurveyPrintPrevlew?ContextSurveyID-SV_OAlaaboDHikAGc2GscontextLIDraryID-UR_e... 
Sincerely,

Elvira Kizilova

PhD Candidate

Marketing Department

West Virginia University

I agree

I disagree

\section{Screening}

Before starting the survey, we need to know a little bit about you. Please respond to the following questions to see if you qualify for this study.

Prior to the COVID-19 pandemic, have you traveled ( at least once in the last 3 years?

Yes No

Assuming the COVID-19 pandemic is over and health authorities permit traveling, are you willing to travel (to spend at least once within the next 12 months?

Yes No Assuming the COVID-19 pandemic is over and health authorities permit traveling, are you able to travel (to spend at least once within the next 12 months?

Yes

No 
Cell 1: Anthro label, positive framing

\section{Section 1:}

This is the website of a travel destination that will be open for tourists after the COVID-19 pandemic. Please browse the website. We ask you to imagine you are considering this as a potential place to visit. Imagine that this destination is a 2-3 hour drive from where you live.

The link below will take you to the website and you should spend several minutes viewing the pages. After viewing the website, please return to the survey and complete the survey questions. We ask that you make this choice as naturally as you would in real setting.

Please read these instructions CAREFULLY!

1. Look at the travel destination website using the link below. Most of the questions that follow are related to this destination.

When you click on the link below, it will open in a new tab. Please DO NOT close the Qualtrics tab. To get compensated, you will have to return to the Qualtrics survey and complete it.

2. When you finish browsing the website please enter your mTurk ID in a box located at the bottom of the website:

htps//wwu.ca1.qualtric5.com/Q/EditSection/Blocks/AJax/GetSurveyPrintPreview?ContextSurveyID-SV_OAlaabooHk4Gc2G8ContextLIbraryID-UR_e... 3/20 


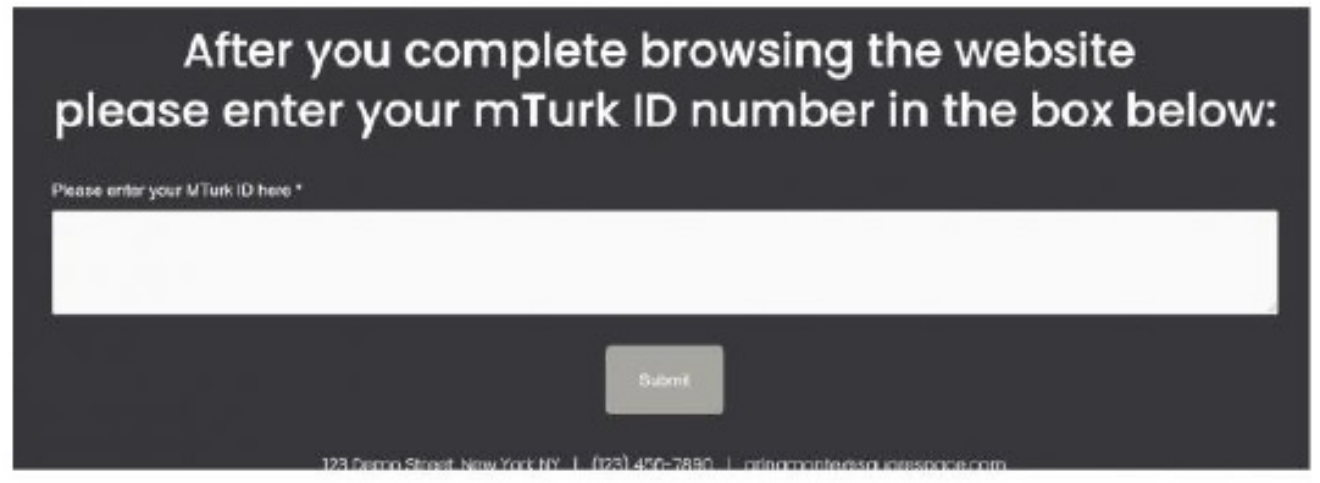

3. Go back to the Qualtrics tab and complete the survey.

You will only be compensated if you fulfil all the requirements mentioned above.

Please proceed to the website by clicking on the following link:

http:-l/grinamonte-ap.squarespace.com

Cell 2: Anthro label, neutral framing

\section{Section 1:}

This is the website of a travel destination that will be open for tourists after the COVID-19 pandemic. Please browse the website. We ask you to imagine you are considering this as a potential place to visit. Imagine that this destination is a 2-3 hour drive from where you live. 
The link below will take you to the website and you should spend several minutes viewing the pages. After viewing the website, please return to the survey and complete the survey questions. We ask that you make this choice as naturally as you would in real setting.

Please read these instructions CAREFULLY!

1. Look at the travel destination website using the link below. Most of the questions that follow are related to this destination.

When you click on the link below, it will open in a new tab. Please DO NOT close the Qualtrics tab. To get compensated, you will have to return to the Qualtrics survey and complete it.

2. When you finish browsing the website please enter your mTurk ID in a box located at the bottom of the website:

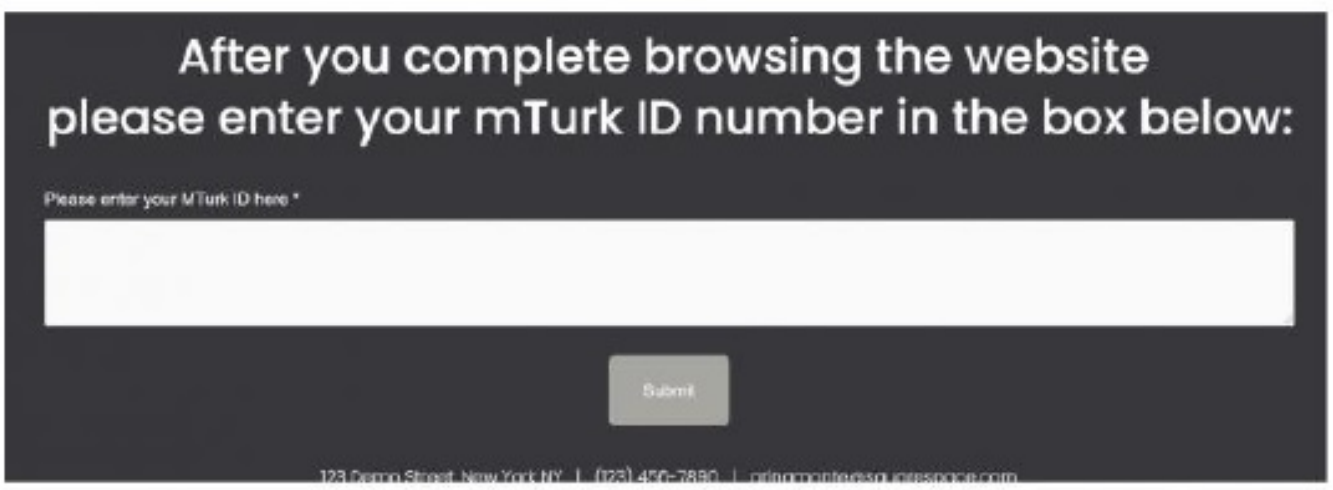

3. Go back to the Qualtrics tab and complete the survey.

You will only be compensated if you fulfil all the requirements mentioned above.

Please proceed to the website by clicking on the following link:

http:l/grinamonte-an.squarespace.com

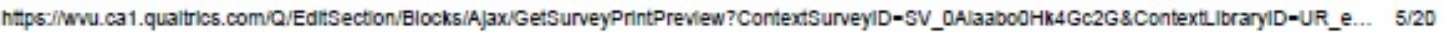




\section{Cell 3: Non-anthro label}

\section{Section 1:}

This is the website of a travel destination that will be open for tourists after the COVID-19 pandemic. Please browse the website. We ask you to imagine you are considering this as a potential place to visit. Imagine that this destination is a 2-3 hour drive from where you live.

The link below will take you to the website and you should spend several minutes viewing the pages. After viewing the website, please return to the survey and complete the survey questions. We ask that you make this choice as naturally as you would in real setting.

Please read these instructions CAREFULLY!

1. Look at the travel destination website using the link below. Most of the questions that follow are related to this destination.

When you click on the link below, it will open in a new tab. Please DO NOT close the Qualtrics tab. To get compensated, you will have to return to the Qualtrics survey and complete it.

2. When you finish browsing the website please enter your mTurk ID in a box located at the bottom of the website:

htps:/Wwu.ca1.qualtrics.com/Q/EditSection/Blocks/AJax/GetSurveyPrintPrevlew?ContextSurveyID-SV_OAlaabooHik4GC2G8_ContextL/braryID-UR_e... 6/20 


\section{After you complete browsing the website please enter your mTurk ID number in the box below:}

Pease ents your MTurkio hese.

3. Go back to the Qualtrics tab and complete the survey.

You will only be compensated if you fulfil all the requirements mentioned above.

Please proceed to the website by clicking on the following link:

http:llgrinamonte-na.squarespace.com

Cell 4: No label (control)

\section{Section 1:}

This is the website of a travel destination that will be open for tourists after the COVID-19 pandemic. Please browse the website. We ask you to imagine you are considering this as a potential place to visit. Imagine that this destination is a 2-3 hour drive from where you live.

The link below will take you to the website and you should spend several minutes viewing the pages. After viewing the website, please return to the survey and complete the survey questions. We ask that you make this choice as naturally as you would in real setting. 
Please read these instructions CAREFULLY!

1. Look at the travel destination website using the link below. Most of the questions that follow are related to this destination.

When you click on the link below, it will open in a new tab. Please DO NOT close the Qualtrics tab. To get compensated, you will have to return to the Qualtrics survey and complete it.

2. When you finish browsing the website please enter your mTurk ID in a box located at the bottom of the website:

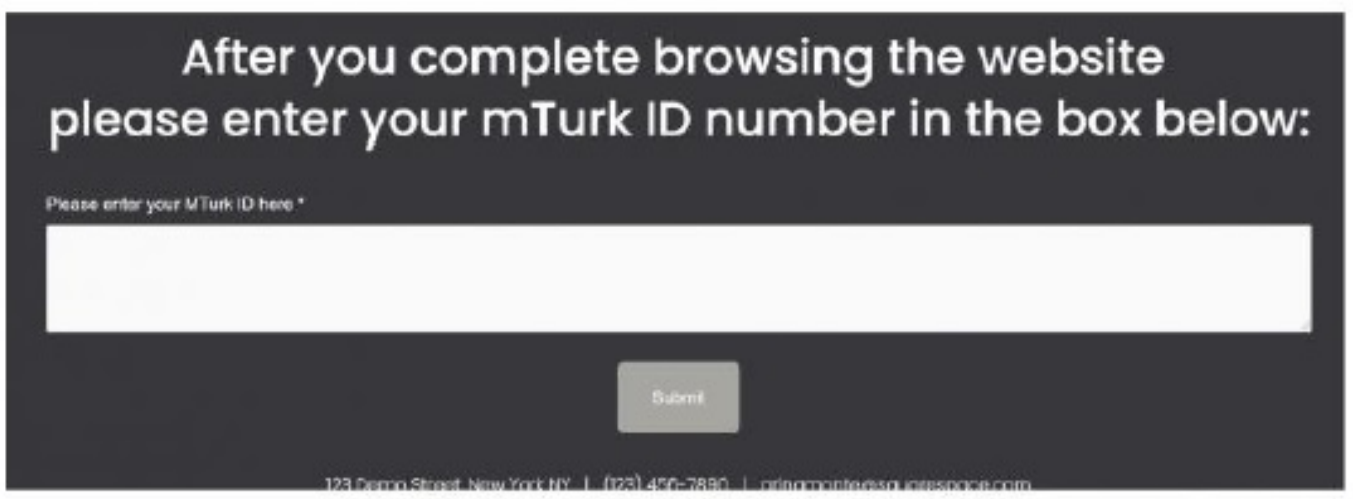

3. Go back to the Qualtrics tab and complete the survey.

You will only be compensated if you fulfil all the requirements mentioned above.

Please proceed to the website by clicking on the following link:

http://grinamonte-cont.squarespace.com

DVs 
Section 2: Regarding the information you saw in the previous section, please respond carefully to the following questions.

Based on the travel destination's website you have seen, please indicate if you would consider visiting Grinamonte in future

Very unlikely Unlikely $\begin{gathered}\text { Somewhat } \\ \text { unlikely }\end{gathered} \quad$ Neutral $\quad \begin{gathered}\text { Somewhat likely } \\ \text { Likely Very likely }\end{gathered}$

Please explain why you made this choice

After 30 seconds, you may proceed (the "NEXT" button will be on the lower right-hand side of your screen)

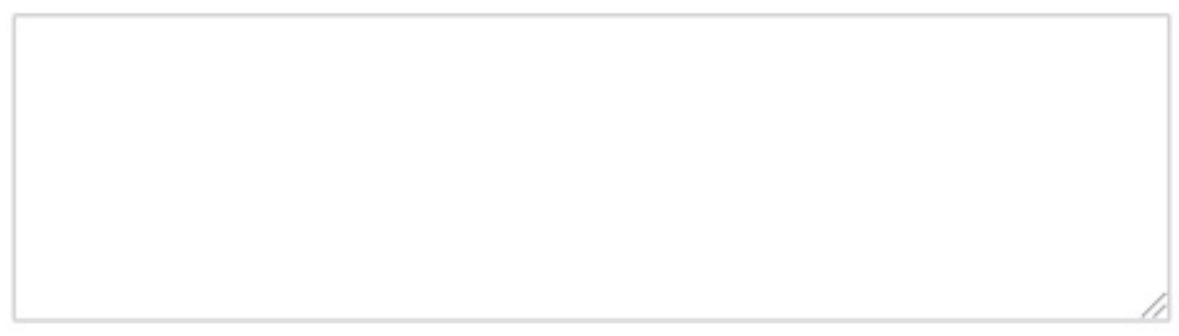

How likely are you to say positive things about Grinamonte to other people?

Very unlikely Unlikely $\begin{gathered}\text { Somewhat } \\ \text { unlikely }\end{gathered} \quad$ Neutral $\quad \begin{gathered}\text { Somewhat likely } \\ \text { Likely Very likely }\end{gathered}$

I will recommend Grinamonte as a vacation destination to someone who seeks my advise Very unlikely Unlikely $\begin{gathered}\text { Somewhat } \\ \text { unlikely }\end{gathered} \quad$ Neutral $\quad \begin{gathered}\text { Somewhat likely } \\ \text { likely Very likely }\end{gathered}$

I will encourage friends and relatives to visit Grinamonte

Very unlikely Unlikely $\begin{gathered}\text { Somewhat Neutral } \\ \text { unlikely }\end{gathered} \quad \begin{gathered}\text { Somewhat likely } \\ \text { Likely Very likely }\end{gathered}$


Weekly packaged tours to Grinamonte are typically priced between $\$ 1,000$ and $\$ 3,000$ per person. How much would you be willing to pay for your tour?

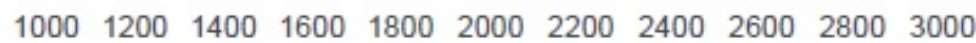

Price, USD

\section{Mediators}

As you think about Grinamonte, please rate the following statements:

\begin{tabular}{|c|c|c|c|c|c|c|c|}
\hline & $\begin{array}{l}\text { Very } \\
\text { unlikely }\end{array}$ & Unlikely & $\begin{array}{l}\text { Somewhat } \\
\text { unlikely }\end{array}$ & Neutral & $\begin{array}{l}\text { Somewhat } \\
\text { likely }\end{array}$ & Likely & $\begin{array}{l}\text { Very } \\
\text { likely }\end{array}$ \\
\hline $\begin{array}{l}\text { Grinamonte reflects } \\
\text { who I am }\end{array}$ & $\bigcirc$ & $\mathrm{O}$ & $\mathrm{O}$ & $\bigcirc$ & $\mathrm{O}$ & $\mathrm{O}$ & $\mathrm{O}$ \\
\hline $\begin{array}{l}\text { Grinamonte is } \\
\text { congruent with my } \\
\text { lifestyle }\end{array}$ & 0 & $\mathrm{O}$ & 0 & 0 & 0 & 0 & $\mathrm{O}$ \\
\hline $\begin{array}{l}\text { It seems that } \\
\text { Grinamonte can } \\
\text { speak for me }\end{array}$ & $\mathrm{O}$ & 0 & $\mathrm{O}$ & $\mathrm{O}$ & $\mathrm{O}$ & $\mathrm{O}$ & \\
\hline $\begin{array}{l}\text { I identify with the } \\
\text { image of Grinamonte }\end{array}$ & 0 & $\mathrm{O}$ & 0 & 0 & 0 & 0 & 0 \\
\hline
\end{tabular}

As you think about Grinamonte, please rate the following statements:

\begin{tabular}{|c|c|c|c|c|c|c|c|}
\hline & $\begin{array}{l}\text { Very } \\
\text { unlikely }\end{array}$ & Unlikely & $\begin{array}{c}\text { Somewhat } \\
\text { unlikely }\end{array}$ & Neutral & $\begin{array}{c}\text { Somewhat } \\
\text { likely }\end{array}$ & Likely & $\begin{array}{l}\text { Very } \\
\text { likely }\end{array}$ \\
\hline $\begin{array}{l}\text { I and Grinamonte } \\
\text { have different goals }\end{array}$ & 0 & O & 0 & 0 & 0 & 0 & 0 \\
\hline $\begin{array}{l}\text { I and Grinamonte } \\
\text { have compatible } \\
\text { goals. }\end{array}$ & 0 & 0 & 0 & 0 & $\mathrm{O}$ & $\mathrm{O}$ & $\mathrm{O}$ \\
\hline $\begin{array}{l}\text { I and Grinamonte } \\
\text { support each other's } \\
\text { objectives }\end{array}$ & 0 & 0 & 0 & 0 & 0 & 0 & $\mathrm{O}$ \\
\hline $\begin{array}{l}\text { I and Grinamonte } \\
\text { share the same } \\
\text { goals in the } \\
\text { relationship }\end{array}$ & 0 & 0 & 0 & 0 & 0 & 0 & 0 \\
\hline
\end{tabular}




\section{Moderators}

Section 3: This next set of questions pertains to your general interests

Please rate the following statements:

I often think about the
harm we are doing to
our environment.
$\begin{aligned} & \text { The whole } \\ & \text { environmental issue is } \\ & \text { very important to me. }\end{aligned}$




$\begin{aligned} & \text { The positive benefits } \\ & \text { of economic growth far } \\ & \text { outweigh any negative } \\ & \text { environmental impact. }\end{aligned}$
$\begin{aligned} & \text { To make sure you are } \\ & \text { paying attention to the } \\ & \text { survey please check } \\ & \text { number } 5 \text { for this } \\ & \text { question }\end{aligned}$
$\begin{aligned} & \text { The current attention } \\ & \text { to the environment is } \\ & \text { basically raised by the } \\ & \text { media and we don't } \\ & \text { really need to do } \\ & \text { anything about it. }\end{aligned}$

Please rate how the following statements describe you:

\begin{tabular}{|c|c|c|c|c|c|c|}
\hline & $\begin{array}{c}1 \\
\text { Not at all }\end{array}$ & 2 & 3 & 4 & 5 & 6 \\
\hline $\begin{array}{l}\text { I am concerned about } \\
\text { the environment }\end{array}$ & O & 0 & $\bigcirc$ & 0 & 0 & 0 \\
\hline $\begin{array}{l}\text { The condition of the } \\
\text { environment affects } \\
\text { the quality of my life }\end{array}$ & 0 & O & 0 & O & O & 0 \\
\hline $\begin{array}{l}\text { I am willing to make } \\
\text { sacrifices to protect } \\
\text { the environment }\end{array}$ & 0 & 0 & 0 & O & O & 0 \\
\hline $\begin{array}{l}\text { My actions impact the } \\
\text { environment }\end{array}$ & 0 & 0 & 0 & 0 & 0 & 0 \\
\hline
\end{tabular}


Covariates

More than once a year

Annually

Every 2-3 years

Very rarely (once in 5-10 years)

Never

ow often do you travel for vacation purposes?

More than once a year

Annually

Every 2-3 years

Very rarely (once in 5-10 years)

Never

How likely is it that you have heard about Grinamonte before:

$\begin{array}{clllllc}1 & 2 & 3 & 4 & 5 & 6 & \begin{array}{c}7 \\ \text { Not at all }\end{array} \\ & & & & & & \text { Very much }\end{array}$

Which major political party do you belong to?

Democrat

Republican

Independent

Other

Decline to disclose

To what extent is (are)...

https:/iwwu.ca1.qualtric5.com/Q/EditSection/Elocks/AJax/GetSurveyPrintPrevlew?ContextSurveyID-SV_QAlaabooHk4GC2G\&ContextLIbraryID-UR_... 13/20 


\begin{tabular}{|c|c|c|c|c|c|c|c|}
\hline \multirow[t]{2}{*}{ 6/1/2021 } & \multicolumn{6}{|c|}{ Cualtics Survey Sotware } & \multirow[b]{2}{*}{$\begin{array}{l}\text { Very } \\
\text { likely }\end{array}$} \\
\hline & $\begin{array}{l}\text { Very } \\
\text { unlikely }\end{array}$ & Unlikely & $\begin{array}{l}\text { Somewhat } \\
\text { unlikely }\end{array}$ & Neutral & $\begin{array}{l}\text { Somewhat } \\
\text { likely }\end{array}$ & Likely & \\
\hline the desert lethargic? & $\bigcirc$ & $\mathrm{O}$ & $\mathrm{O}$ & $\mathrm{O}$ & $\mathrm{O}$ & $\bigcirc$ & $\mathrm{O}$ \\
\hline $\begin{array}{l}\text { the average } \\
\text { computer active }\end{array}$ & $\mathrm{O}$ & $\mathrm{O}$ & $\mathrm{O}$ & $\mathrm{O}$ & $\mathrm{O}$ & O & $\mathrm{O}$ \\
\hline $\begin{array}{l}\text { the average cloud } \\
\text { good-looking? }\end{array}$ & $\mathrm{O}$ & $\mathrm{O}$ & $\mathrm{O}$ & $\mathrm{O}$ & O & $\mathrm{O}$ & $\mathrm{O}$ \\
\hline $\begin{array}{l}\text { the average } \\
\text { amphibian lethargic? }\end{array}$ & $\mathrm{O}$ & $\mathrm{O}$ & $\mathrm{O}$ & $\mathrm{O}$ & $\mathrm{O}$ & $\bigcirc$ & $\mathrm{O}$ \\
\hline pets useful? & $\mathrm{O}$ & $\mathrm{O}$ & $\mathrm{O}$ & $\mathrm{O}$ & $\mathrm{O}$ & $\mathrm{O}$ & $\mathrm{O}$ \\
\hline $\begin{array}{l}\text { the average robot } \\
\text { good-looking? }\end{array}$ & $\mathrm{O}$ & O & $\bigcirc$ & $\mathrm{O}$ & $\mathrm{O}$ & $\bigcirc$ & $\mathrm{O}$ \\
\hline $\begin{array}{l}\text { the average camera } \\
\text { lethargic? }\end{array}$ & $\mathrm{O}$ & $\mathrm{O}$ & $\mathrm{O}$ & $\mathrm{O}$ & $\mathrm{O}$ & $\mathrm{O}$ & $\mathrm{O}$ \\
\hline a tree active? & O & $\mathrm{O}$ & $\mathrm{O}$ & O & O & O & $\mathrm{O}$ \\
\hline a river useful? & O & O & O & O & $\mathrm{O}$ & O & $\mathrm{O}$ \\
\hline $\begin{array}{l}\text { the average kitchen } \\
\text { appliance useful? }\end{array}$ & $\mathrm{O}$ & $\mathrm{O}$ & $\mathrm{O}$ & $\mathrm{O}$ & $\mathrm{O}$ & O & $\mathrm{O}$ \\
\hline $\begin{array}{l}\text { technology-devices } \\
\text { and machines for } \\
\text { manufacturing, } \\
\text { entertainment, and } \\
\text { productive processes } \\
\text { (e.g., cars, } \\
\text { computers, television } \\
\text { sets)—durable? }\end{array}$ & $\mathrm{O}$ & $\mathrm{O}$ & $\mathrm{O}$ & O & $\mathrm{O}$ & O & $\mathrm{O}$ \\
\hline $\begin{array}{l}\text { the average cat } \\
\text { active? }\end{array}$ & $\mathrm{O}$ & $\mathrm{O}$ & 0 & $\mathrm{O}$ & $\mathrm{O}$ & $\bigcirc$ & $\mathrm{O}$ \\
\hline the forest durable? & O & $\mathrm{O}$ & $\mathrm{O}$ & $\mathrm{O}$ & $\mathrm{O}$ & O & $\mathrm{O}$ \\
\hline a tortoise durable? & O & $\mathrm{O}$ & $\mathrm{O}$ & $\mathrm{O}$ & $\mathrm{O}$ & 0 & 0 \\
\hline $\begin{array}{l}\text { the average dog } \\
\text { good-looking? }\end{array}$ & 0 & 0 & O & O & $\mathrm{O}$ & $\mathrm{O}$ & $\mathrm{O}$ \\
\hline
\end{tabular}

To what extent do (does)...

$\begin{array}{cccc}\text { Very } & \text { Somewhat } & \text { Somewhat } & \text { Very } \\ \text { unlikely } & \text { Unlikely } & \text { unlikely } & \text { Neutral } \\ \text { likely }\end{array}$ Likely likely


Qualtrics Survey Sotware

\begin{tabular}{|c|c|c|c|c|c|c|c|}
\hline & $\begin{array}{l}\text { Very } \\
\text { unlikely }\end{array}$ & Unlikely & $\begin{array}{l}\text { Somewhat } \\
\text { unlikely }\end{array}$ & Neutral & $\begin{array}{l}\text { Somewhat } \\
\text { likely }\end{array}$ & Likely & $\begin{array}{l}\text { Very } \\
\text { likely }\end{array}$ \\
\hline $\begin{array}{l}\text { technology-devices } \\
\text { and machines for } \\
\text { manufacturing, } \\
\text { entertainment, and } \\
\text { productive processes } \\
\text { (e.g., cars, } \\
\text { computers, television } \\
\text { sets)-have } \\
\text { intentions? }\end{array}$ & $\mathrm{O}$ & $\mathrm{O}$ & $\mathrm{O}$ & $\mathrm{O}$ & $\mathrm{O}$ & $\mathrm{O}$ & $\mathrm{O}$ \\
\hline $\begin{array}{l}\text { the average fish have } \\
\text { free will? }\end{array}$ & $\mathrm{O}$ & $\mathrm{O}$ & $\mathrm{O}$ & $\mathrm{O}$ & $\mathrm{O}$ & $\mathrm{O}$ & $\mathrm{O}$ \\
\hline $\begin{array}{l}\text { the average } \\
\text { mountain have free } \\
\text { will? }\end{array}$ & $\mathrm{O}$ & $\mathrm{O}$ & $\mathrm{O}$ & $\mathrm{O}$ & $\mathrm{O}$ & $\mathrm{O}$ & $\mathrm{O}$ \\
\hline $\begin{array}{l}\text { a television set } \\
\text { experience } \\
\text { emotions? }\end{array}$ & $\mathrm{O}$ & $\mathrm{O}$ & $\mathrm{O}$ & $\mathrm{O}$ & $\mathrm{O}$ & $\mathrm{O}$ & $\mathrm{O}$ \\
\hline $\begin{array}{l}\text { the average robot } \\
\text { have consciousness? }\end{array}$ & $\mathrm{O}$ & $\mathrm{O}$ & $\mathrm{O}$ & $\mathrm{O}$ & $\mathrm{O}$ & $\mathrm{O}$ & $\mathrm{O}$ \\
\hline $\begin{array}{l}\text { cows have } \\
\text { intentions? }\end{array}$ & $\mathrm{O}$ & $\mathrm{O}$ & $\mathrm{O}$ & $\mathrm{O}$ & $\mathrm{O}$ & $\mathrm{O}$ & $\mathrm{O}$ \\
\hline a car have free will? & $\mathrm{O}$ & $\mathrm{O}$ & $\mathrm{O}$ & $\mathrm{O}$ & $\mathrm{O}$ & $\mathrm{O}$ & $\mathrm{O}$ \\
\hline $\begin{array}{l}\text { the ocean have } \\
\text { consciousness? }\end{array}$ & $\mathrm{O}$ & $\mathrm{O}$ & $\mathrm{O}$ & $\mathrm{O}$ & $\mathrm{O}$ & $\mathrm{O}$ & $\mathrm{O}$ \\
\hline $\begin{array}{l}\text { the average } \\
\text { computer have a } \\
\text { mind of its own? }\end{array}$ & $\mathrm{O}$ & $\mathrm{O}$ & $\mathrm{O}$ & $\mathrm{O}$ & $\mathrm{O}$ & $\mathrm{O}$ & 0 \\
\hline $\begin{array}{l}\text { a cheetah experience } \\
\text { emotions? }\end{array}$ & $\mathrm{O}$ & $\mathrm{O}$ & $\mathrm{O}$ & $\mathrm{O}$ & $\mathrm{O}$ & $\mathrm{O}$ & $\mathrm{O}$ \\
\hline $\begin{array}{l}\text { the environment } \\
\text { experience } \\
\text { emotions? }\end{array}$ & $\mathrm{O}$ & $\mathrm{O}$ & $\mathrm{O}$ & $\mathrm{O}$ & $\mathrm{O}$ & $\mathrm{O}$ & $\mathrm{O}$ \\
\hline $\begin{array}{l}\text { the average insect } \\
\text { have a mind of its } \\
\text { own? }\end{array}$ & $\mathrm{O}$ & $\mathrm{O}$ & $\mathrm{O}$ & $\mathrm{O}$ & $\mathrm{O}$ & $\mathrm{O}$ & $\mathrm{O}$ \\
\hline $\begin{array}{l}\text { a tree have a mind of } \\
\text { its own? }\end{array}$ & $\mathrm{O}$ & $\mathrm{O}$ & $\mathrm{O}$ & $\bigcirc$ & $\bigcirc$ & $\mathrm{O}$ & $\mathrm{O}$ \\
\hline $\begin{array}{l}\text { the wind have } \\
\text { intentions? }\end{array}$ & $\mathrm{O}$ & $\mathrm{O}$ & $\mathrm{O}$ & $\mathrm{O}$ & $\mathrm{O}$ & $\mathrm{O}$ & \\
\hline $\begin{array}{l}\text { the average reptile } \\
\text { have consciousness? }\end{array}$ & $\mathrm{O}$ & $\mathrm{O}$ & $\mathrm{O}$ & $\mathrm{O}$ & $\mathrm{O}$ & $\mathrm{O}$ & \\
\hline
\end{tabular}




\section{Demographics}

Section 4: These last questions are designed for classification purposes only.

Which logo did you see on the travel destination website?
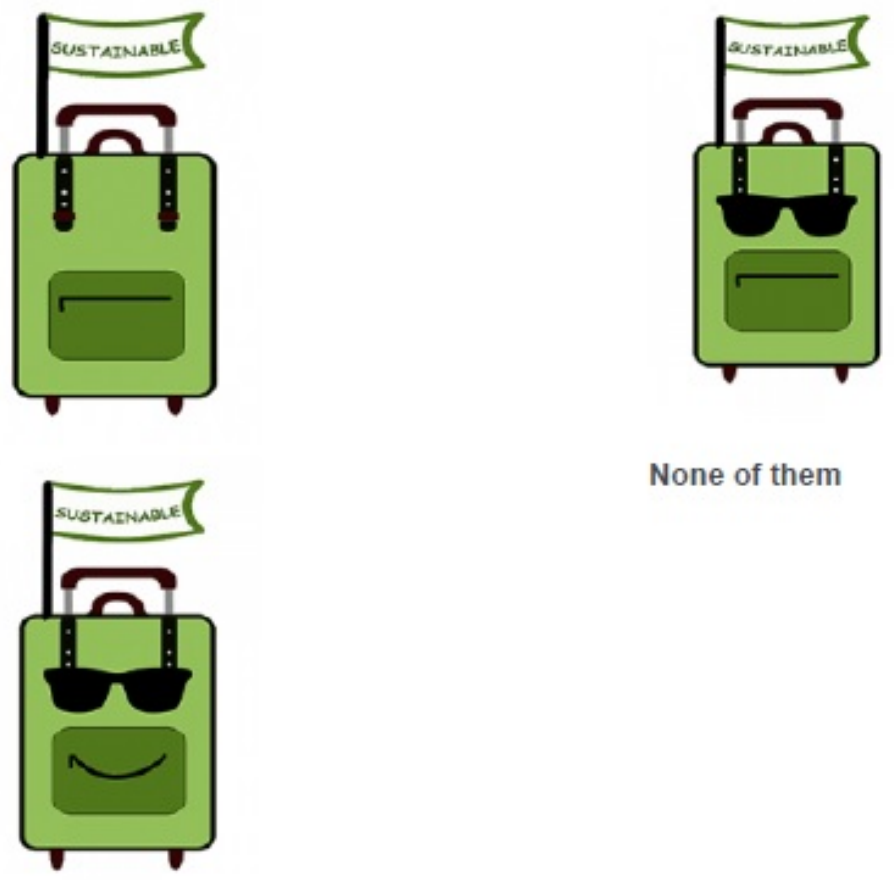

None of them

I don't remember

Do you recall seeing the TripAdvisor logo earlier in this survey?

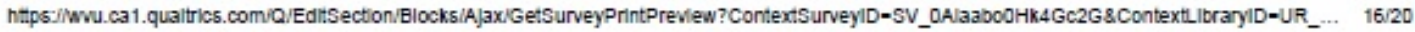




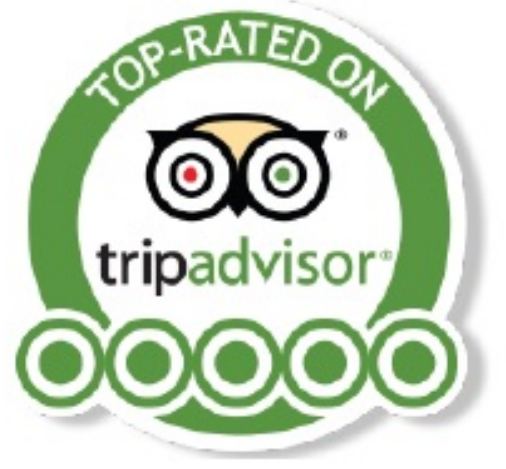

Yes

No

I don't remember

Are you:

Male

Female

Other

Prefer not to answer

In what year were you born?

Please type the 4-digit year.

What is the highest level of education you have completed?

Less than 7 th grade

Less than High School

High School Graduate / GED

Some College

2-year College Degree

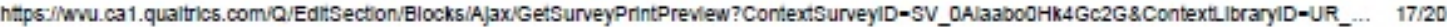


4-year College Degree

Completed Graduate Degree

What is your ethnicity (choose all that apply):

White

Black or African American

American Indian or Alaska Native

Asian

What is your marital status?

Single, never married

Married or domestic partnership

Widowed

Divorced

Separated

What is your combined annual household income (for 2020)?

less than $30 \mathrm{~K}$

$30,000-49,999$

$50,000-69,999$

$70,000-99,999$

$100 \mathrm{~K}$ or more

What is your Mechanical Turk worker ID?

Are there any other thoughts or comments you would like to share with us? We read every single comment and greatly value your insight and opinions.
Native Hawaiian or Pacific Islander

Latino or Hispanic

Other

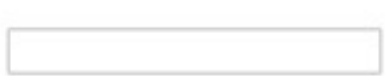

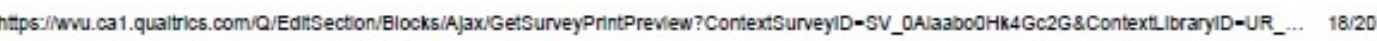


This is not a required question.

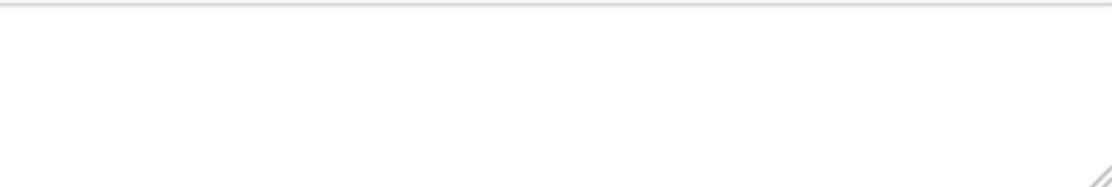

\section{Final block}

IMPORTANT: In order for your responses to be recorded, you must click on the "SUBMIT" button (example shown below):

You have successfully submitted your responses when you see the following screen:

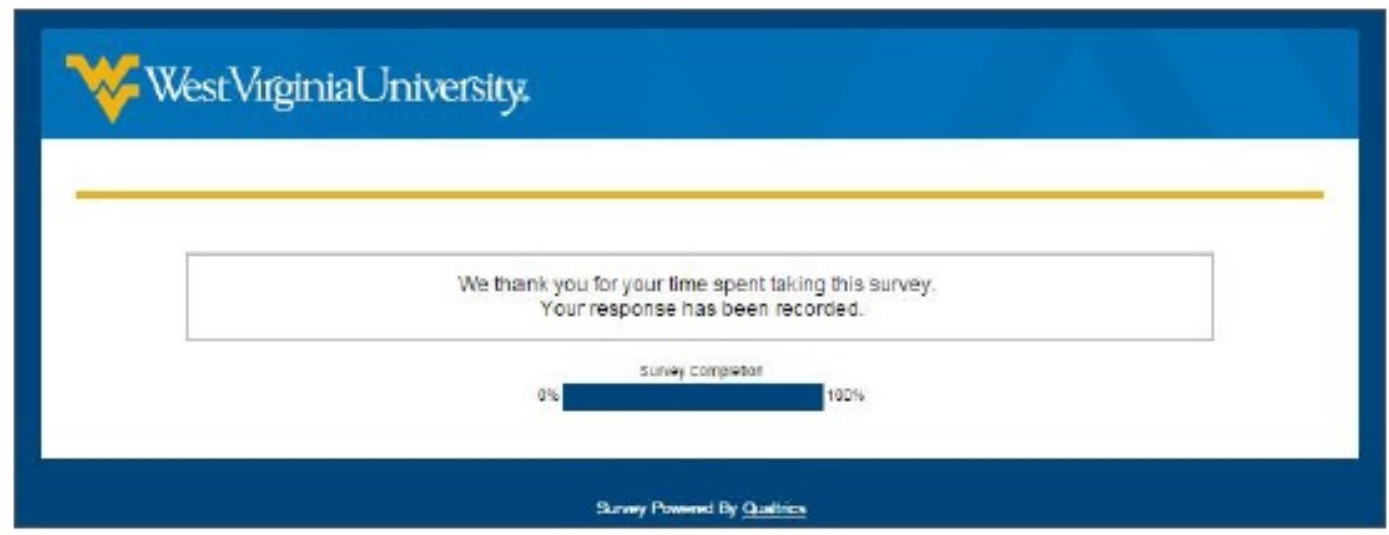

Again, in order for any of your responses to be recorded you must click on the "SUBMIT" button on the next page. 

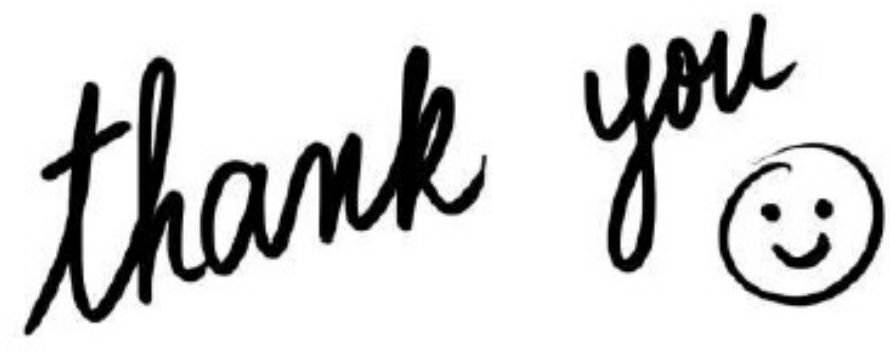

Thank you very much for your help with this survey.

We greatly appreciate your time and effort.

Please click on the "submit" button (lower right-hand side) to submit your answers.

Powered by Qualtrics 